\title{
Recent Advances in the Synthesis of Pyrroles
}

Sarosh Iqbal, ${ }^{a *}$ Shumaila Kiran, ${ }^{a}$ Bushra Perveen ${ }^{b}$, Asma Mukhtar ${ }^{c}$, Irfan Ahmad $^{b}$, Muhammad

Zawar $\operatorname{Khan}^{b}$,

${ }^{a}$ Department of Applied Chemistry, Government College University, Faisalabad-38000,

Faisalabad, Pakistan

${ }^{b}$ Department of Chemistry, Government College University, Faisalabad-38000, Faisalabad,

Pakistan

${ }^{c}$ Department of Chemistry and Chemical Engineering, Syed Babar Ali School of Science and Engineering Lahore University of Management Sciences, Lahore-54792, Lahore, Pakistan

*Corresponding Author : sarosh.iqbal@yahoo.com, Tel.: 0092-41-9200886; 


\begin{abstract}
Pyrroles are one of the most prevalent heterocyclic compounds, which are present as the basic cores in many natural products such as vitamin B12, bile pigments like bilirubin and biliverdin, the porphyrins of heme, chlorophyll, chlorins, bacteriochlorins, and porphyrinogens. The biological activities of compounds having pyrrole analogs include antimicrobial (antibacterial, antifungal), anti-cancer (anti-cytotoxic, anti-mitotic), anti-tumor, anti-hyperlipidemic, antidepressant, anti-inflammatory, antihyperglycemic, antiproliferative, anti-HIV and anti-viral activities. Accordingly, significant attention has been given to develop competent methods for the synthesis of pyrroles with improved yields in short times. This review gives an overview of different methods for the synthesis of pyrrole using easily available precursors using the following routes.
\end{abstract}

Synthesis of monosubstituted pyrrole using 2,5-dimethoxyfuran

$>$ Synthesis of pyrrole using dialkylacetylene dicarboxylate

$>$ Synthesis of pyrroles using $\beta$-ketoester

$>$ Synthesis of pyrrole using 1,2-dicarbonyl compounds

$>$ Synthesis of pyrroles using 1,3-dicarbonyl compounds

$>$ Synthesis of pyrroles using 1,3-dicarbonyl, amine, nitro and aldehyde group

$>$ Synthesis of pyrroles using 1,4-dicarbonyl compound and amines

$>$ Synthesis of pyrrole using enones

$>$ Synthesis of pyrroles using moieties having acetylene group 


\subsection{Introduction}

The existence of pyrrole was first discovered by Runge in 19?8?34 who named this substance "pyrrole" (Greek meaning red) though he did not recognize its chemical composition and supposed it to be a gas. In 1857, pyrrole was first isolated, purified, analyzed and characterized from the product of bone pyrolysis [1-2] and established to be an aromatic five membered ring with the formula $\mathrm{C}_{4} \mathrm{H}_{5} \mathrm{~N}$. Pyrrole is a colorless liquid having m.p. $23.4^{\circ} \mathrm{C}$, b.p. $129.8^{\circ} \mathrm{C}$ at 760 torr, and density $0.970 \mathrm{~g} / \mathrm{ml}$ at $20{ }^{\circ} \mathrm{C}$. It has an odor slightly resembling that of chloroform. It progressively turns brown in air, and is somewhat hygroscopic. It has a low solubility in water but is soluble in most organic solvents [3-4].

Pyrrole is a very widely occuring nitrogen-containing heterocycle, and exhibits anticonvulsant, antifungicidal, anticoagulant, anti-inflammatory, antibiotics, antiviral, anticancer and cholesterol reducing activity [5-7]. Well-known natural products containing the pyrrole nucleus are the heme derivatives, bile pigments, vitamin B12 and chlorophyll, which comprise four pyrrole groups [8]. 


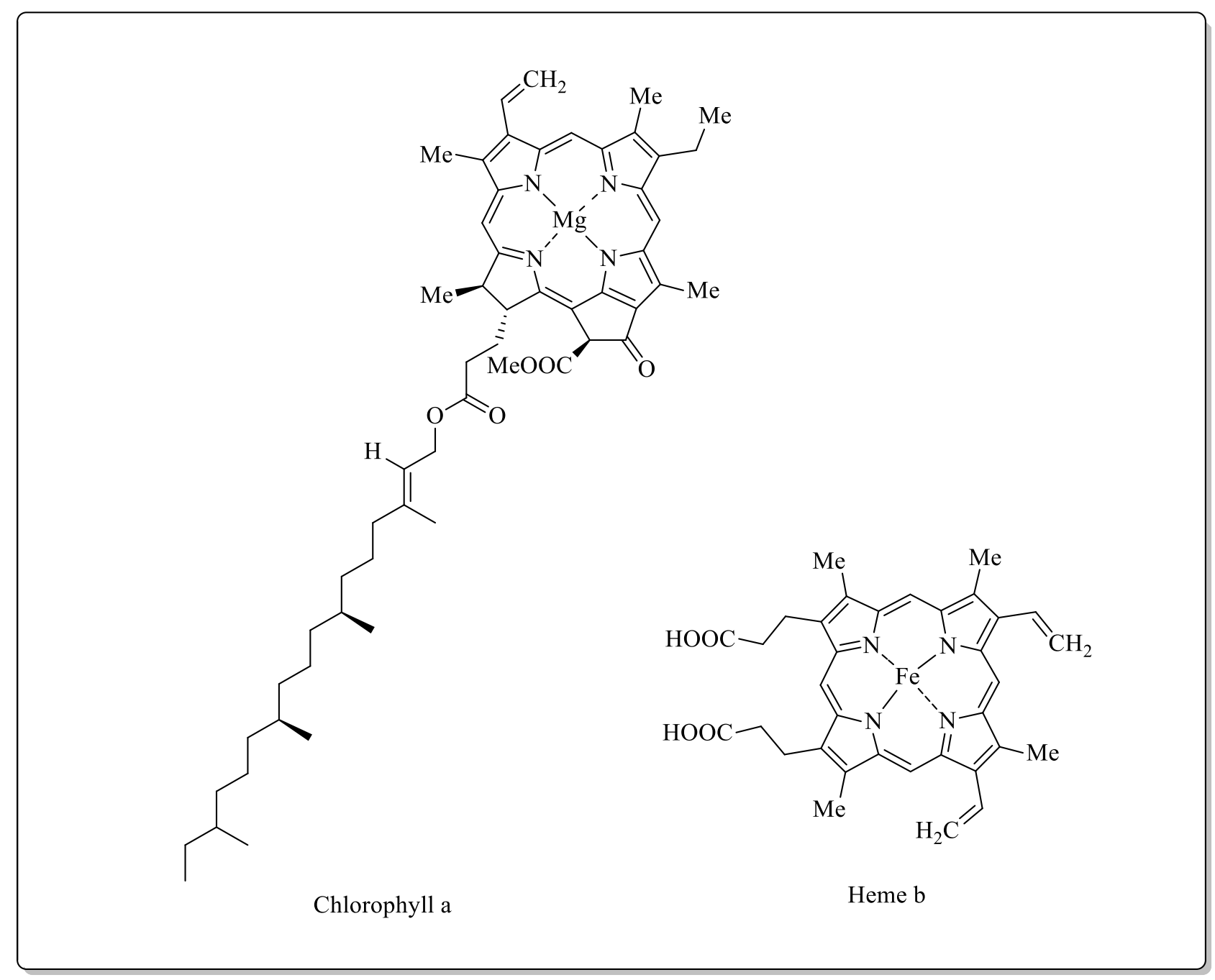

Figure-1: Two naturally occurring pyrroles 


\subsection{Biological Applications of Pyrrole Derivatives}

Tetramic acids (1), known for wide-spectrum antimicrobial activity [9], contain the pyrrolidine nucleus. Marinopyrroles A and B (2) have shown high activity against methicillin-resistant bacteria [10]. Pyrrole-2-ones are also found in Nature. For example, the marine alkaloids amathaspiramides B (3), isolated from the marine bryozoan Amathia wilsoni, display antimicrobial, cytotoxic and antiviral activities [11]. Diguanidino 1-methyl-2,5-diaryl-1H-pyrrole derivatives (4) have shown significant anti-fungal activity against Candida species [12]. Clausenamide (5), which is extracted from the leaves of the traditional Chinese herb Clausena lansium, displays hepatoprotective activities [13]. The pyrrole ring is an important core for the design and synthesis of novel anti-inflammatory agents because of its occurrence in the pharmacophore system of a large amount of non-steroidal anti-inflammatory drugs. The drug zomepirac (6) NSAIDs is widely marketted [14]. The lamellarins, extracted from marine prosobranch mollusk invertebrates, Lamellaria, show antitumor and anti-HIV activities [15].

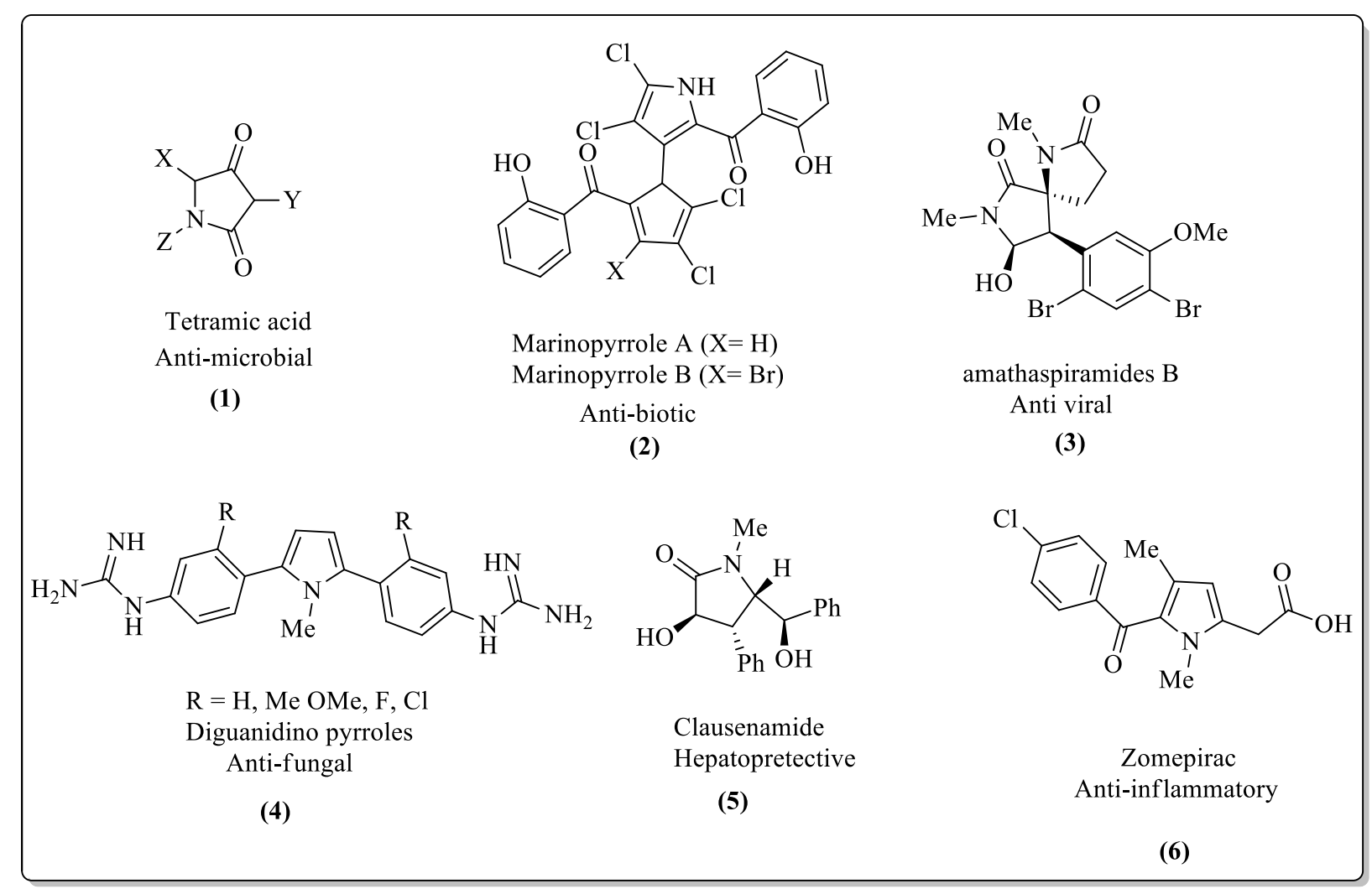

Figure-2: Some biologically important pyrrole as anti-microbial, anti-viral, anti-inflammatory and hepatoprotective agent. 
Lamellarin K (7) showed biological activities such as cytotoxicity, HIV-1 integrase inhibition and multidrug-resistance (MDR) reversal [16]. Atrovastatin (8) is a best seller drug broadly used as a cholesterol-lowering agent and it works by inhibiting 3-hydroxy-3-methylglutaryl coenzyme A reductase in the cholesterol biosynthesis pathway [17]. 2,3,4-Triaryl-1H-pyrrole derivatives (9) act as antihyperglycemic agents [18]. 3-[1-Methyl-4-phenylacetyl-1H-pyrrol-2-yl]-N-hydroxy-2propenamide (10) have shown outstanding anti-proliferative and cyto-differentiating activity in erythro leukemia [19].

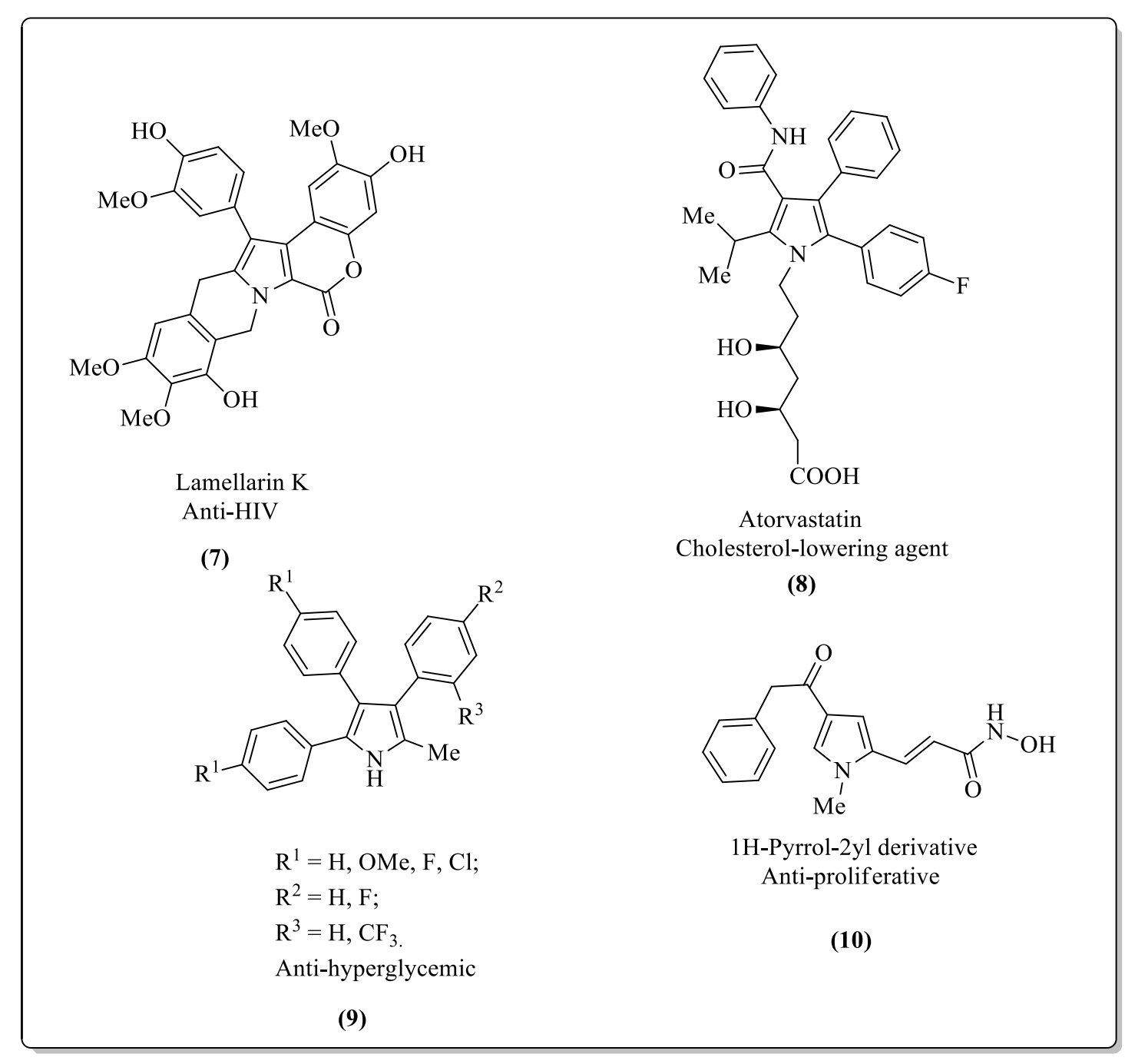

Figure-3: Some pyrrole derivatives as anti-HIV, anti-hyperlipidemic, anti-hyperglycemic and anti-proliferative agents. 
Halitulin (11) is a cytotoxic spongian natural product, extracted from Haliclona tulearensis [20]. Lamellarin O (12), a pyrrole alkaloid from an Australian marine sponge, was characterized as a selective inhibitor of breast cancer resistant protein (BCRP) [21]. Sunitinib (13) is a commercially available pyrrole derived drug, effective for the oral treatment of renal cancer and works as a multitargeted receptor tyrosine kinase inhibitor [22]. Verrucarin E (14), 3,4-disubstituted pyrrole, is an antimitotic isolated from Myrothecium verrucaria [23]. Obatoclax (GX-15-070) (15), a prodiginine, triggers cell death through autophagy and is in phase II clinical studies for the treatment of various tumours [24-26]. Pyrrole derivative (16) is three times more effective antipsychotic agent than already discovered antipsycotic drugs [27]. Arylpiperazine (17) comprising pyrrole-3-carboxamide derivatives exhibits potential anti-depressant activity [28]. Few pyrrole derivatives (18) were reported which show potential anti-convulsant activity [29]. 4-Aroyl2-( $\alpha$-aminoacyl) pyrroles (19) signify an innovative, structurally new class of anticonvulsant agents [30]. 


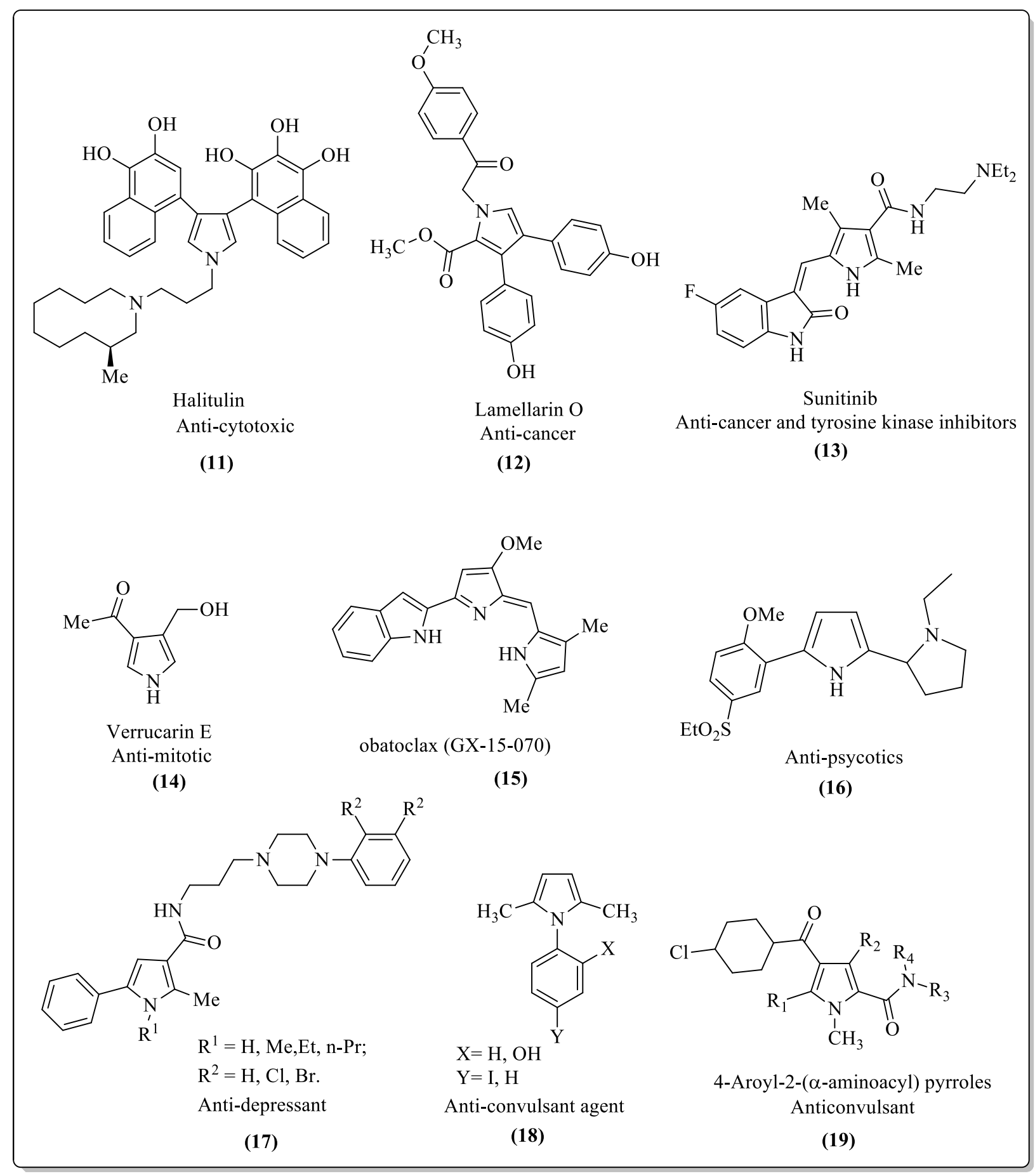

Figure-4: Some medicinally important compounds having a pyrrole ring. 


\subsection{Different routes for the synthesis of pyrrole derivatives}

\subsubsection{Synthesis of monosubstituted pyrrole using 2,5-dimethoxyfuran}

The synthesis of pyrrole derivatives using 2,5-dimethoxyfuran under different conditions has been widely reported. For instance, Gourlay and co-workers (2006) used a modified Clauson-Kaas synthesis for the synthesis of pyrrole using and amine and dimethoxyfuran in the presence of acetate buffer (Scheme-1) [31] Rivera and colleagues (2009) reported the synthesis of $N$ substituted pyrroles using microwave-induced bismuth nitrate as catalyst to obtain the pyrrole products in outstanding yield (Scheme 2) [32]. Abid and co-workers (2009) have reported a new rapid one-pot synthesis of $\mathrm{N}$-substituted pyrroles through reaction of aniline and dimethoxyfuran in the presence of K-10 montmorillonite under microwave radiations (Scheme 3) [33]. Wilson and his co-workers (2009) have reported a rapid and green method for synthesis of $N$-aryl sulfonyl and $\mathrm{N}$-aryl pyrroles in water under microwave irradiation (Scheme 4) [34]. Abid and his colleagues (2007) have reported one-pot cyclization/annelation to produce a variety of $N$-sulfonyl pyrroles from primary sulfonamides and methoxy furan by using an appropriate ratio of reactant/triflic acid (scheme 5) [35].

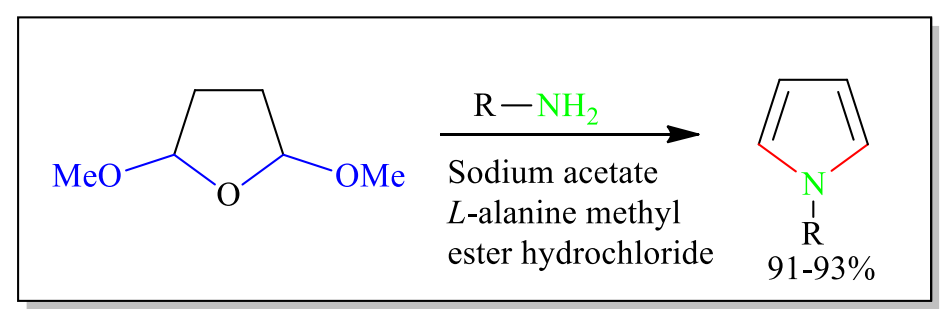

Scheme 1: Modified Clauson-Kaas pyrrole synthesis.

$$
\overbrace{\mathrm{OMe}}+\mathrm{R}-\mathrm{NH}_{2} \underset{\mathrm{MWI}}{\stackrel{\mathrm{Bi}\left(\mathrm{NO}_{3}\right)_{3} .5 \mathrm{H}_{2} \mathrm{O}}{\longrightarrow}} \underset{\substack{\mathrm{R} \\ 85-100 \%}}{\longrightarrow}
$$

Scheme 2: Synthesis of $N$-substituted pyrroles via microwave-induced bismuth nitrate. 


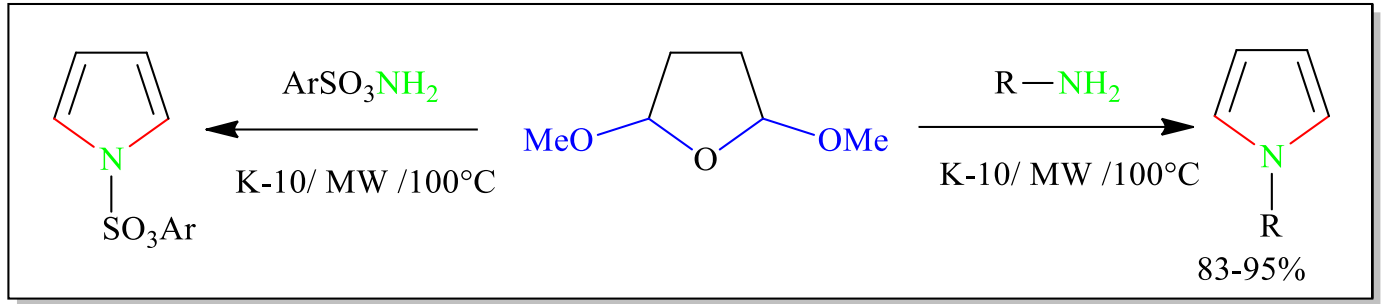

Scheme 3: Synthesis of $N$ - substituted pyrroles by microwave.

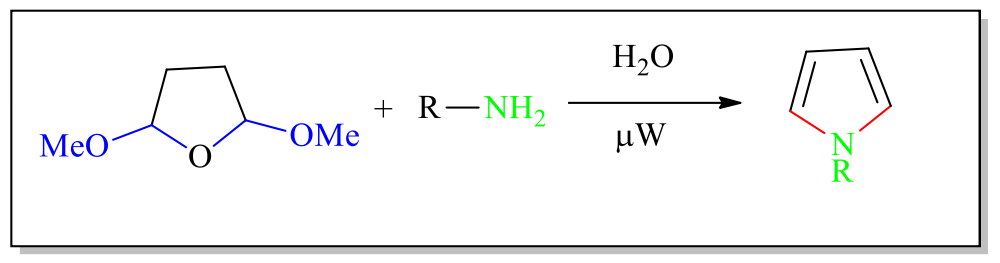

Scheme 4: The synthesis of $N$-aryl pyrroles by microwave assistance.

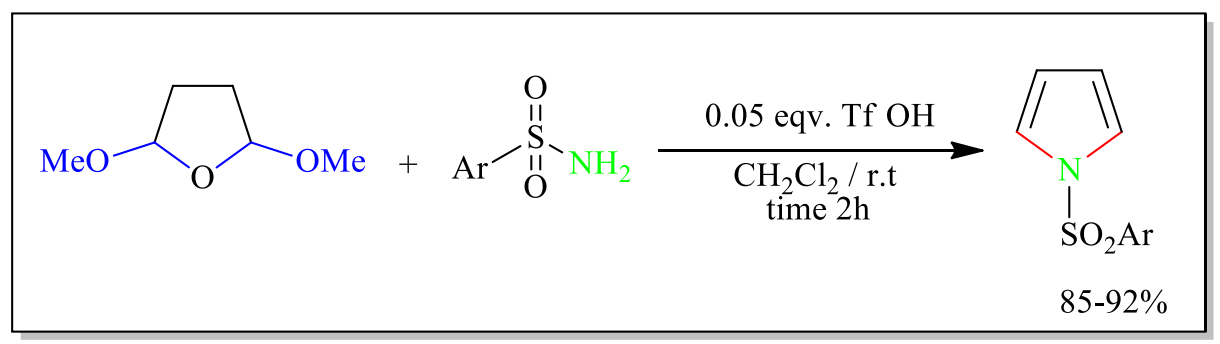

Scheme 5: Triflic acid catalyzed synthesis of $N$-phenylsulfonyl pyrrole.

Cárdenas et al. (2012) have reported a new method for the synthesis of pyrrole by treating amines with 2,5-dimethoxytetrahydrofuran in the presence of a catalyst (polystyrenesulfonate) and under microwave radiations (Scheme 6) [36].

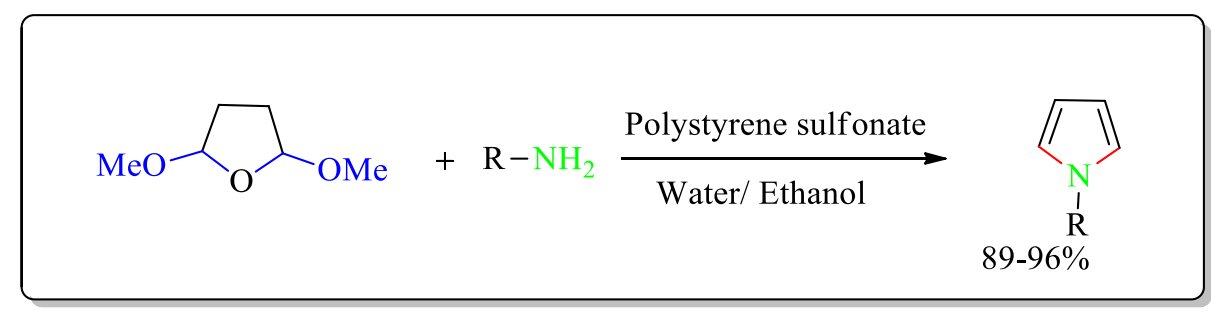

Scheme 6: Polystyrene sulfonate-catalyzed simple synthesis of $\mathrm{N}$-substituted pyrroles

Hosseini-Sarvari and his colleagues (2014) synthesized $N$-substituted pyrrole by treating 2,5dimethoxytetrahydrofuran with amines and diamines in the presence of nano-sulfated titania and without using solvent (Scheme 7) [37]. 


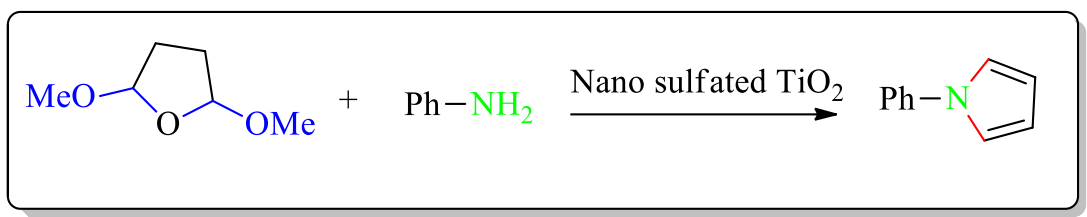

Scheme 7: Synthesis of $N$-Phenylpyrrole in the Presence of nano Sulfated TiO2

\subsubsection{Synthesis of pyrrole using dialkylacetylene dicarboxylate.}

There are many reports of the synthesis of pyrrole derivatives using dialkylacetylene dicarboxylate. Alizadeh and his co-workers (2006) used a one-pot synthesis of trisubstituted pyrroles i-e??? 2-[(4-methylphenyl)sulfonyl] $1 H$-pyrrole-3,4-dicarboxylates by the reaction of dialkyl acetylenedicarboxylates with tosylmethyl isocyanide (TsMIC) in the presence of $\mathrm{Ph}_{3} \mathrm{P}$ (Scheme 8) [38]. Galliford and Scheidt (2007) have reported the synthesis of 1,2-diarylpyrrole from three components, an imine, diazoacetonitrile (DAN) and an alkynyl using dirhodium (II) salt as a catalyst (Scheme 9) [39]. Kassaee et al. (2008) have reported the one-pot synthesis of dialkyl 4,5-dimethyl-1 $H$-pyrrole-2,3-dicarboxylates by treating butane-2,3-dione with $\alpha$ aminophosphorous ylides, which were prepared in situ by 1:1:1 addition reaction between triphenylphosphine, dialkyl acetylenedicarboxylate, and ammonium acetate (Scheme 10) [40]. Yavari and his partner (2009) have reported the preparation of tetrasubstituted pyrrole through the condensation of three components, namely an acid chloride, a dialkyl acetylenedicarboxylate and an amino acid, using ionic liquids (RTILs) in water (Scheme 11) [41]. Yavari and his co-workers (2009) have reported an effective way to prepare funtionalized pyrroles by condensation of acid chlorides, amino acids, and dialkyl acetylenedicarboxylates in the presence of 1-butyl-3methylimidazolium hydroxide ([bmim] OH) $-\mathrm{H}_{2} \mathrm{O}$ as a catalyst (Scheme 12) [42].

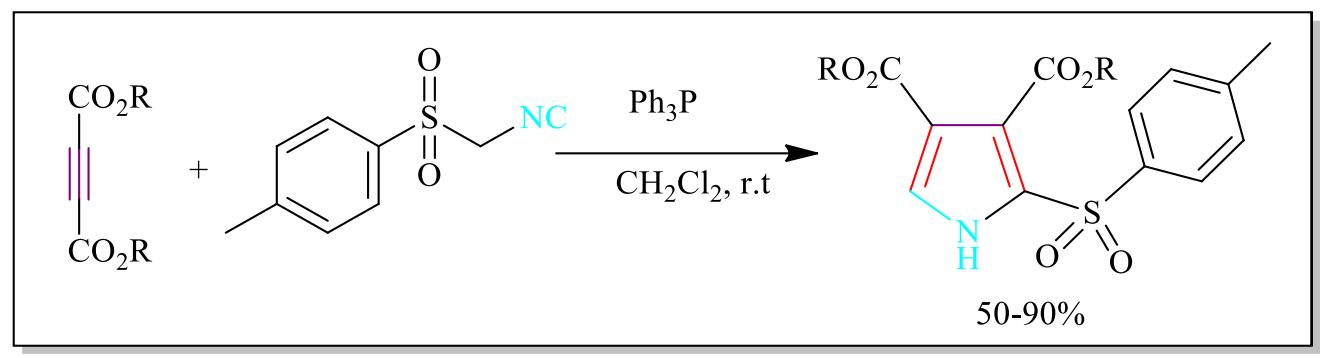

Scheme 8: Synthesis of Dialkyl 2-[(4-Methylphenyl)sulfonyl]-1 $H$-pyrrole-3,4dicarboxylates 


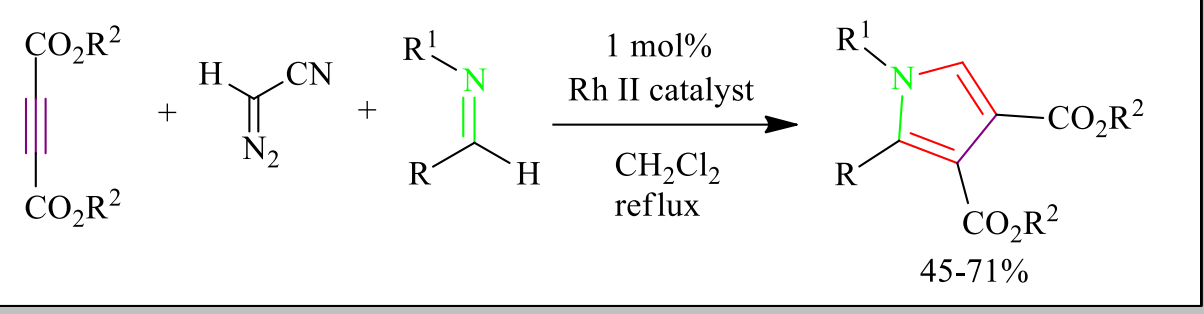

Scheme 9: Multicomponent assembly reaction for the synthesis of pyrroles

$$
\left.\right|_{\mathrm{CO}_{2} \mathrm{R}} ^{\mathrm{CO}_{2} \mathrm{R}}+\mathrm{Ph}_{3} \mathrm{P}+\mathrm{MeCOONH}_{4}+{ }_{\mathrm{O}}^{\mathrm{Me}} \stackrel{\mathrm{MeCN}}{12 \mathrm{~h}, \mathrm{r} . \mathrm{t}}
$$

Scheme 10: Synthesis of Tetrasubstituted pyrroles

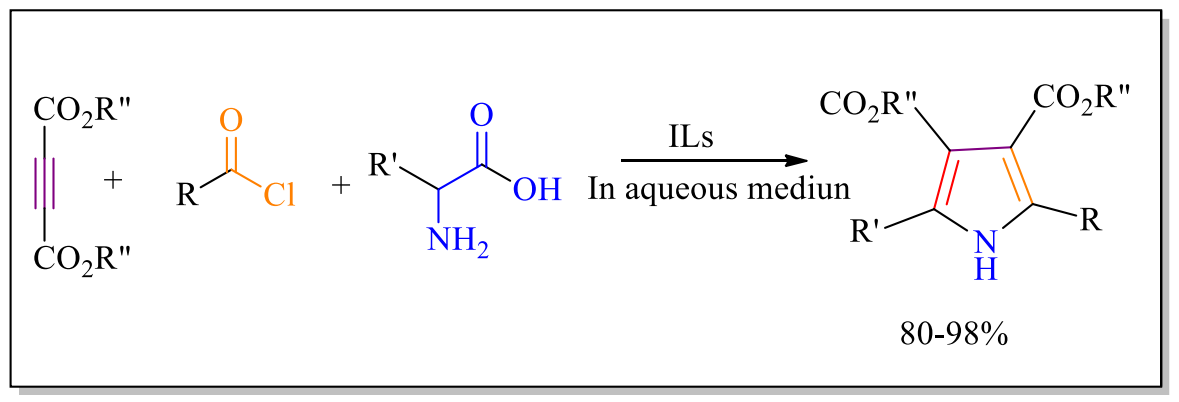

Scheme 11: The three-component, one-pot condensation of acid chlorides, amino acids, and dialkyl acetylene dicarboxylates in the presence of different ILs

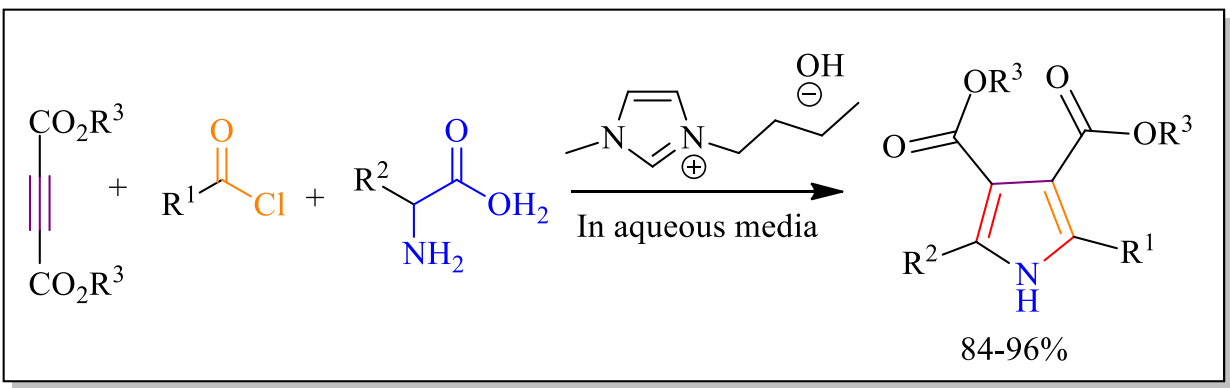

Scheme 12: The formation of functionalized pyrroles

Ghabraie (2011) have reported a one-pot synthesis of tetra-substituted pyrroles by reaction of primary amines, dialkyl acetylenedicarboxylates and $\beta$-nitrostyrene derivatives in the presence of iron (III) chloride which generates 1,2,3,4-tetra-substituted pyrroles in give high yields (Scheme 
13) [43]. Han and his co-workers (2012) have reported an efficient synthesis of pentasubstituted pyrroles through one-pot reaction of arylamines, acetylenedicarboxylates, and 3phenacylideneoxindoles (Scheme 14) [44]. Feng et al. (2013) have described the highly efficient synthesis of polysubstituted pyrroles through a four-component domino reaction of an aryl glyoxal monohydrate, an aniline, a dialkyl but-2-ynedioate, and malononitrile (Scheme 15) [45]. Khan et al. (2012) have reported a one-pot four-component synthesis of multi-functionalized dihydro-2oxypyrrole domino reaction from dialkylacetylene dicarboxylate, amines, and formaldehyde. Iodine was used as a catalyst at room temperature (Scheme 16) [46]. Sajadikhah (2013) has reported one pot synthesis of highly functionalized piperidines and dihydro-2-oxypyrroles using the catalyst of $\mathrm{Al}\left(\mathrm{H}_{2} \mathrm{PO}_{4}\right)_{3}$. (Scheme 17) [47]. Sajadikhah et al. (2013) have described one-pot multi-component reaction of amines, dialkyl acetylenedicarboxylates and formaldehyde to synthesize the of $\mathrm{N}$-aryl-3-aminodihydropyrrol-2-one-4-carboxylates under catalysis of oxalic acid dihydrate (20 mol\%) along with methanol (Scheme 18) [48]. Sayyed-Alangi et al. (2012) have described the one-pot synthesis of pyrroles derivatives, obtained from reactions of primary amines with acetylenic esters by using catalyst $N$-methylimidazole in water (Scheme-19) [49]. Ardakani et al. (2012) have reported the reaction between dialkyl acetylenedicarboxylates, arylsulfonamides and ethyl chlorooxoacetate accelarated by triphenylphosphine and triethylamine, which produce functionalized 3-pyrrolin-2-one derivatives in high yields (Scheme 20) [50]. Rana (2013) has reported an efficient method for the synthesis of densely substituted 2-oxodihydropyrroles by clean, reusable, and heterogeneous catalyst titanium dioxide $\left(\mathrm{TiO}_{2}\right)$ nanopowder by the four component coupling reaction of dialkyl but-2-ynedioate, two different amines, and an aldehyde (Scheme 21) [51].

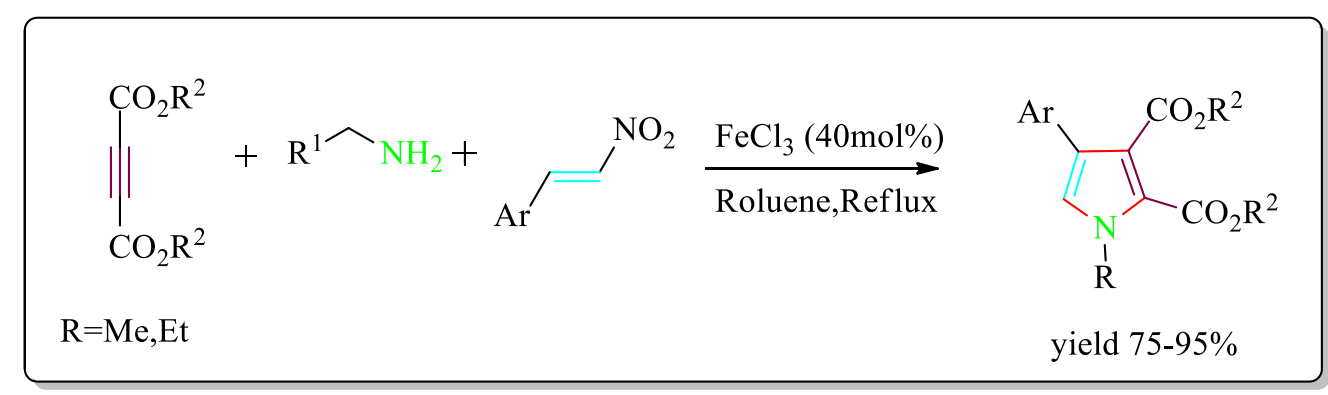

Scheme 13: One-pot synthesis of tetra-substituted pyrroles. 


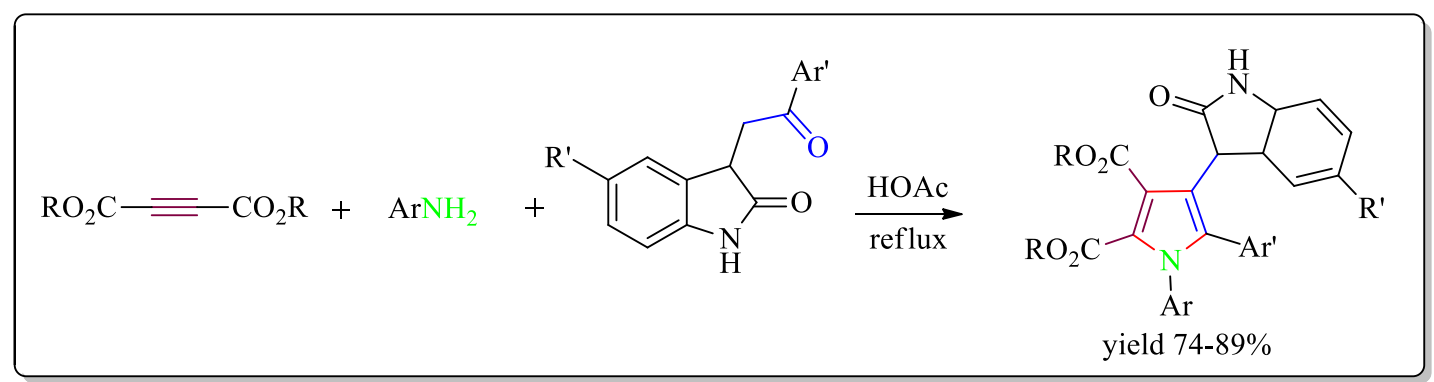

Scheme 14: Synthesis of pentasubstituted pyrroles via domino reactions.

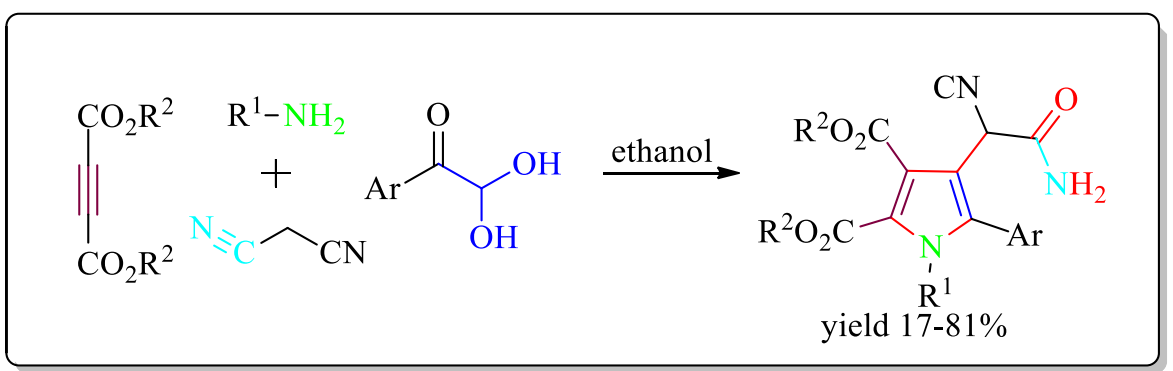

Scheme 15: Synthesis of Polysubstituted Pyrroles.

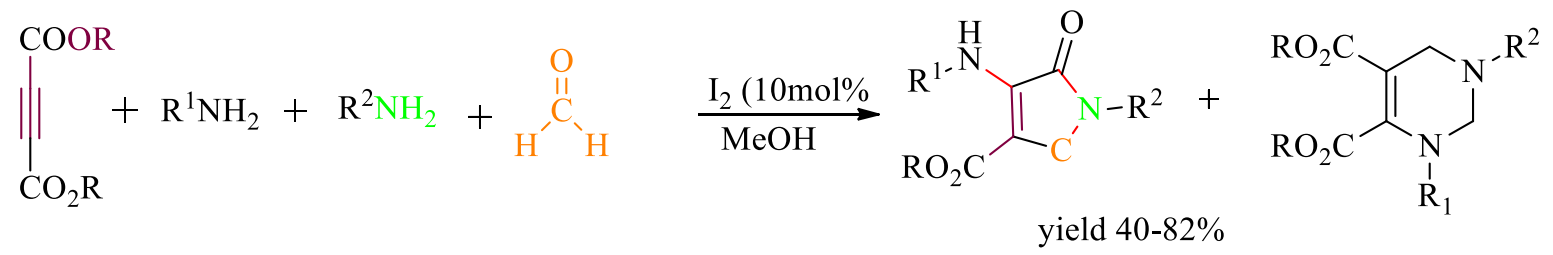

Scheme 16: Synthesis of substituted dihydro-2-oxypyrroles.

$$
\|_{\mathrm{CO}_{2} \mathrm{R}^{2}}^{\mathrm{COOR}}+\mathrm{R}^{1}-\mathrm{NH}_{2}+\mathrm{Ar}-\mathrm{NH}_{2}+\underset{\mathrm{H}^{\mathrm{C}}}{\stackrel{\mathrm{O}}{\mathrm{C}} \frac{\mathrm{Al}\left(\mathrm{H}_{2} \mathrm{PO}_{4}\right)_{3}(0.1 \mathrm{~g})}{\mathrm{MeOH}, \text { r.t. }}}
$$

Scheme 17: Synthesis of highly substituted dihydro-2-oxypyrrole. 


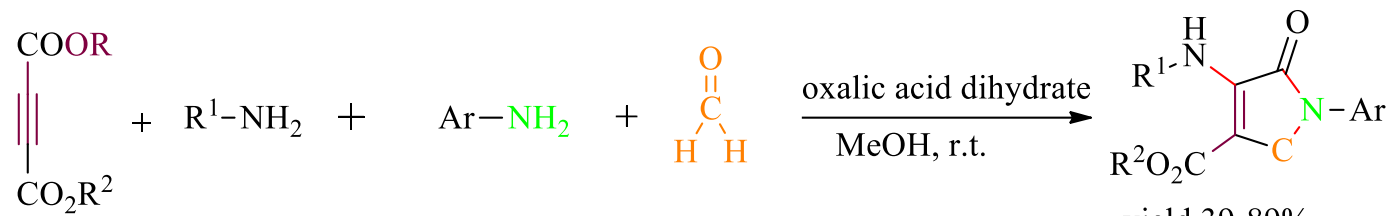

$$
\begin{aligned}
& \text { yield 39-89\% }
\end{aligned}
$$

Scheme 18: Synthesis of $N$-aryl-3-aminodihydropyrrol-2-one-4-carboxylate.

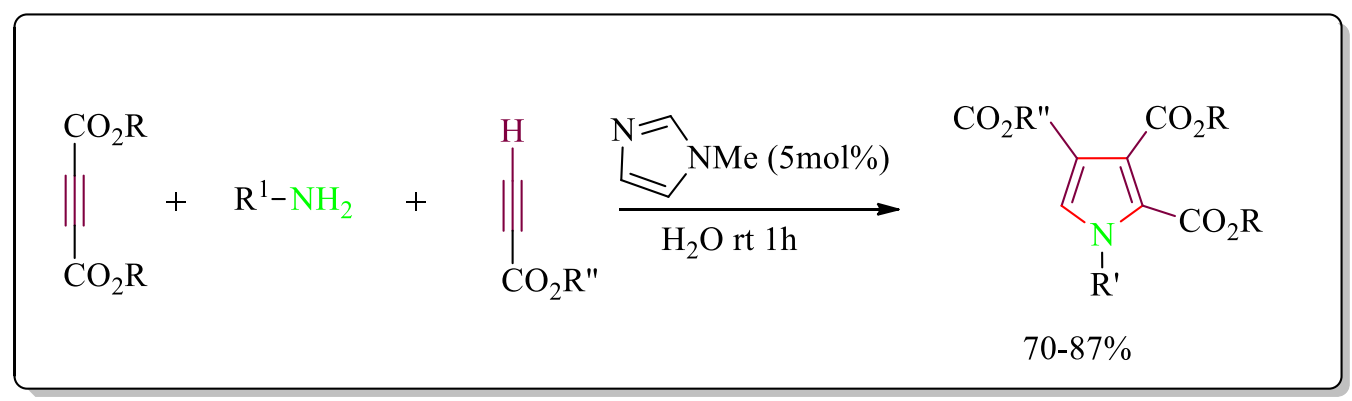

Scheme 19: Synthesis of highly functionalized pyrroles.

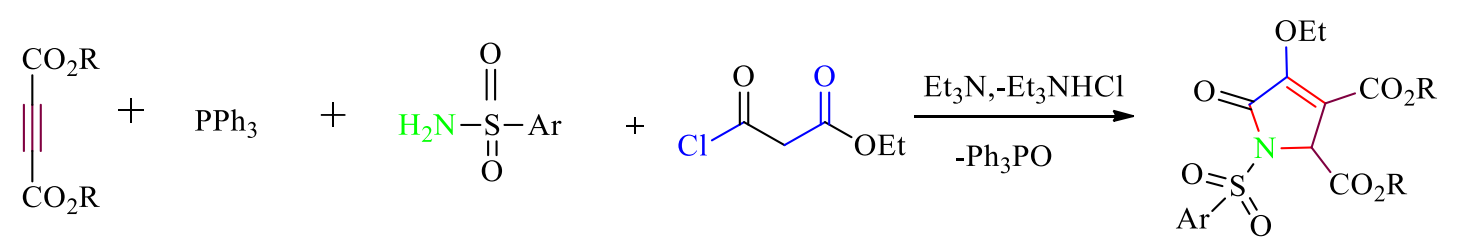

$$
\begin{aligned}
& 60-88 \%
\end{aligned}
$$

Scheme 20: Three-component reaction between arylsulfonamides, DAAD, triphenylphosphine and ethyl chlorooxoacetate.

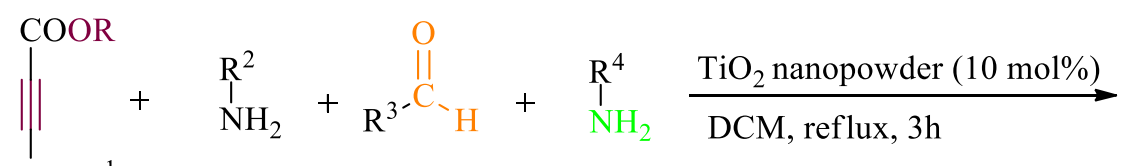

$$
\begin{aligned}
& \mathrm{CO}_{2} \mathrm{R}^{1}
\end{aligned}
$$

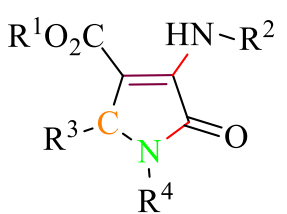

yield $84-85$ 
Scheme 21: $\mathrm{TiO}_{2}$ nanopowder catalyzed multicomponent synthesis of fully substituted dihydropyrroles.

Zhao and his colleagues (2014) have reported the synthesis of substituted pyrroles by the efficient copper-promoted oxidative coupling between enamides and alkynes in mild conditions (Scheme 22) [52]. Reddy (2015) have developed the one-pot novel synthesis of poly-substituted pyrrole from nitrocompounds, phenacyl bromide and dialkyl acetylenedicarboxylates in the presence of indium in dilute aqueous $\mathrm{HCl}$ at room temperature (Scheme 23) [53]. Zarei and Sajadikhah (2016) have developed a one-pot synthesis of dihydropyrrole-2-ones by treating amines, dialkyl acetylenedicarboxylates and formaldehyde in the presence of ethylenediammonium diformate under ethanol and reflux conditions (Scheme 24) [54]. Kangani (2016) have reported the one-pot synthesis of $\mathrm{N}$-aryl-3-aminodihydropyrrol-2-one-carboxylates by the condensation of formaldehyde, amines and dialkylacetylenedicarboxylates in the presence of Vitamin B12 as a catalyst at ambient temperature along with EtOH (Scheme 25) [55]. Soltani and colleagues (2016) have described the one-pot synthesis of polysubstituted pyrroles by reacting three component amines, $\alpha$-bromo ketones and dialkyl acetylenedicarboxylate in the presence of $\mathrm{H}_{3} \mathrm{PW}_{12} \mathrm{O}_{40}$, a noncorrosive and reusable heterogenous catalyst, under solvent-free conditions (Scheme 26) [56]. Dhinakaran et. al. (2016) have reported the chemoselective, one-pot multicomponent synthesis of polysubstituted pyrroles in high yield by reacting ethyl (E)-3-(aryl/alkyl amino) acrylates, 2,2dihydroxy-1-arylethan-1-ones and malononitrile without using solvent and catalyst grinding conditions (Scheme 27) [57]. Rahmani and Darehkordi (2017) have reported the one-pot synthesis of trifluoromethylated pyrrole in high yield by reacting $N$-aryl-2,2,2-trifluoroacetimidoyl chlorides, dimethyl or diethyl acetylene dicarboxylate and isocyanides under dry dichloromethane in catalyst-free conditions (Scheme 28) [58]. Kangani (2017) have developed the one-pot synthesis of pyrrole derivatives by reacting an amine, dialkyl acetylenedicarboxylate, aromatic amine and formaldehyde in the presence of lactic acid which serves as an efficient green catalyst, at ambient temperature in EtOH (Scheme 29) [59]. 


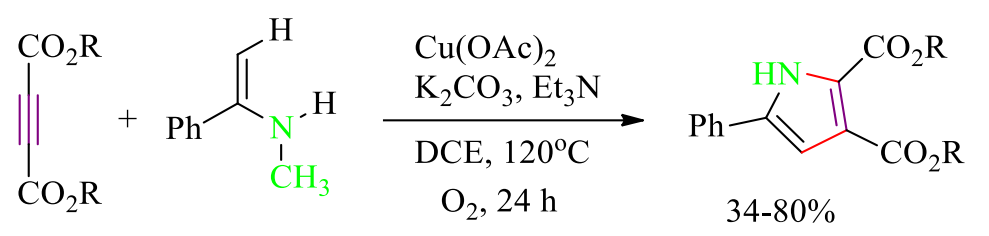

Scheme 22: Coupling reactions of enamides and activated alkynes.

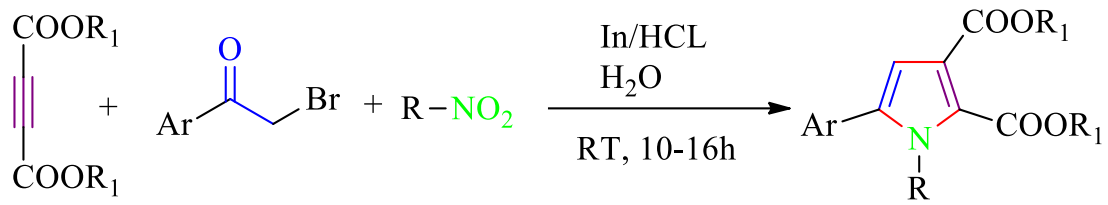

Scheme 23: Synthesis of polysubstituted pyrroles using indium metal in aqueous $\mathrm{HCl}$ at room temperature.

$$
\left.\right|_{\text {EDDF: }} ^{\mathrm{COOR}}+\mathrm{R}^{1}-\mathrm{NH}_{2}+\mathrm{Ar}-\mathrm{NH}_{2} \underset{\mathrm{EtOH} \text {, reflux }}{\stackrel{\mathrm{EDDF}(20 \mathrm{~mol} \%)}{\mathrm{CO}_{2} \mathrm{R}^{2}}}
$$

Scheme 24: Synthesis of $N$-aryl-3-amino dihydropyrrol-2-one-4-carboxylate.

$$
\|_{\mathrm{CO}_{2} \mathrm{R}^{2}}^{\mathrm{CO}_{2} \mathrm{R}^{2}}+\mathrm{Ar}-\mathrm{NH}_{2}+\mathrm{R}^{1}-\mathrm{NH}_{2}+{ }_{\mathrm{H}} \underset{\mathrm{H}}{\stackrel{\text { cat. } \mathrm{B} 12}{\mathrm{OtOH}(2 \mathrm{ml}), \text { r.t. }}}
$$

Scheme 25: Synthesis of $N$-aryl-3-aminodihydropyrrol-2-one-4-carboxylates in the presence of vitamin $\mathrm{B} 12$ as catalyst in $\mathrm{EtOH}$ at ambient temperature. 


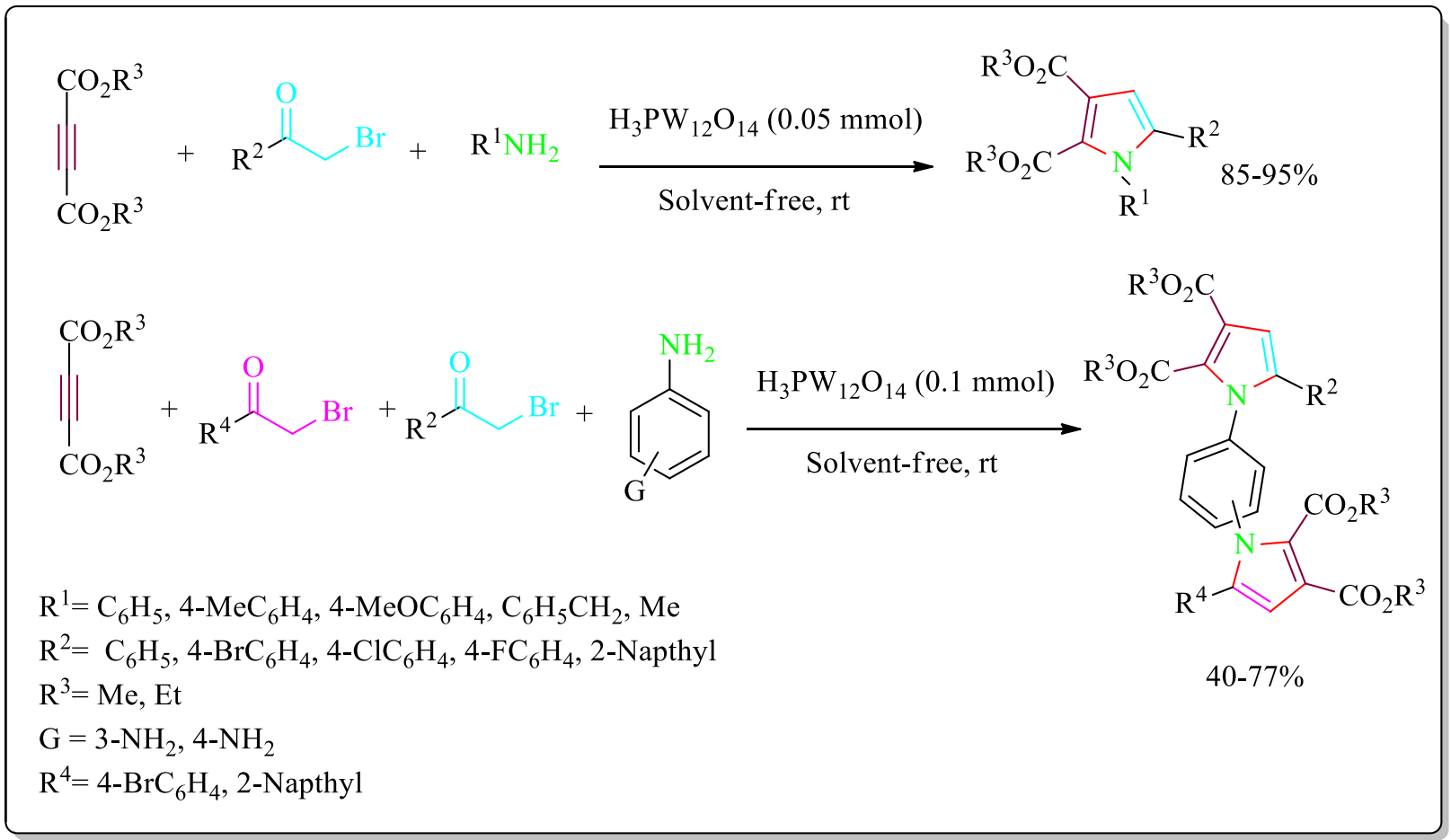

Scheme 26: Synthesis of polysubstituted pyrroles and bis-pyrroles catalyzed by $\mathrm{H}_{3} \mathrm{PW}_{12} \mathrm{O}_{40}$.

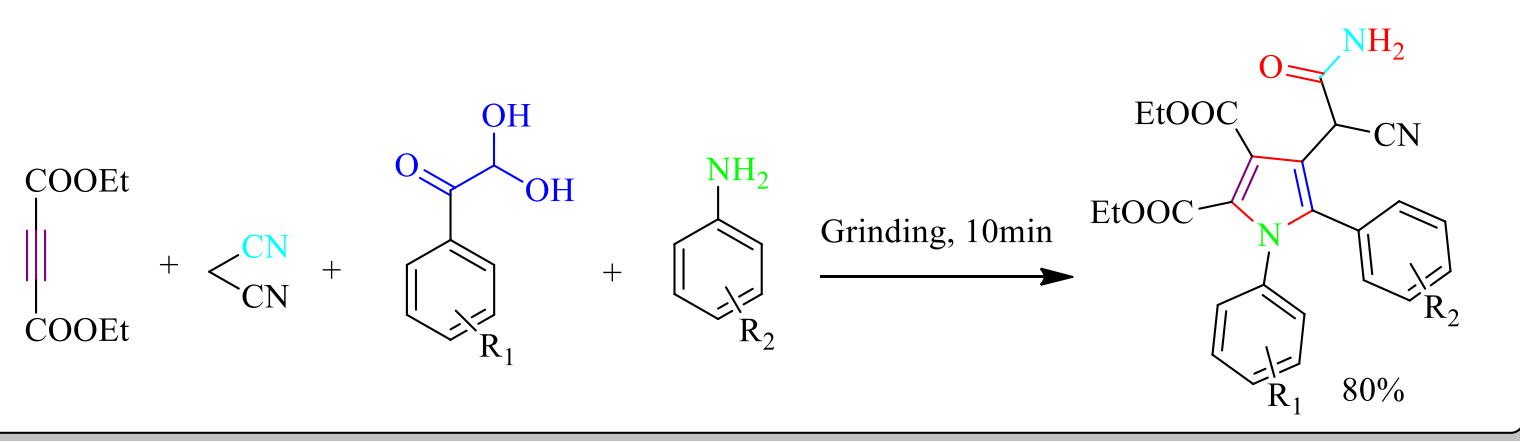

Scheme 27: Synthesis of fully substituted pyrroles. 


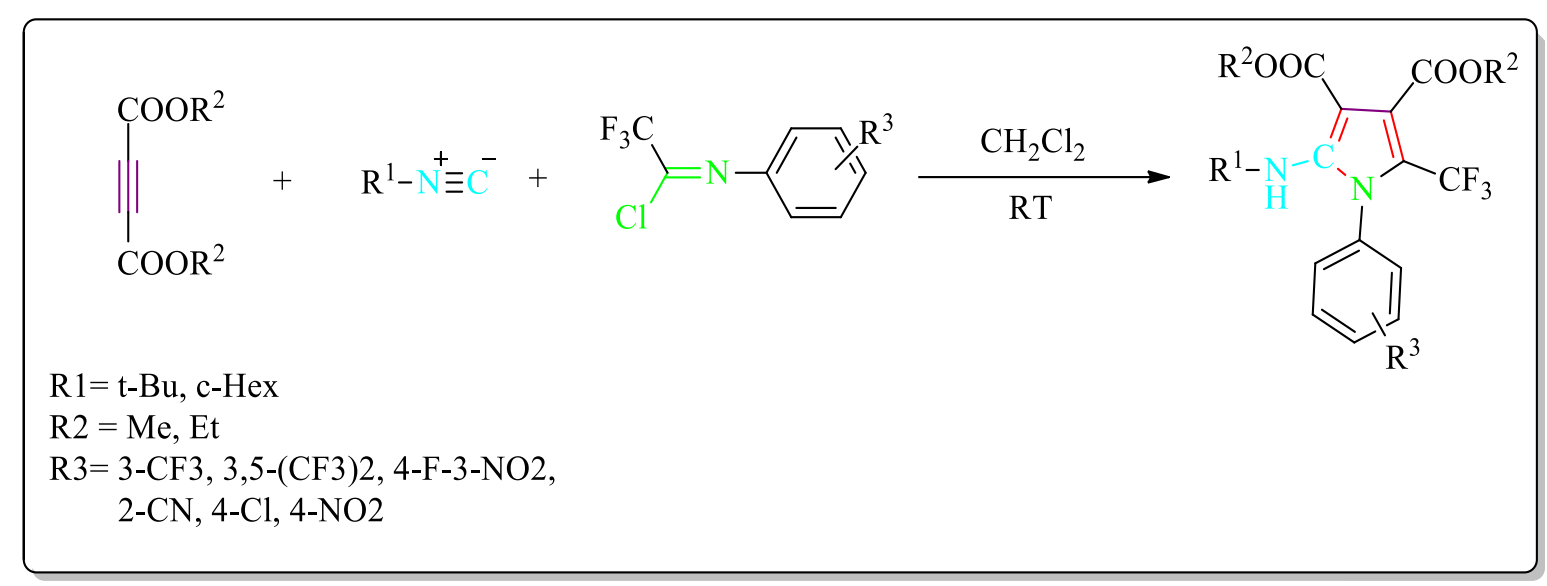

Scheme 28: Synthesis of new trifluoromethylated pyrrole derivatives.

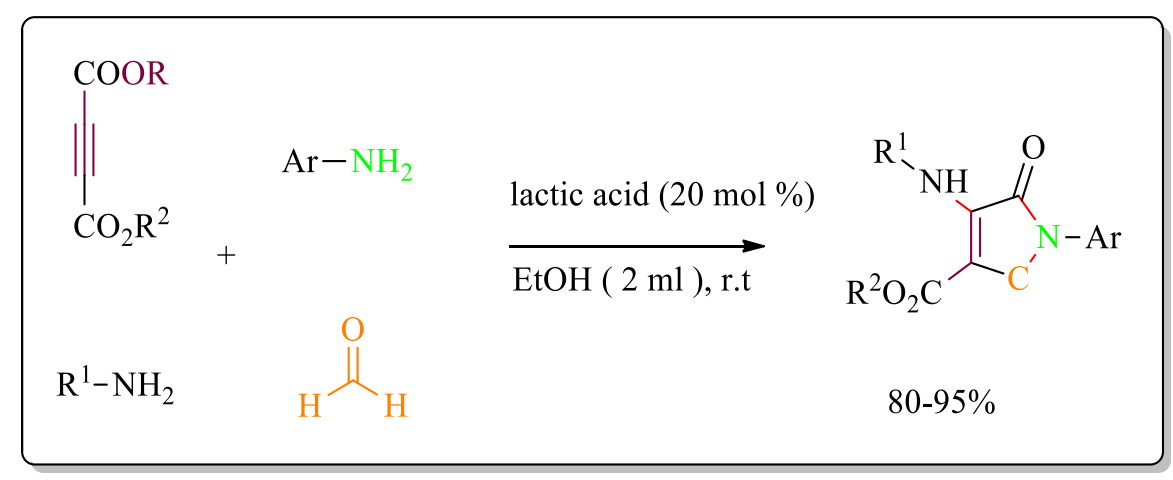

Scheme 29: Synthesis of $N$-aryl-3-aminodihydropyrrol-2-one-4-carboxylates.

\subsubsection{Synthesis of pyrroles using $\beta$-ketoesters.}

Demir and his colleagues (2006) has reported that the preparation of 2-aminopyrrole-4carboxylates through amination and annulation of $\alpha$-cyanomethyl- $\beta$-ketoesters in the presence of $\mathrm{Zn}\left(\mathrm{ClO}_{4}\right)_{2}$, under mild reaction conditions readily gives the product (Scheme 30) [60]. Metten (2006) has described the synthesis of 2-oxo-5-(hetero)arylpyrroles using 2,3-dioxo-5(hetero)arylpyrrolidines. This 2,3-dioxopyrrolidines could be synthesized by a simple reaction of diethyl oxaloacetate, aldehydes and primary amines (Scheme 31) [61]. Cadierno (2007) has reported the one-pot multicomponent synthesis of highly substituted pyrroles using secondary propargylic alcohols, 1,3-dicarbonyl compounds and primary amines in the presence of $\left[\mathrm{Ru}\left(\eta^{3}-\right.\right.$ $\left.2 \mathrm{C}_{3} \mathrm{H}_{4} \mathrm{Me}\right) \quad(\mathrm{CO})\left[\mathrm{SbF}_{6}\right] / \mathrm{CF}_{3} \mathrm{CO}_{2} \mathrm{H}$ (dppf: 1,1'-bis(diphenylphosphanyl)ferrocene) catalysts (Scheme 32, 33) [62]. Wang and his co-worker (2008) has reported the synthesis of tri- or tetrasubstituted $\mathrm{N}-\mathrm{H}$ pyrroles by reacting vinyl azides and 1,3-dicarbonyl compounds in the presence 
of $\mathrm{Mn}$ (III) complexes as catalyst (Scheme 34) [63]. Alizadeh and his co-workers (2008) have developed the preparation of pentasubstituted pyrroles through various reactions. Primary amines and alkyl acetoacetate react to form enaminones which then react with fumaryl chloride to give pyrroles (Scheme 35) [64].

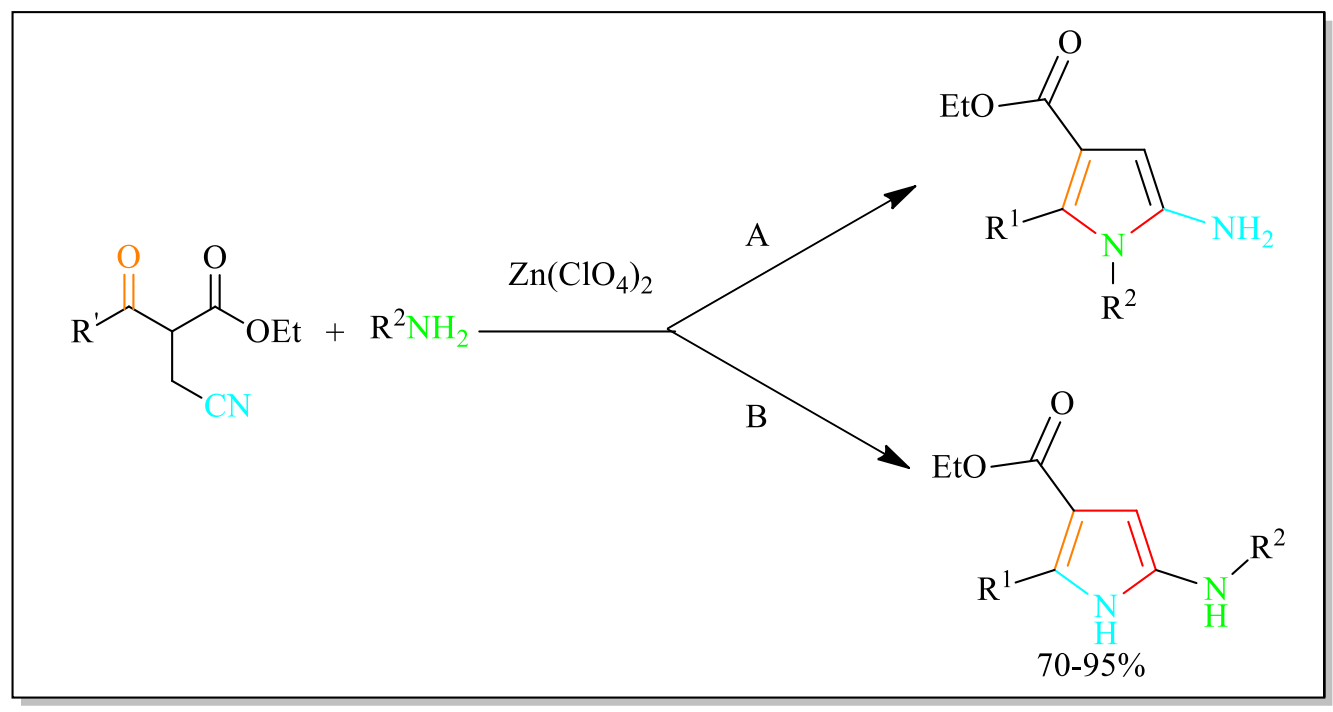

Scheme 30: Regioselective synthesis of 2-aminopyrrole-4-carboxylates using zinc perchlorate catalyzed.

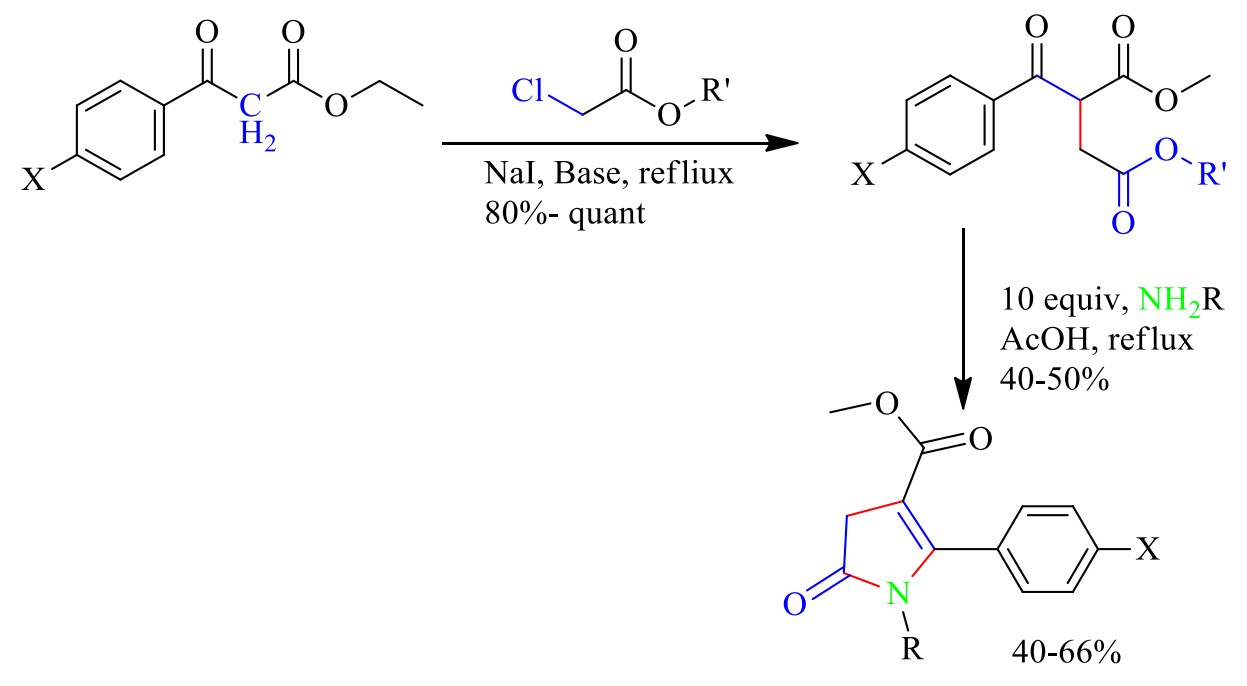

Scheme 31: Synthesis of simple 2-oxo-5-arylpyrroles starting from benzoylacetates. 


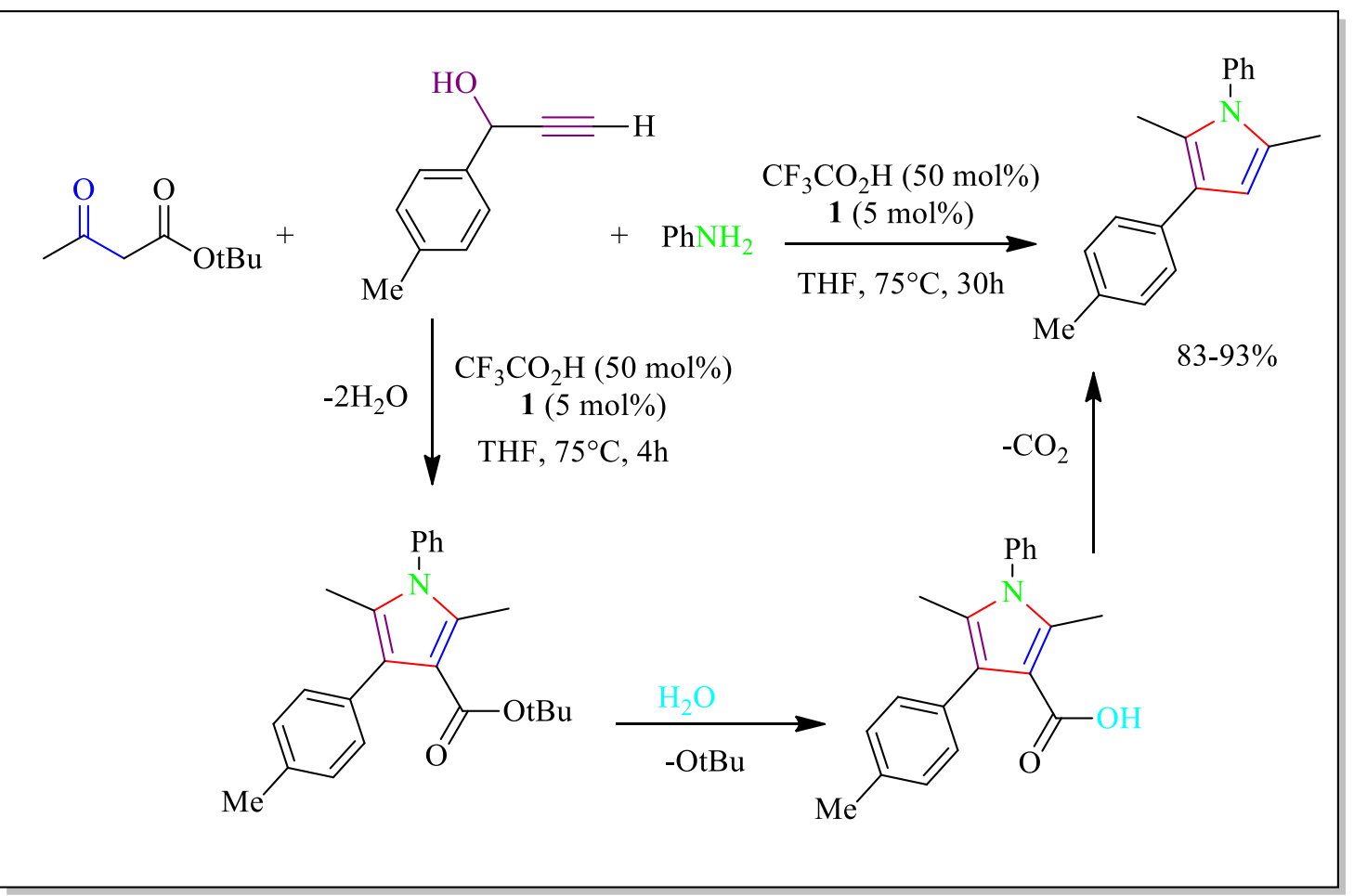

Scheme 32. Synthesis of the tetrasubstituted pyrrole derivative, where, $1=$ dppf: 1,1'bis(diphenylphosphanyl)ferrocene)

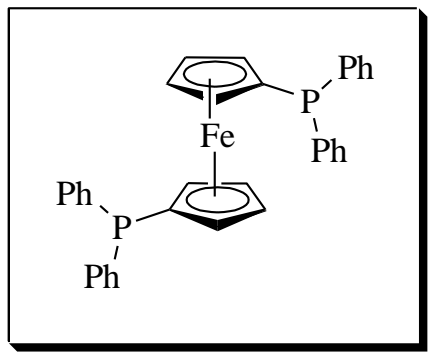

Dppf: 1,1'-bis(diphenylphosphanyl)ferrocene)

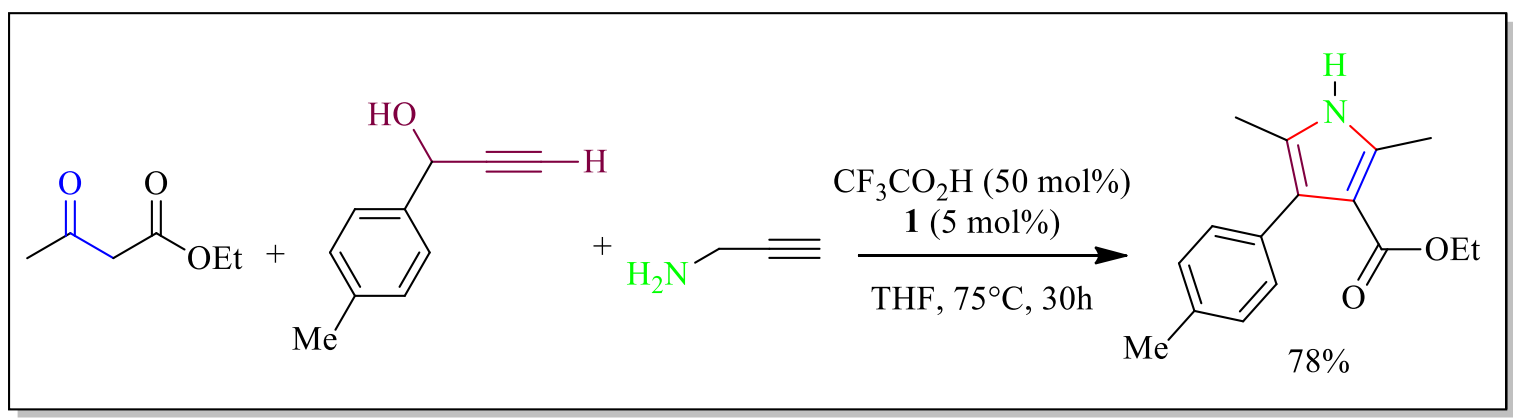


Scheme 33. Synthesis of the NH pyrrole

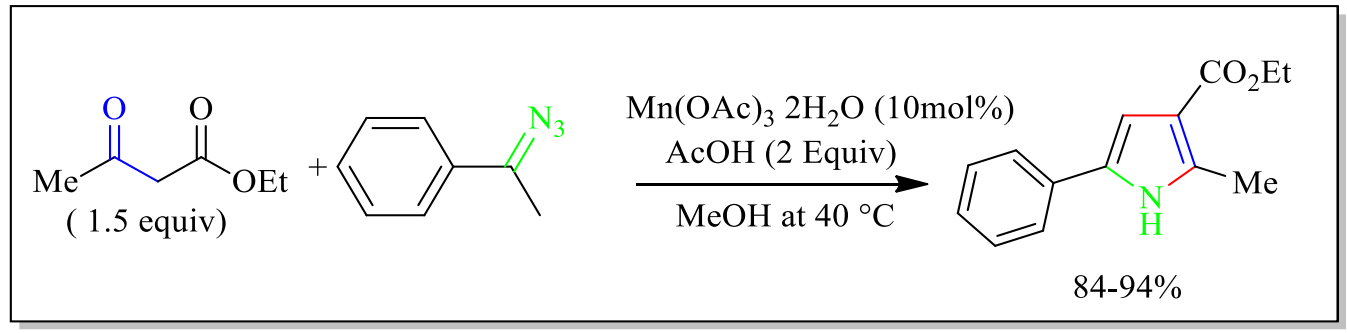

Scheme 34: Reaction of Vinyl Azide with Ethyl Acetoacetate by the use of $\mathrm{Mn}(\mathrm{OAc})_{3} \cdot 2 \mathrm{H}_{2} \mathrm{O}$

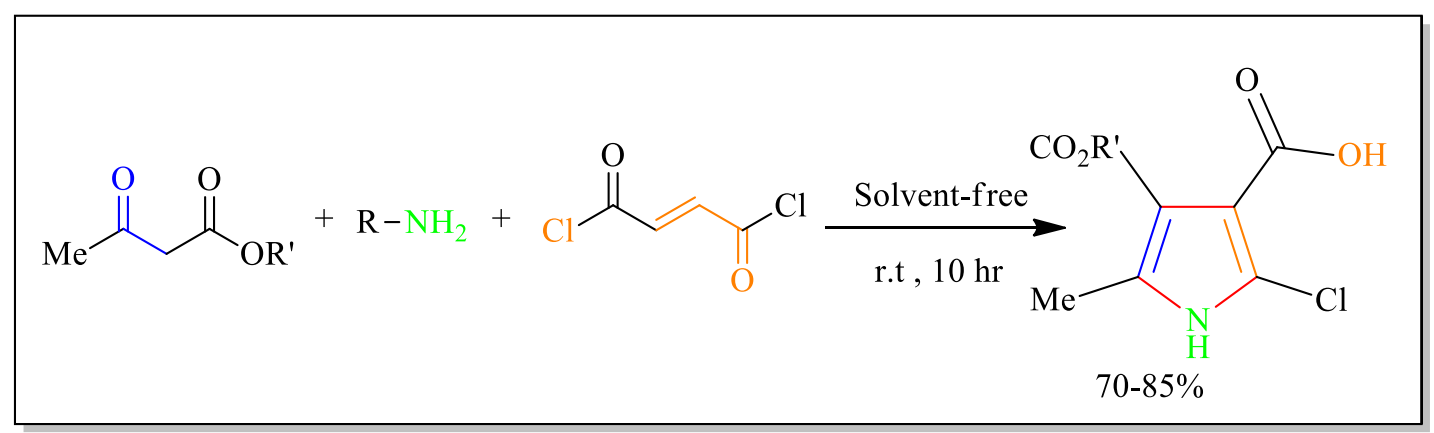

Scheme 35: One pot synthesis of pentasubstituted pyrroles using amine, alkyl acetoacetate, and fumaryl chloride

Reddy (2011) has described the synthesis of 1,2,3,4-tetrasubsttuted pyrroles derivative by using a Pd-mediated multi-component reaction followed by Suzuki or Heck or Sonogashira reaction. (Scheme 36) [65]. Magarr (2013) have reported a one-pot three component synthesis of $\mathrm{N}$ protected tetrasubstituted pyrroles by treating nitroallylic acetates with an amine and a $\beta$-keto ester mediated. Ceric ammonium nitrate in $\mathrm{MeOH}$ was used as a catalyst (Scheme 37) [66].

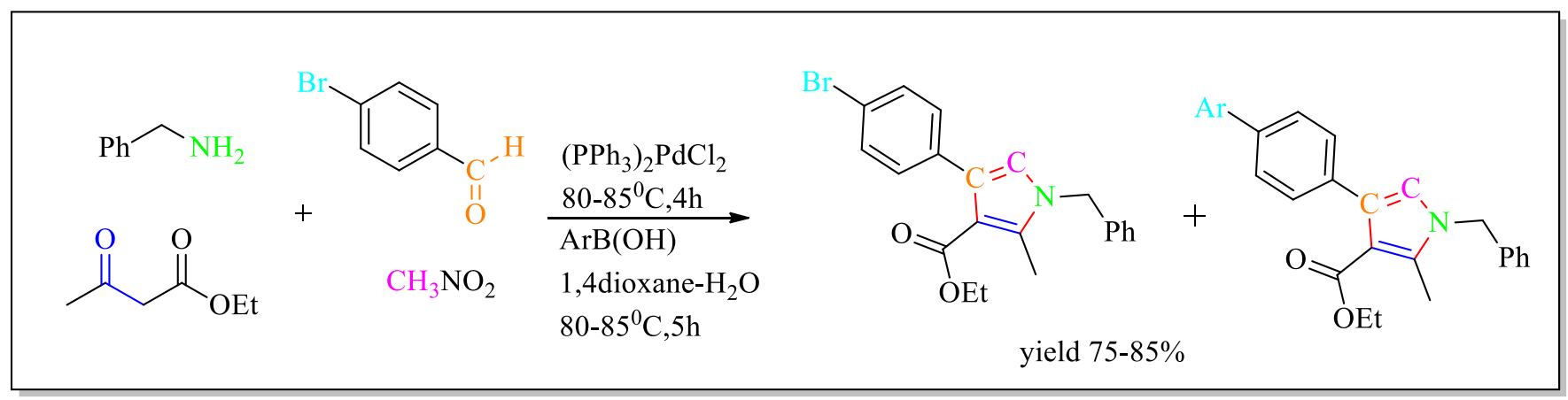

Scheme 36: Synthesis of pyrroles. 


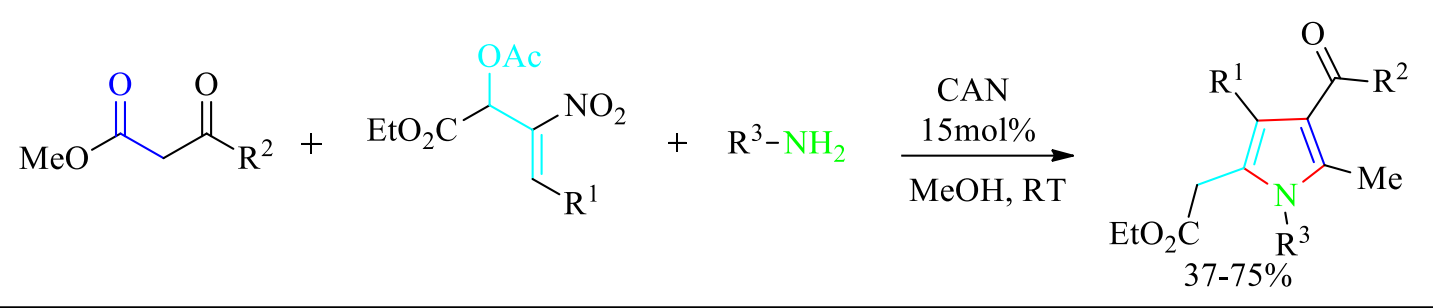

Scheme 37: Substrate scope of the synthesis of functionalized pyrroles.

Umeda et.al. (2014) have described a one pot synthesis of 1H-pyrrole-3-carboxylate derivatives using a selenium catalyzed reaction between a $\beta$-ketoester, a vinyl nitro compound and carbon monoxide (Scheme 38) [67]. Nandesh and his colleagues (2014) have developed a one-pot, facile, expedient synthesis of tetrasubstituted pyrrole by the coupling reaction between ethyl acetoacetate compound or diethyl acetylene dicarboxylate, amines, aromatic aldehydes and nitromethane in the presence of graphite as a catalyst (Scheme 39) [68]. Gujarathi and his co-workers (2014) have developed a one-pot, effective synthesis of fully substituted pyrroles via propargylation/animation/cycloisomerization of propargylic alcohols, $\beta$ keto esters and aliphatic amines in the presence of $\mathrm{AgSbF}_{6}$ as catalyst under mild temperature along with acetic acid, thus preventing the formation of furan as side product (Scheme 40) [69]. Karamthulla and his colleagues (2014) have reported a synthesis of pentasubstituted pyrroles by reacting arylglyoxal monohydrate, $\beta$-keto esters, amines and various cyclic 1,3-dicarbonyls in mild conditions without catalyst and column chromatography for purification (Scheme 41) [70]. Shinde et.al. (2015) have reported a solvent-free one-pot synthesis of varied pyrrole derivatives by multicomponent reaction between aldehydes, nitroalkanes, amine and enolizable active $\mathrm{C}-\mathrm{H}$ reactants in the presence of polystyrene-supported $p$-toulenesulfonic acid (PS-PTSA) and under microwave irradiation (Scheme 42) [71].

$$
\underbrace{}_{\mathrm{COOC}_{2} \mathrm{H}_{5}}+\mathrm{R}_{\mathrm{R}^{1}}{ }_{\mathrm{NO}_{2}}^{\mathrm{O}}+\mathrm{CO}
$$


Scheme 38: Synthesis of $1 \mathrm{H}$-pyrrole-3-carboxylate derivatives.

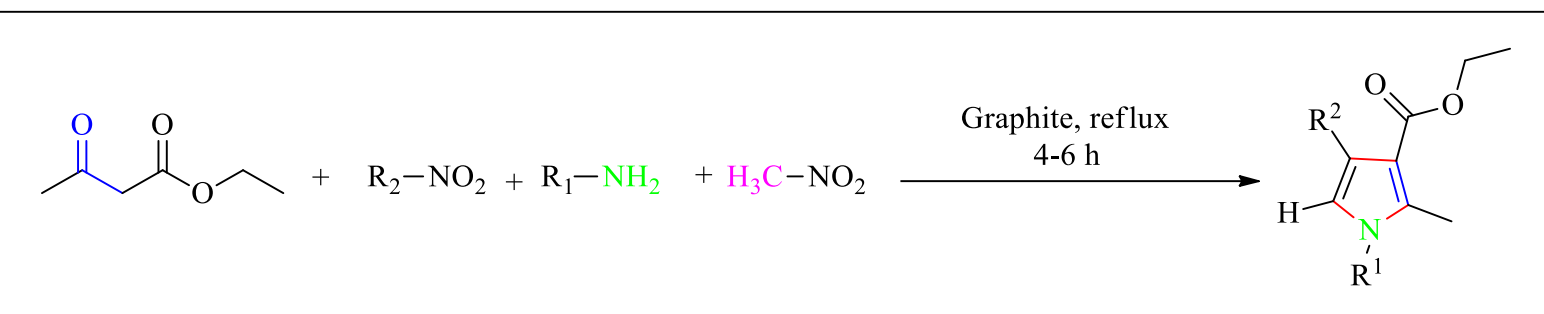

Scheme 39: Graphite-mediated synthesis of functionalized pyrroles.

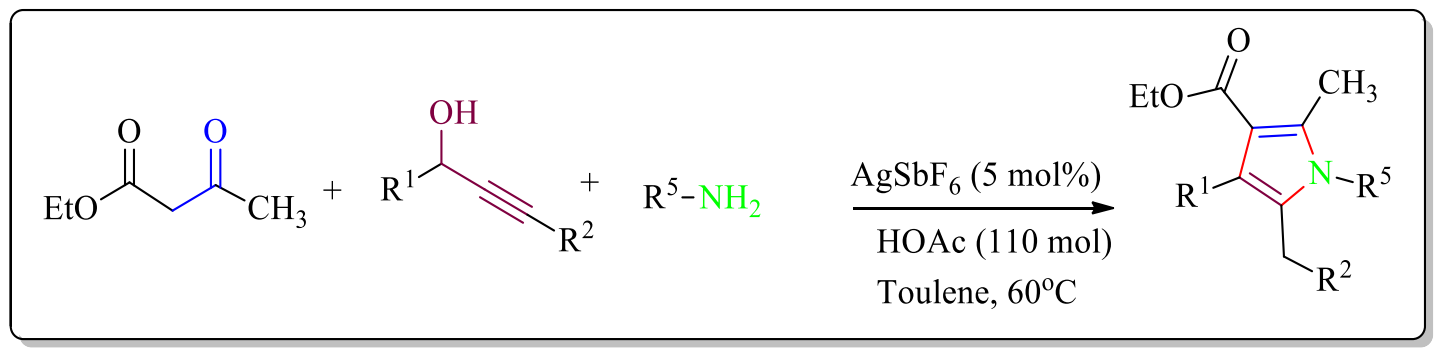

Scheme 40: Synthesis of fully substituted pyrroles from aliphatic primary amines.

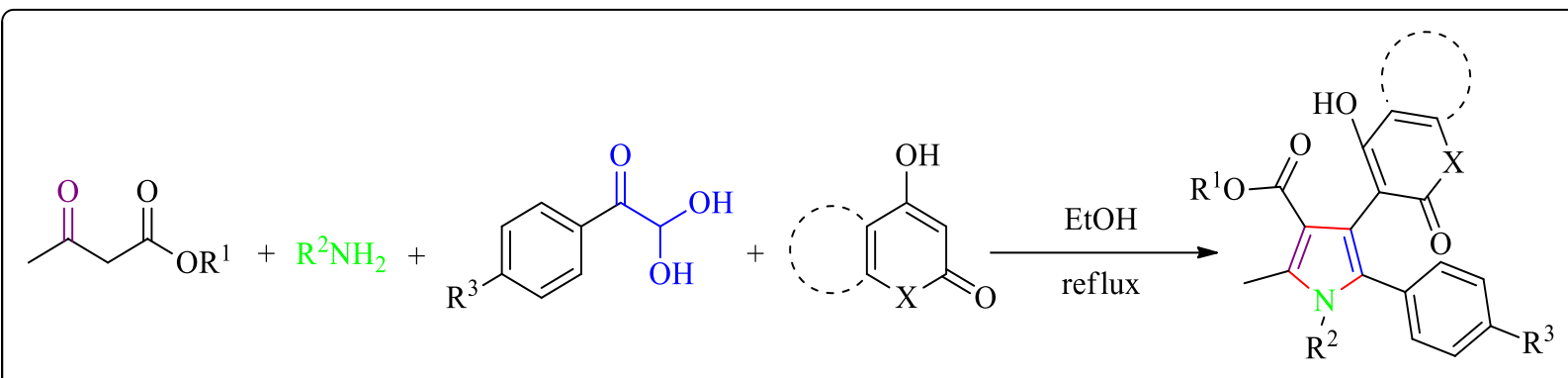

Scheme 41: Synthesis of Pentasubstituted Pyrroles.<smiles>[R]N[I+]C([R])CC(=O)O[R]</smiles><smiles>COc1ccc(S(=O)(=O)O)cc1</smiles><smiles></smiles>

Scheme 42: Synthesis of tetrasubstituted pyrrole derivative catalyzed by PS-PTSA.

\subsubsection{Synthesis of pyrrole by using 1,2dicarbonyl group}


Ghashang et al. (2011) have reported the preparation of 1,5-diaryl-3-(arylamino)-1H-pyrrol$2(5 H)$-ones via the cyclo-condensation reaction of aldehydes, amines and ethyl pyruvate which used silica-supported ferric chloride $\left(\mathrm{SiO}_{2} . \mathrm{FeCl}_{3}\right)$ as a returnable heterogeneous catalyst (Scheme43) [72]. Lin et al. (2013) have reported a one-pot multicomponent synthesis of polysubstituted pyrroles from primary amines, ethyl glyoxalate and 2-bromoacetophenones. Pyridine and acetonitrile were used as catalyst (Scheme 44) [73].

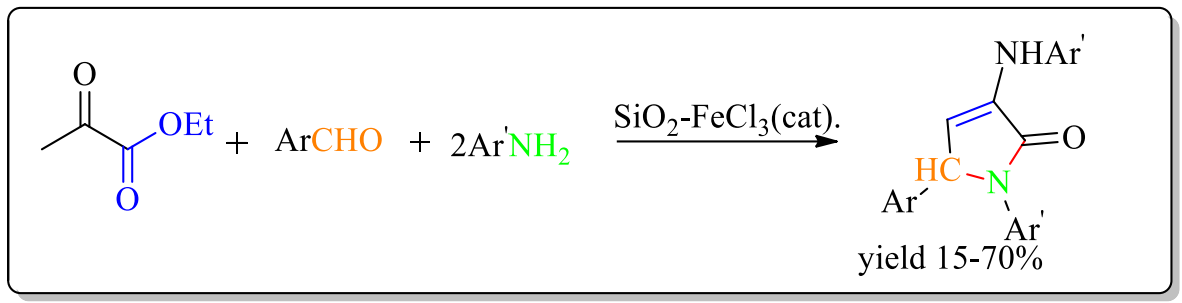

Scheme 43: Synthesis of 1,5-diaryl-3-(arylamino)-1 $\mathrm{H}$-pyrrol- $2(5 \mathrm{H})$-one derivatives using $\mathrm{SiO}_{2}$ $\mathrm{FeCl}_{3}$ as catalyst.

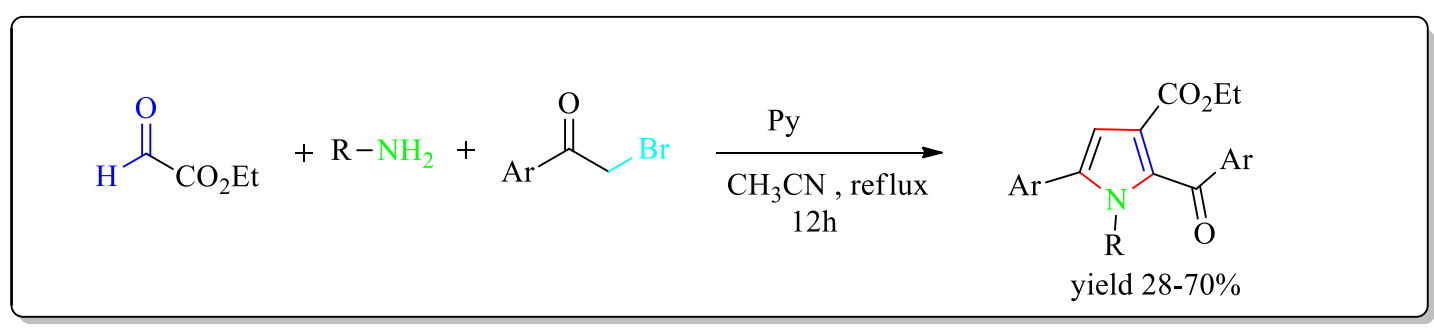

Scheme 44: One-pot multicomponent reactions for the synthesis of pyrrole.

Yavari and his co-workers (2014) have reported that an imidoyl chloride, produced from isocyanides and acyl chlorides, when treated with trialkyl phosphites using a Perkow-type reaction generates 3-(alkylimino)-2-[(dialkyloxyphosphoryl)oxy]acrylates, which in turn on treatment with tosylmethyl isocyanide (TsMIC) produces 4-(alkylamino)-3-[(dialkyloxyphosphoryl)oxy]-5-[(4methylphenyl)sulfonyl]-3H-pyrrole-3-carboxylates in high yield (Scheme 45) [74]. Zheng et al. (2015) have reported the synthesis polysubstituted pyrroles via the organocatalyzed three component reaction of 1,2-diones, aldehydes and arylamines in the presence of 4methylbenzenesulfonic acid monohydrate (Scheme 46) [75]. Farahi and his co-workers (2016) 
have developed the one-pot synthesis of tetrasubstituted pyrroles in high yield by treating three components i.e. $\alpha$-hydroxyketones, malonitrile and ammonium acetate in the presence of tungstate sulfuric acid (TSA) and solvent free conditions (Scheme 47) [76].

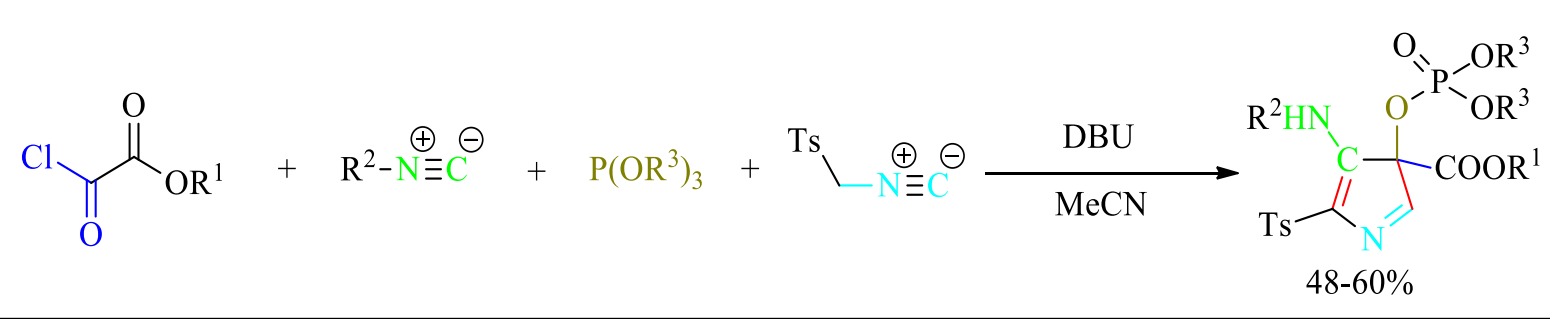

Scheme 45: Synthesis of Functionalized 3-[(Dialkyloxyphosphoryl)oxy]-3H-pyrrole3-carboxylates.

$$
\prod_{\mathrm{O}}+\mathrm{Ar}^{1}-\mathrm{NH}_{2}+\mathrm{R}^{1} \mathrm{CHO} \frac{\mathrm{CH}_{3} \mathrm{CN}, \mathrm{rt}}{\stackrel{\mathrm{TsOH} \cdot \mathrm{H}_{2} \mathrm{O}(20 \mathrm{~mol} \%)}{\longrightarrow}}
$$

Scheme 46: Substrate scope of the organocatalyzed three-component Reactions.

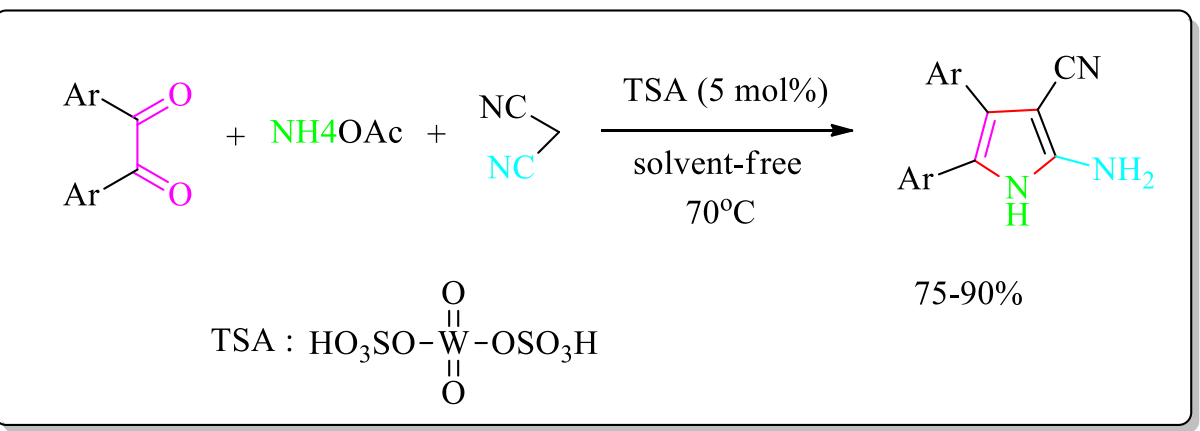

Scheme 47: TSA-catalyzed one-pot synthesis of tetrasubstituted pyrroles.

\subsubsection{Synthesis of pyrroles using 1,3-dicarbonyl compound}

Bellur and his partner (2006) have described the synthesis of a variety of pyrroles by condensation of 1,3-dicarbonyl compounds with 2-azido-1,1-diethoxyethane and followed by cyclization (Scheme 48) [77]. Khalili and his co-workers (2008) have developed a one-pot preparation of new 2-alkyl-5-aryl-(1H)-pyrrole-4-ol derivatives using $\beta$-dicarbonyl compounds and arylglyoxals 
under ammonium acetate in water as a catalyst (Scheme 49) [78]. Dou and his co-workers (2008) have developed the preparation of 1,2,3,5-tetra and 1,2,3,4,5-penta substituted pyrroles from three components 1,3-diketones, aldehydes, and amines mediated by a $\mathrm{TiCl}_{4} / \mathrm{Sm}$ system (Scheme 50, 51) [79]. Liu (2008) has developed a one-pot synthesis of highly substituted pyrroles by propargylic alcohols, 1,3dicarbonyl compounds and primary amines via indium (III) chloride as catalyst (Scheme 52, 53) [80].

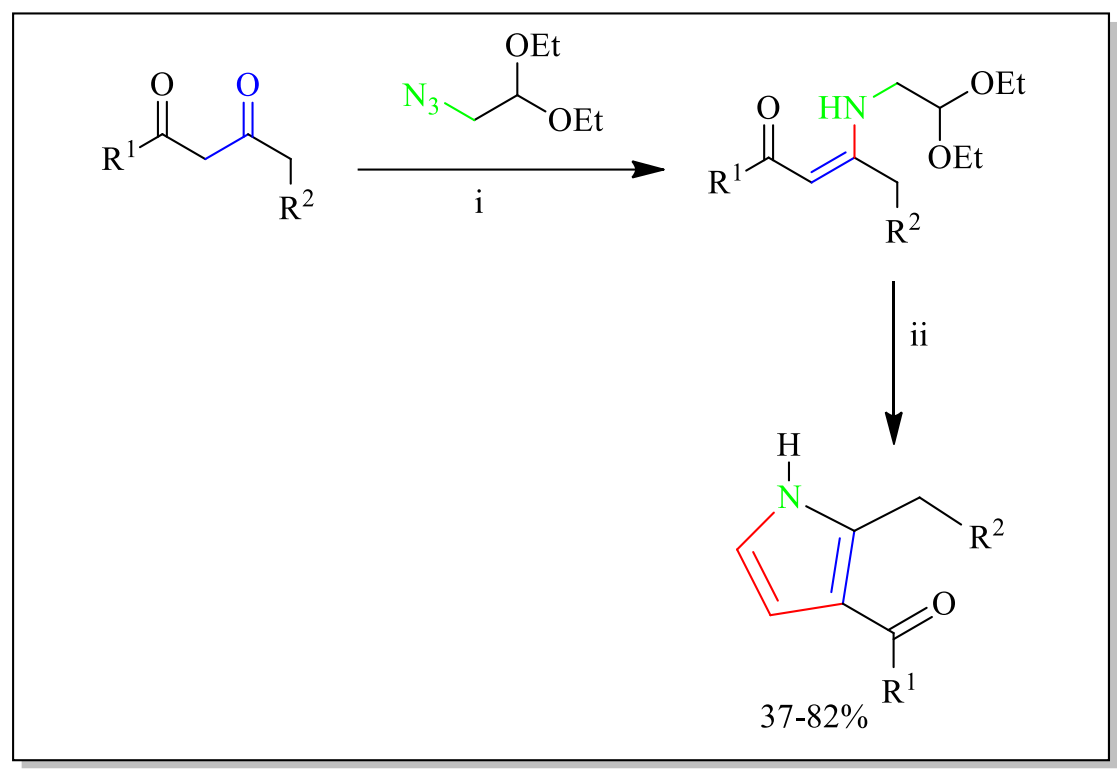

Scheme 48: Synthesis of functionalized pyrrole. Reagents and conditions: (i) $\mathrm{PPh}_{3}$, THF, reflux, $8 \mathrm{~h}$; (ii). Method A: TFA (10 equiv), $\mathrm{CH}_{2} \mathrm{Cl}_{2}, 0$ - $20^{\circ} \mathrm{C}, 12 \mathrm{~h}$; method B: Me $3 \mathrm{SiOTf}$ (1 equiv), $\mathrm{CH}_{2} \mathrm{Cl}_{2},-78-20{ }^{\circ} \mathrm{C}$ (for b-ketoesters) or 0 - $20{ }^{\circ} \mathrm{C}$ (for 1,3-diketones), $12 \mathrm{~h}$; method C: DMSO, $150{ }^{\circ} \mathrm{C}, 24 \mathrm{~h}$.

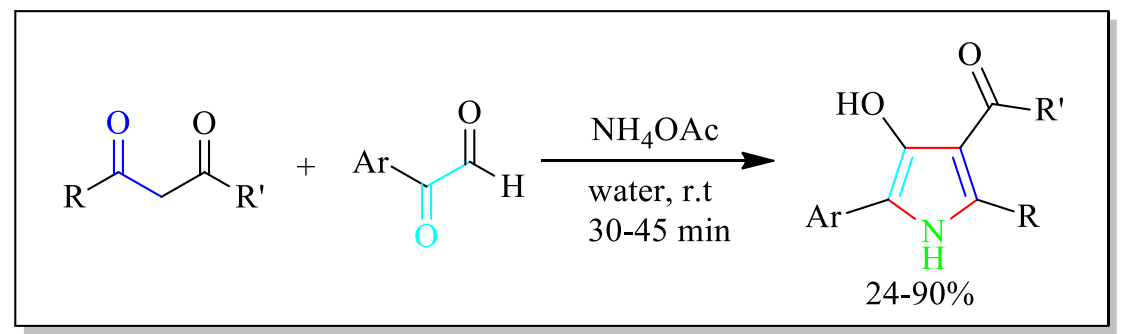

Scheme 49: Synthesis of 5-Aryl-(1H)-pyrrole-4-ol. 


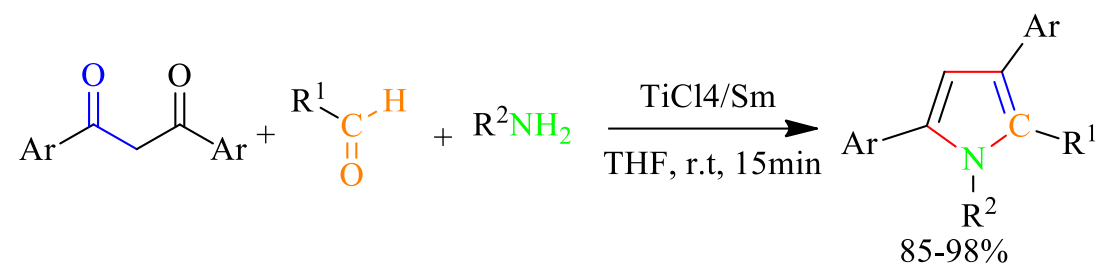

Scheme 50: Three-Component Reaction of Symmetrical 1,3-Diketones, Aldehydes, and Amines Induced by Low-Valent Titanium (TiCl4/Sm).

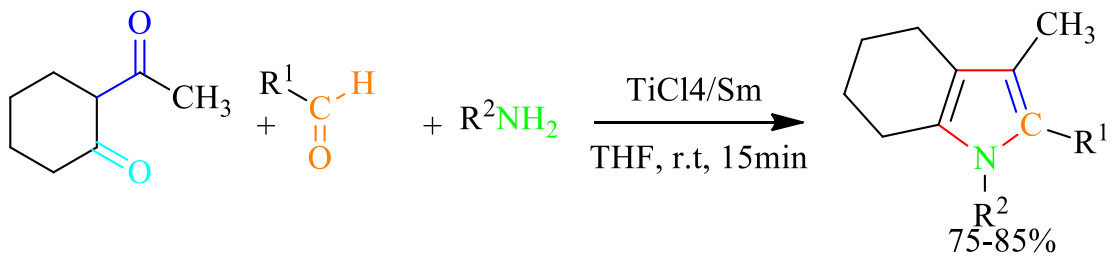

Scheme 51: Three-Component Reaction of Unsymmetry 1,3-Diketone, Aldehydes and Amines Induced by Low-Valent Titanium Reagent (TiCl4/Sm).

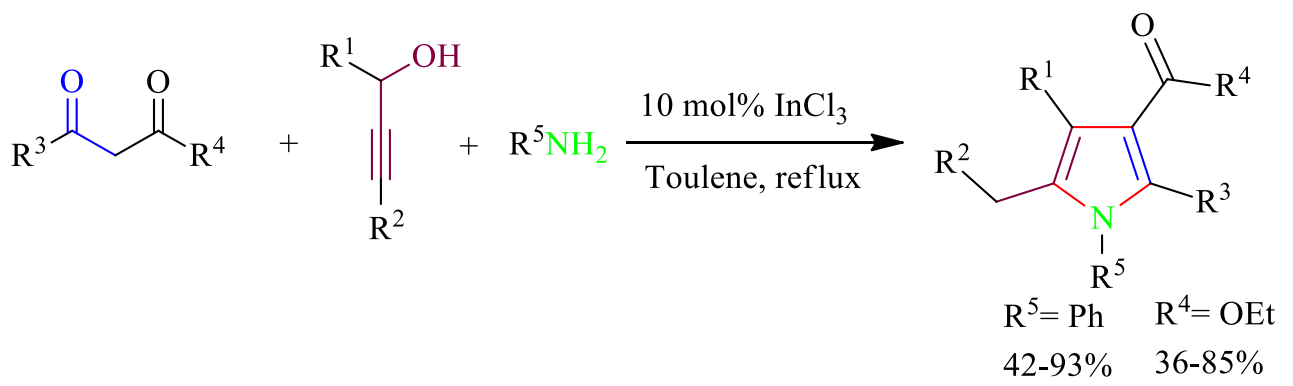

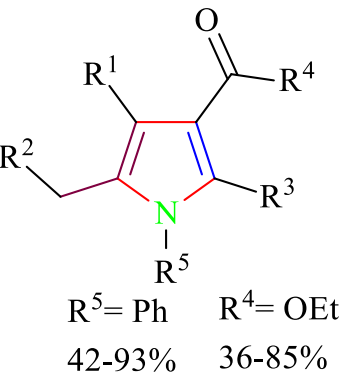

Scheme 52: Synthesis of highly substituted pyrroles from propargylic alcohols, 1,3-dicarbonyl compounds and primary amines. 


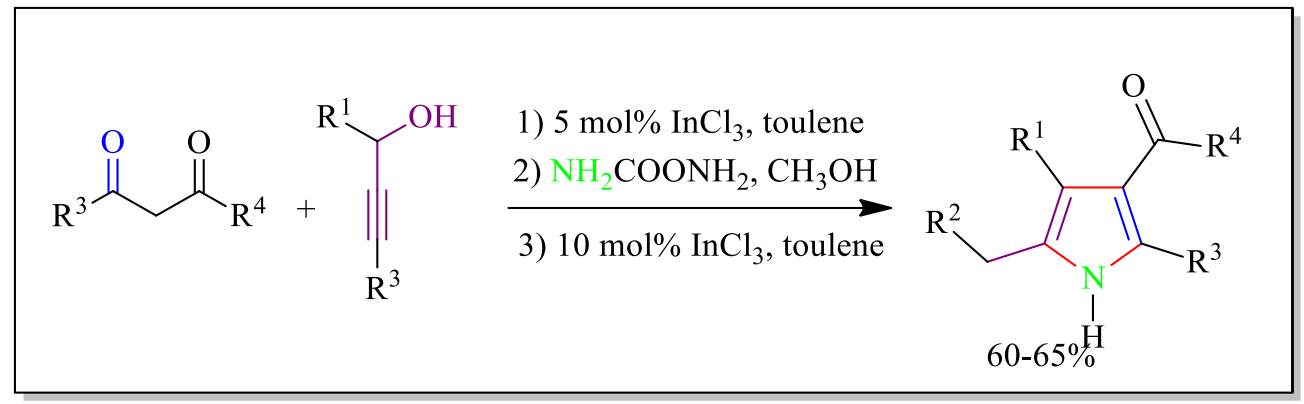

Scheme 53: Synthesis of the N-H pyrroles.

Cadierno (2010) reported the three-component synthesis of tetrasubstituted NH pyrroles, functionalized with ester or ketone groups at the C-3 position, prepared by one-pot coupling of secondary propargylic alcohols with 1,3-dicarbonyl compounds and tert-butyl carbamate, via in situ deprotection of the corresponding pentasubstituted $N$-Boc pyrroles. The three-component coupling process was promoted by the combined use of the 16electron ruthenium (II) catalyst $\left[\mathrm{Ru}\left(\eta^{3}-2-\mathrm{C}_{3} \mathrm{H}_{4} \mathrm{Me}\right) \quad(\mathrm{CO})(\mathrm{dppf})\right] \quad[\mathrm{SbF} 6] \quad(\mathrm{dppf} \quad 1 / 4 \quad 1,10-$ bis(diphenylphosphino)ferrocene) and trifluoroacetic acid (TFA) (Scheme 54) [81]. Tamaddon and his associates (2012) have reported that a new method for the three component reaction of benzoin derivatives, 1,3-dicarbonyls, and ammonium acetate generated the desired products in good yield in the presence of solvent-free conditions (Scheme 55) [82]. Estvez (2013) has reported a newly developed one-pot multicomponent synthesis of polysubstituted, functionalized pyrroles under solvent-free mechanochemical conditions using ketones, primary amines and a $\beta$-di carbonyl with cerium (IV) ammonium nitrate and silver nitrate catalyst (Scheme 56) [83]. Bhat et al. (2013) have reported the facile method for the regioselective synthesis of tetrasubstituted pyrroles from 1,3-dicarbonyl, benzoin derivatives and ammonium acetate, was developed (Scheme 57) [84].

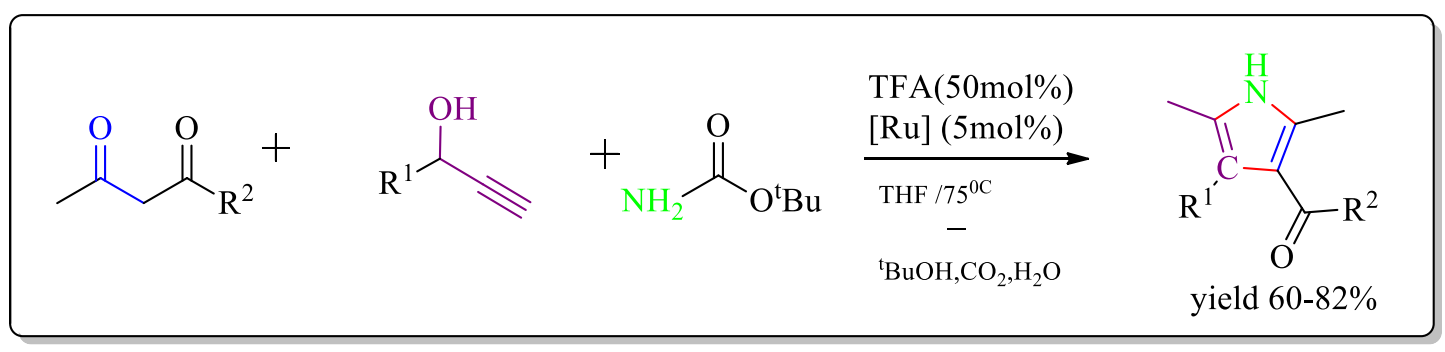

Scheme 54: Synthesis of Tetrasubstituted NH Pyrroles from Secondary Propargylic Alcohols, 1,3-Dicarbonyl Compounds and tert-Butyl Carbamate. 


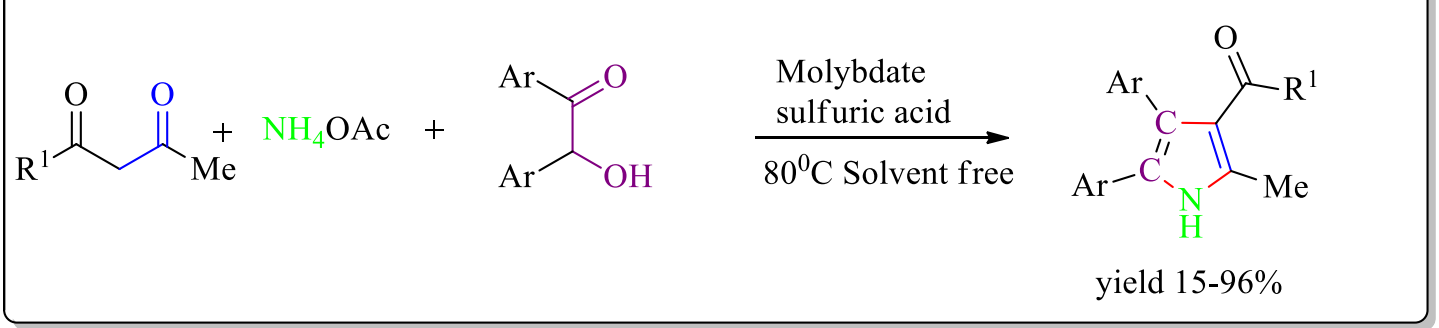

Scheme 55: Molybdate sulfuric acid catalyzes the synthesis of 2,3,4,5-tetrasubstituted pyrroles.

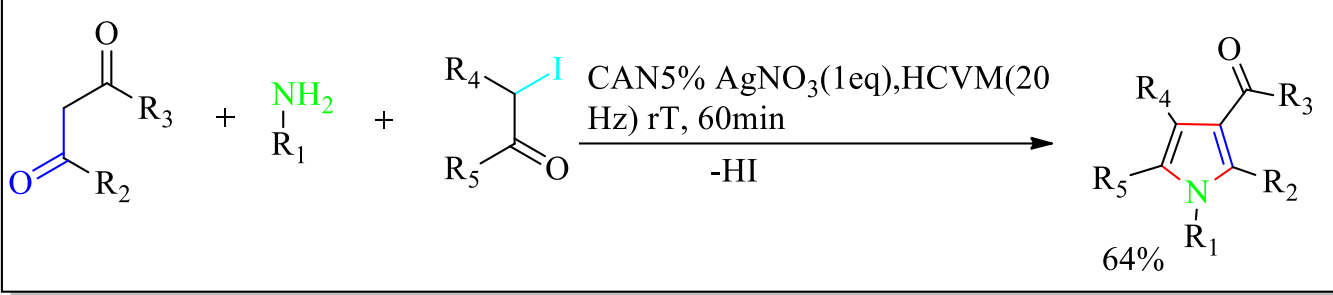

Scheme 56: Sequential three-component pyrrole synthesis.

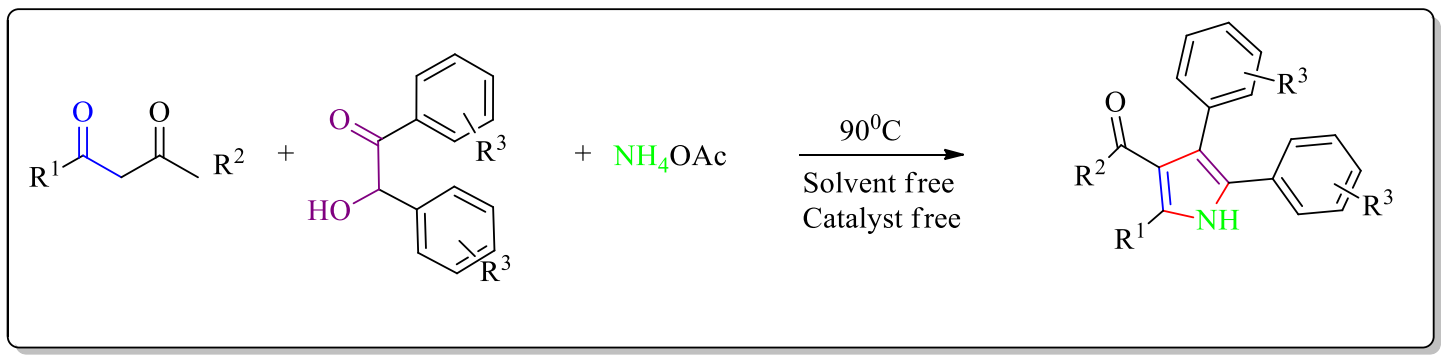

Scheme 57: One pot three- component synthesis tetrasubstituted pyrroles.

Abdelmohsen and El-Ossaily (2015) have reported the synthesis of 5-( $N$-substituted pyrrol-2-yl)8-hydroxyquinolines by treatment of 5-chloroacetyl-8-hydroxyquinoline, acetylacetone pentane2,4-dione, and amines in the presence of 1,4-diazabicyclo [2.2.2] octane as catalyst at $60^{\circ} \mathrm{C}$ (Scheme 58) [85]. Goyal and his co-workers (2015) have reported the one-pot synthesis of multisubstituted pyrroles by reacting amines, $\beta$-dicarbonyl compounds and nitroalkenes in the presence of zirconocene dichloride in ethanol medium as a catalyst (Scheme 59) [86]. Reddy et al. (2016) have reported the one-pot synthesis of 2,4,5-trisubstituted pyrrole by condensation reaction between 1,3-diones, $\alpha$-bromoacetophenones, and ammonium acetate using ionic liquid [bmim]BF 4 (Scheme 60) [87]. Yu (2016) has reported a one-pot synthesis of tetrasubstituted and fused pyrroles in a cascade fashion via $\mathrm{Pd}(\mathrm{TFA})_{2}$-catalyzed [4+1] annulation of chained or cyclic alkenyl 
-dicarbonyl compounds and unprotected primary amines. The annulation products were isolated in high yield with $\mathrm{O}_{2}$ as terminal oxidant in a mild condition (Scheme 61) [88]. Shahvetayati and his co-workers (2017) have reported a rapid, effective and one pot multicomponent synthesis of 1,2,3,5-tetrasubstituted pyrrole derivatives by reacting amines, 1,3-dicarbonyl compounds and $\alpha$ heloketones using $\mathrm{ZnO}$ nanoparticles as a catalyst under ultrasonic irradiation and solvent-free conditions (Scheme 62) [89].

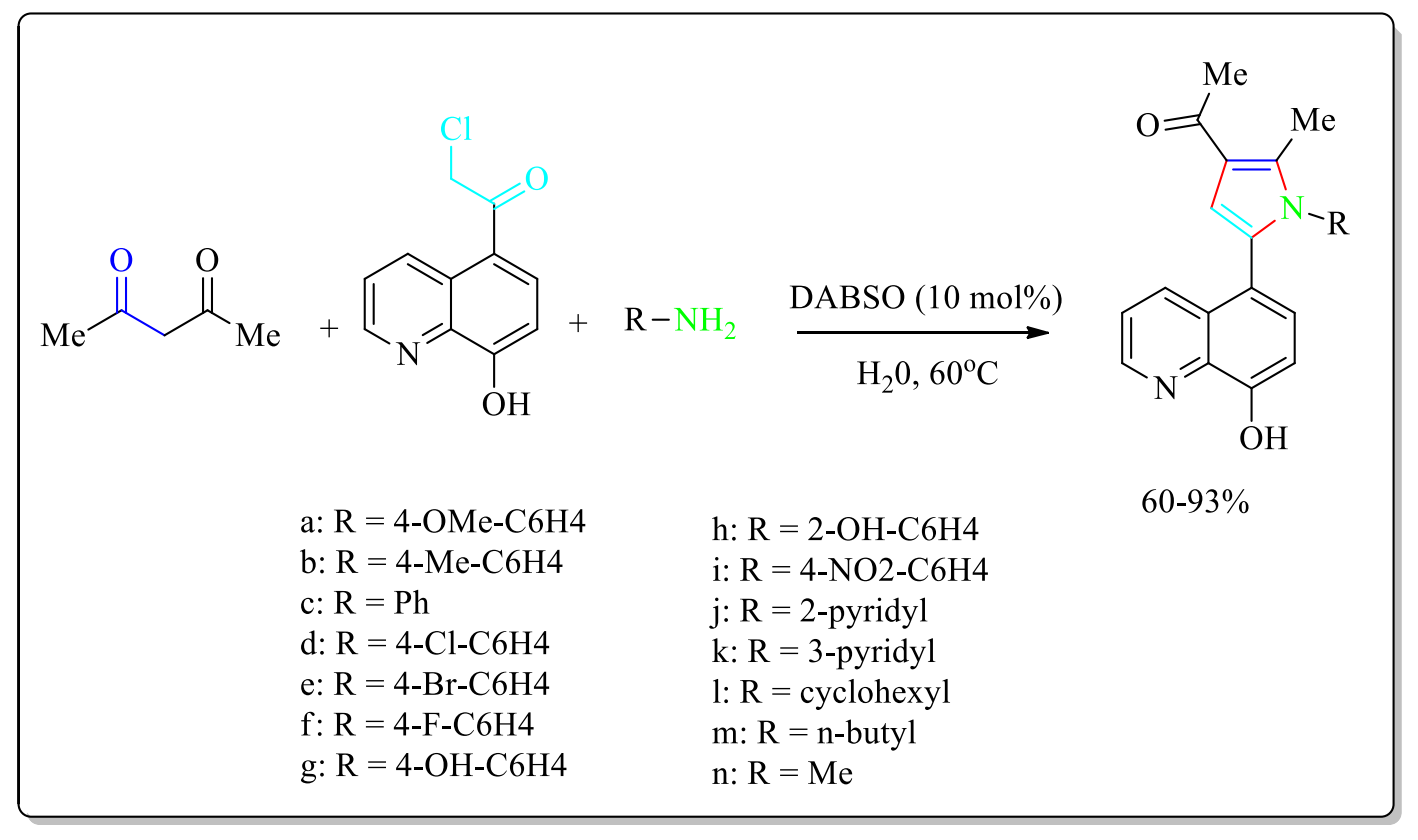

DABSO??

Scheme 58: Synthesis of 5-( $N$-substituted pyrrol-2-yl)-8-hydroxyquinolines.

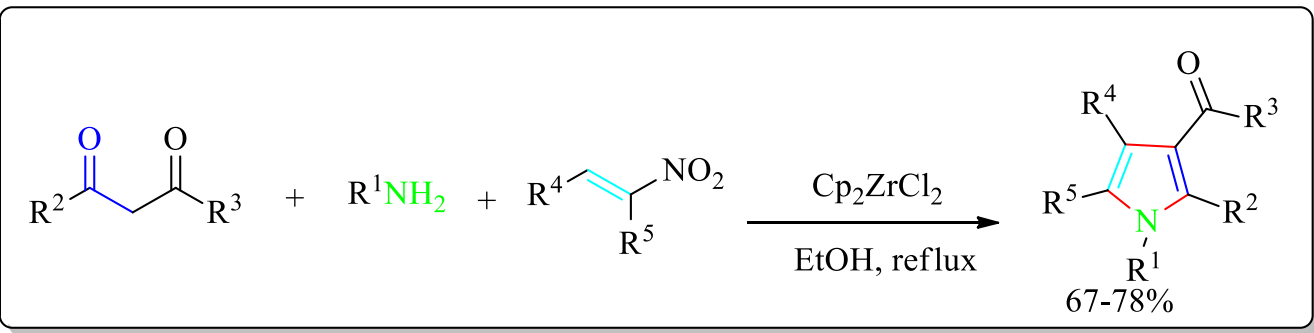

Scheme 59: Synthesis of multi-substituted pyrroles. 


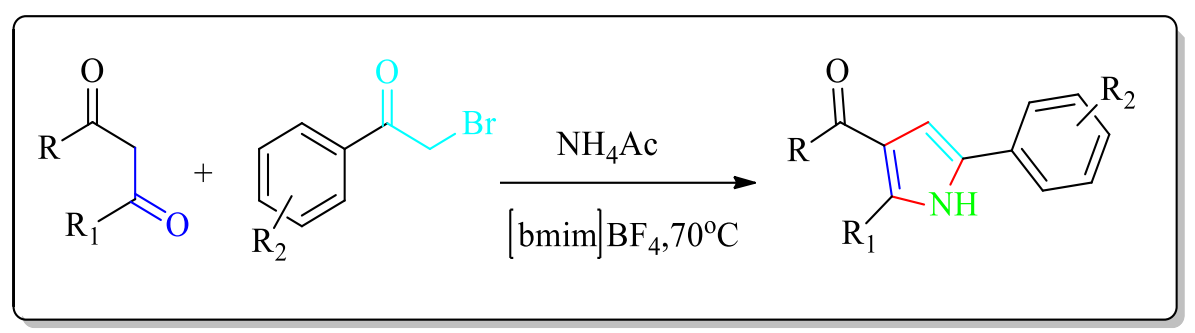

Scheme 60: Screening of solvents using different temperatures and times in synthesis of 2,4,5-trisubstituted pyrroles from 1,3-diketones, $\alpha$-bromoacetophenones, and ammonium acetate.

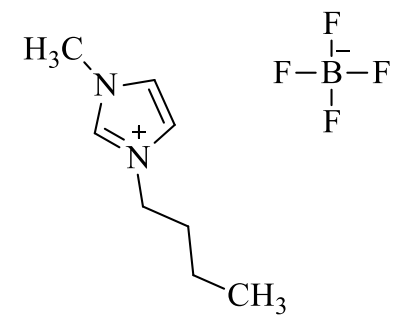

[bmim $] \mathrm{BF}_{4}=1$-Butyl-3-methylimidazolium tetrafluoroborate

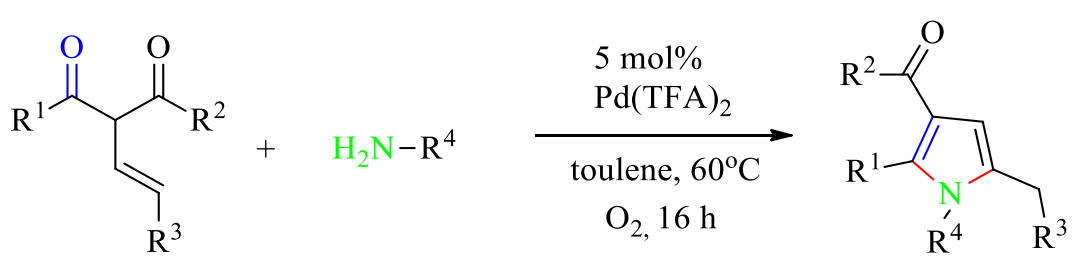

Scheme 61: Scope of $\operatorname{Pd}(\mathrm{TFA})_{2}$-catalzyed synthesis of pyrroles.

$$
\begin{aligned}
& \mathrm{R}^{2} \stackrel{\mathrm{O}}{\mathrm{O}}{ }_{\mathrm{CH}_{3}}^{\mathrm{O}}+\mathrm{R}^{1}-\mathrm{NH}_{2}+\mathrm{R}^{3}+\mathrm{Br} \\
& \underset{\text { solvent free }}{\stackrel{\mathrm{NPs}-Z \mathrm{nO} 15 \mathrm{~mol} \%}{\longrightarrow}} \\
& \text { OO } \\
& \mathrm{R}^{1}=\text { aliphatic, aromatic } \mathrm{R}^{2}=\mathrm{OEt}, \mathrm{OMe} ; \mathrm{R}^{3}=\mathrm{H}, \mathrm{OMe}, \mathrm{Br}, \mathrm{COOEt} \\
& 88-94 \%
\end{aligned}
$$

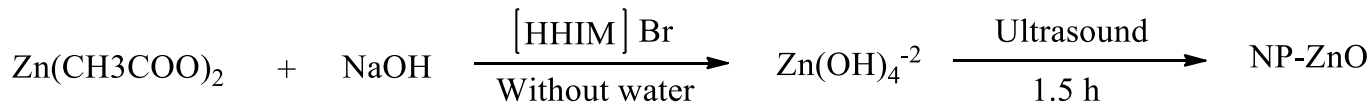


Scheme 62: Synthesis of tetra-substituted pyrroles.

\subsubsection{Synthesis of pyrroles using 1,3-dicarbonyl compounds with amine, nitro and aldehyde groups}

Maiti et al. (2010) have reported a synthesis of functionalized pyrroles from the four component coupling reaction of 1,3-dicarbonyl compounds, amines, aldehydes, and nitroalkanes catalyzed by iron(III) (Scheme 63) [90]. Khan et al. (2012) have reported a synthesis of tetra-substituted pyrroles by using four component reactions starting from amines, $\beta$-ketoesters or 1,3-dicarbonyl compounds, aromatic aldehydes or heteroaromatic aldehydes, and nitroalkanes with $10 \mathrm{~mol} \%$ $\mathrm{NiCl}_{2} .6 \mathrm{H}_{2} \mathrm{O}$ as catalyst in good yields (Scheme 64) [91]. Reddy et al. (2012) has reported one-pot four component synthesis of 1,3-dicarbonyl compounds, amines, aldehydes and nitroalkanes generating polysubstituted pyrroles. Iodine was used as a catalyst (Scheme 65) [92]. Saeidian et al. (2013) have reported a one-pot synthesis of highly substituted pyrroles from aromatic aldehydes, $\beta$-keto esters and nitromethane using an amine catalyst and $10 \mathrm{~mol} \% \mathrm{CuO}$ nanoparticles (Scheme 66) [93]. Atar et al. (2013) have reported the newly developed one-pot synthesis of structurally diverse tetrasubstituted pyrrole derivatives from amines, aldehydes, active methylene compounds and nitroalkanes using heterogeneous silica tungsten acid catalyst (Scheme 67) [94]. $\mathrm{Li}$ and his colleagues (2013) have reported that gluconic acid promotes the synthesis of functionalized pyrroles via a one-pot four component coupling reaction of amines, aldehyde, 1,3dicarbonyl compounds and nitromethane (Scheme 68) [95].

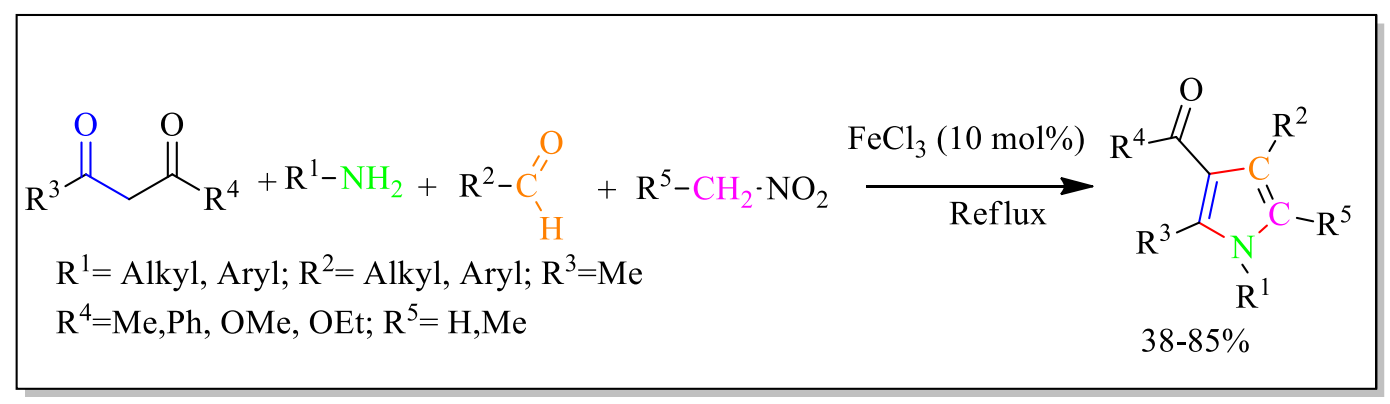

Scheme 63: Strategy for the Lewis Acid Mediated One-Pot Four-Component Coupling. 


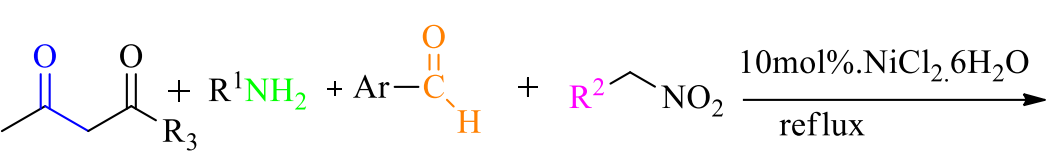

$$
\begin{aligned}
& \overbrace{N_{\mathrm{R}^{\prime}}^{\prime \prime C} \mathrm{C}^{\prime \prime}}^{\mathrm{O}} \\
& \text { 40-78\% }
\end{aligned}
$$

Scheme 64: Synthesis of tetra-substituted pyrrole derivatives.

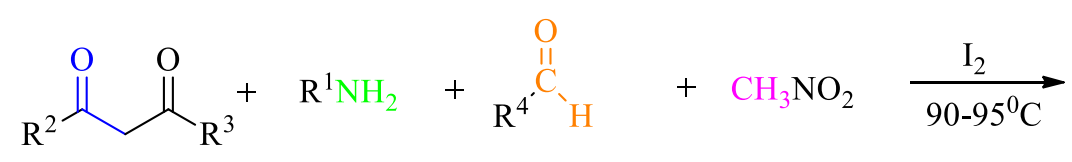

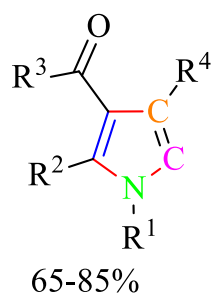

Scheme 65: Iodine-mediated 4-component reaction for the synthesis of functionalized pyrrole derivatives.

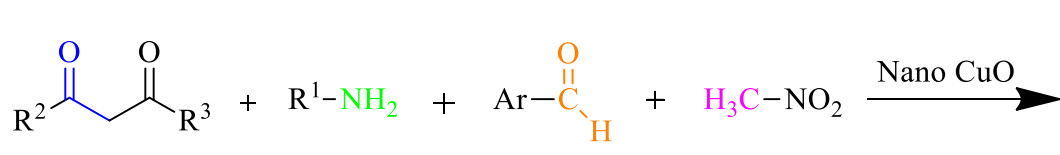

$$
\begin{aligned}
& \mathrm{O}=\overbrace{70-81 \%}^{\mathrm{R}^{3}} \overbrace{\mathrm{R}^{\prime}}^{\mathrm{R}^{1}} \mathrm{C}_{-\mathrm{C}}^{\mathrm{Ar}}
\end{aligned}
$$

Scheme 66: Synthesis route of highly substituted pyrroles via a fourcomponent reaction using nano $\mathrm{CuO}$.

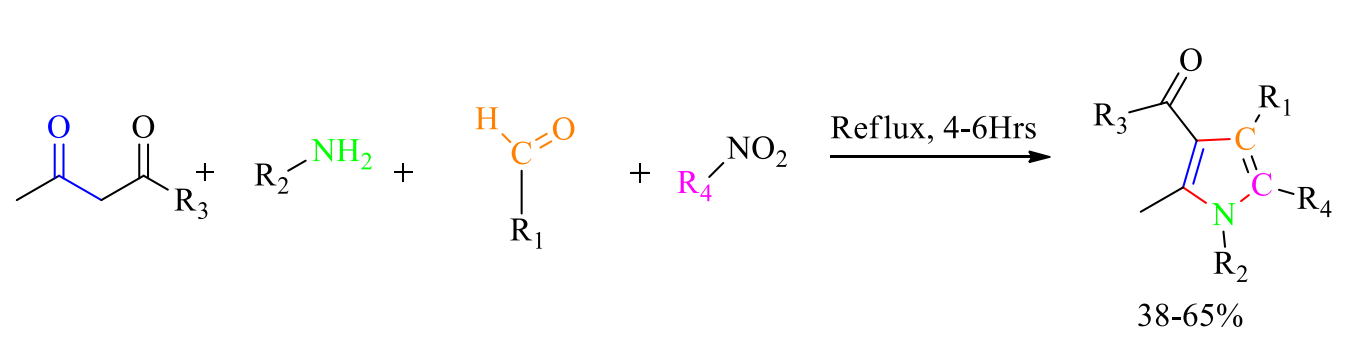


Scheme 67: Synthesizing various multi functionalized derivatives.

$$
\underbrace{}_{\mathrm{R}^{3}}+\mathrm{R}^{1-\mathrm{NH}_{2}} \underset{\mathrm{R}^{2}}{\stackrel{\mathrm{C}}{\mathrm{C}} \mathrm{H}_{\mathrm{H}}+\mathrm{CH}_{3} \mathrm{NO}_{2}} \stackrel{\mathrm{GAAS}(50 \% \mathrm{~mol} \%)}{100^{0} \mathrm{C}}
$$

Scheme 68: Synthesis of functionalized pyrroles in gluconic acid aqueous solution.

Gupta (2014) described a one-pot tandem synthesis of functionalized pyrroles by treating the four components amines, aldehydes, 1,3-dicarbonyl compounds and nitroalkanes in the presence of acidic ionic liquid 1-butyl-3-methylimidazolium hydrogen sulfate as a catalyst (Scheme 69) [96]. Gajengi et al. (2014) have developed a method for the synthesis of highly functionalized pyrroles via cascade reaction of the four components, 1,3-dicarbonyl compounds, amines, aldehydes and nitroalkanes in the presence of heterogenous and vigorous catalyst NiO NPs (scheme 70) [97]. Li and coworkers (2014) have reported a one-pot synthesis of polysubstituted pyrroles by reacting aldehydes, 1,3-dicarbonyl compounds, amines and nitromethane under nano- $\mathrm{CoFe}_{2} \mathrm{O}_{3}$ supported Mo as catalyst (scheme 71) [98]. Tang and his co-workers (2015) have reported the one-pot synthesis of substituted pyrrole by the coupling reaction of four components i.e. 1,3-dicarbonyl compounds, amines, aldehydes and nitromethane in the presence of iron-containing metal organic frameworks as catalyst (Scheme 72) [99]. Hu (2015) has described the one-pot synthesis of functionalized pyrroles by the reaction of the four components, amine, aldehydes, 1,3-dicarbonyl compounds and nitromethane in the presence of a deep eutectic solvent, prepared by choline chloride and malonic acid, providing the medium for the reaction and acting as dual catalyst as well (Scheme 73) [100]. Moghaddam (2015) have reported the one-pot synthesis of substituted pyrroles by reacting nitromethane, aryl aldehyde, 1,3-dicarbonyl compound and amine using an efficient and reusable catalyst, nickel ferrite nanoparticle at $5 \mathrm{~mol} \%$ of catalyst at $100^{\circ} \mathrm{C}$ (Scheme 74) [101]. Gajengi and his colleagues (2017) have described the one-pot synthesis of tetrasubstituted pyrrole by a multicomponent reaction between aldehyde, amine, 1,3-diketone and nitromethane at room temperature in the presence of $\mathrm{Cu}_{2} \mathrm{O} / \mathrm{Ag}$ nanocomposite (NPs) (Scheme 75) [102]. 


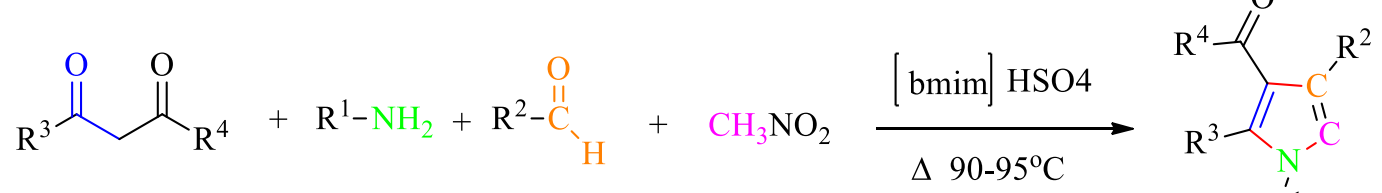

$$
\begin{aligned}
& 68-95 \%
\end{aligned}
$$

Scheme 69: Synthesis of multi-substituted pyrroles.

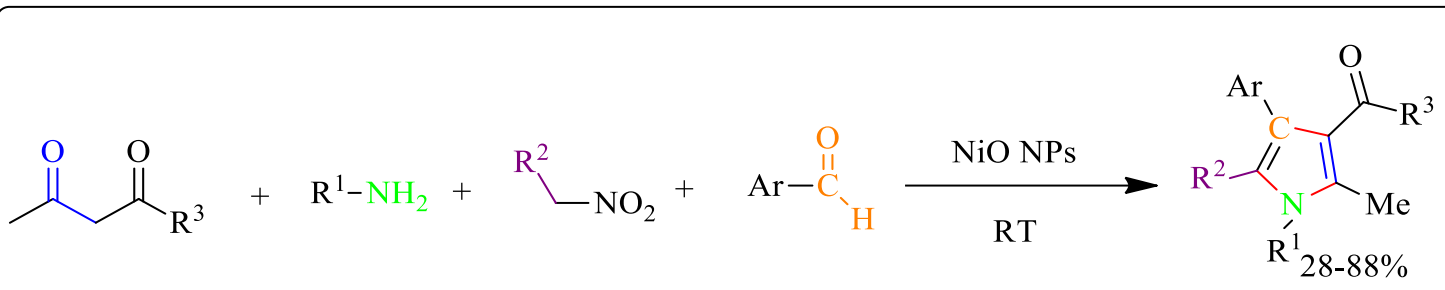

Scheme 70: NiO NPs mediated synthesis of substituted pyrroles.

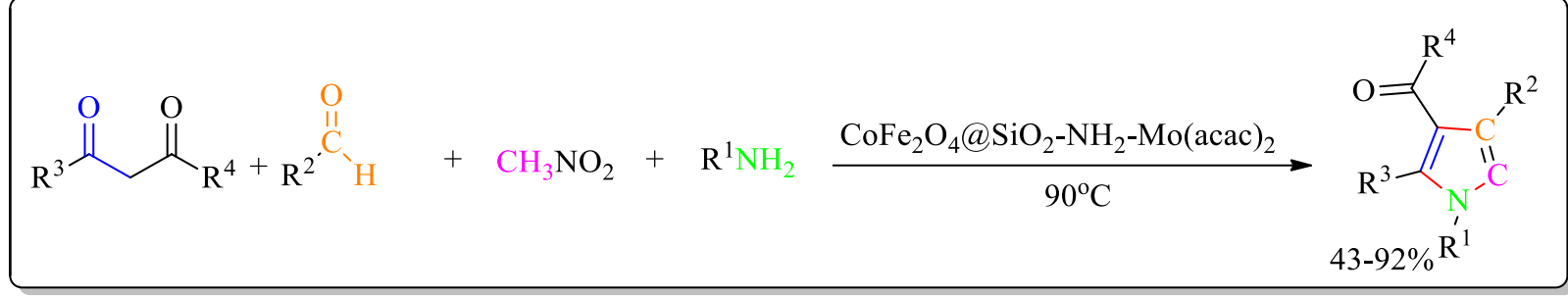

Scheme 71: Synthesis of fuctionalized pyrroles in the presence of $\mathrm{CoFe}_{2} \mathrm{O}_{4} @ \mathrm{SiO}_{2}-$ $\mathrm{NH}_{2}-\mathrm{Mo}(\mathrm{acac})_{2}$.

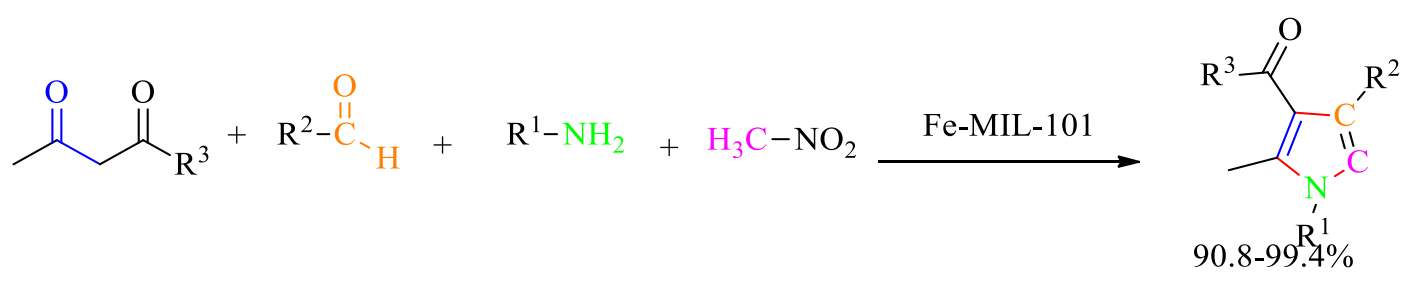

Scheme 72: Synthesis of different substituted pyrroles catalyzed by Fe-MIL-101. 


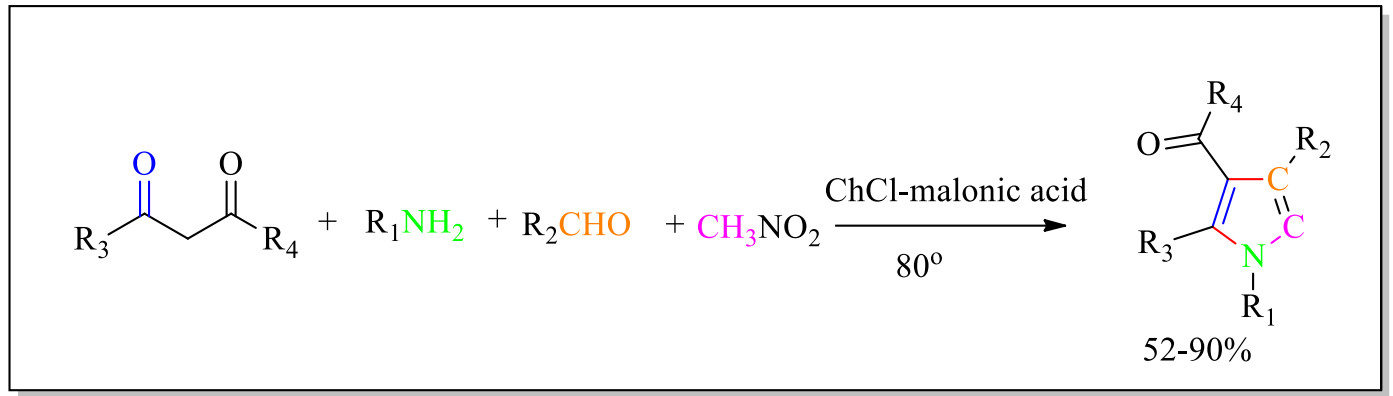

Scheme 73: Synthesis of functionalized pyrroles using ChCl-malonic acid.

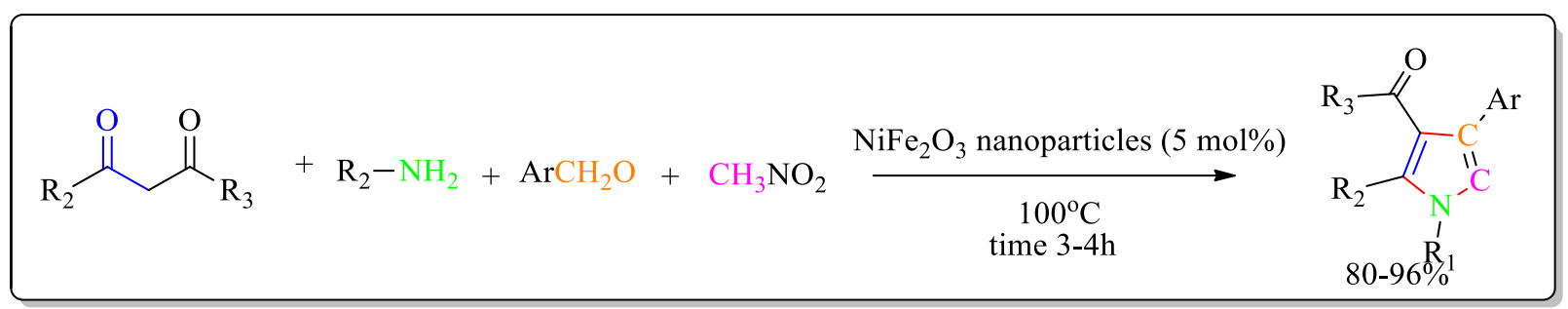

Scheme 74: The preparation of different substituted pyrroles.

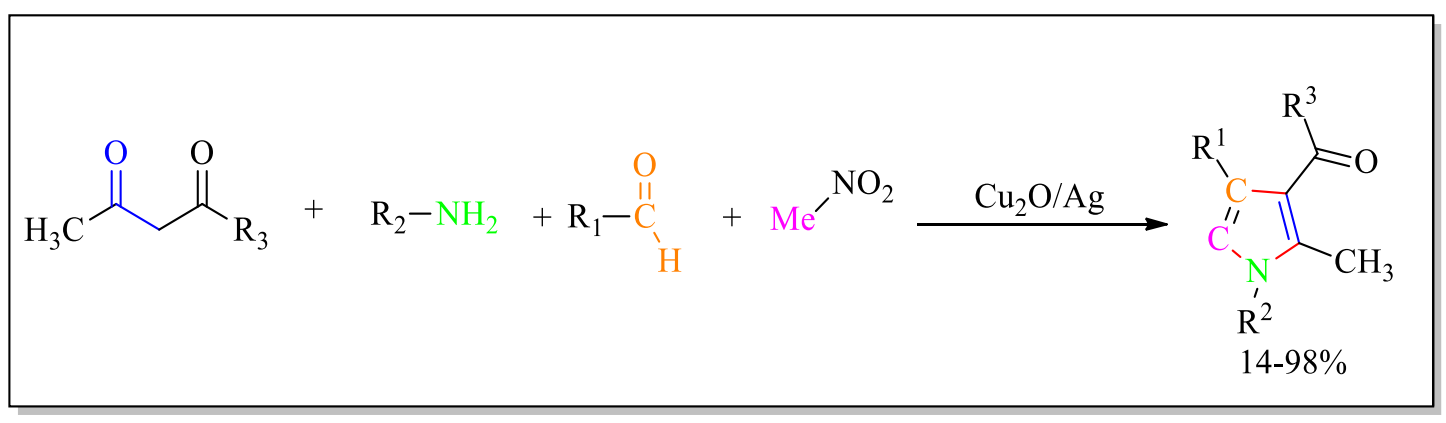

Scheme 75: Synthesis of substituted pyrroles catalysed by $\mathrm{Cu}_{2} \mathrm{O} / \mathrm{Ag}$ NPs by one pot synthesis.

\subsubsection{Synthesis of pyrroles by reacting a 1,4-dicarbonyl compound with amines}

Chen and his co-workers (2009) have reported the synthesis of $\beta$-enamino ketones or pyrroles from amines and 1,3-dicarbonyl or 1,4-dicarbonyl compounds using metal triflates as catalyst under solvent free conditions. $0.5 \mathrm{~mol} \% \mathrm{Ga}(\mathrm{OTf})_{3}$ is best of the metal triflates, which gave outstanding yield (Scheme 76, 77) [103]. 


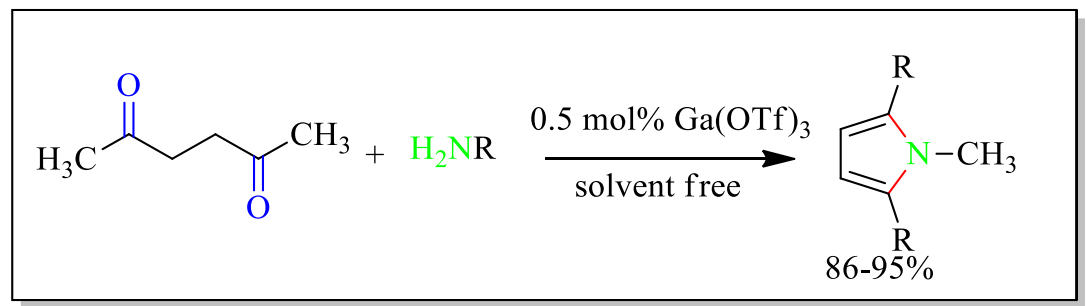

Scheme 76: The reaction of amines with acetonylacetone under solvent-free conditions.

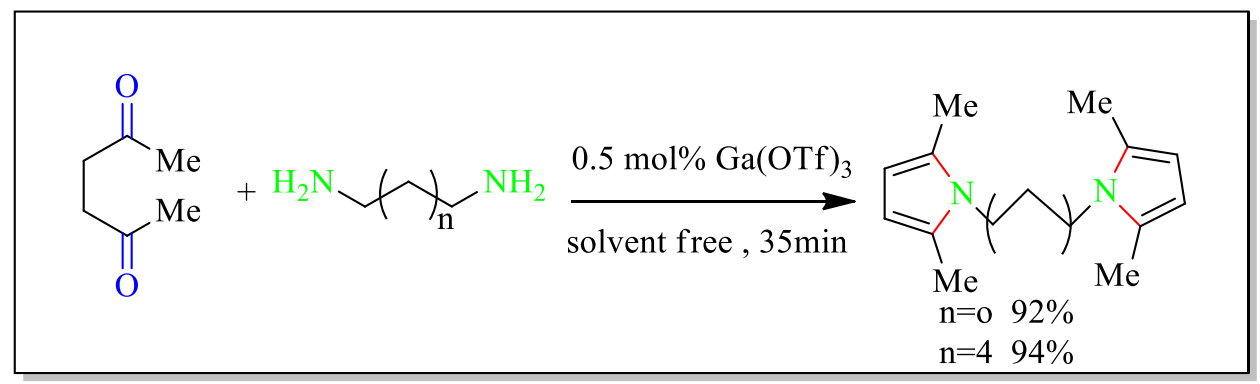

Scheme 77: The reaction of diamines with acetonylacetone under solvent-free conditions.

Veisi and his colleagues (2010) have reported a one-pot synthesis of $N$-substituted pyrroles by reacting $\gamma$-diketones with amines, diamines or triamine under silica sulfuric acid (SSA) (Scheme 78) [104]. Yuan and his colleagues (2010) have reported an efficient synthesis of 2,5-hexanedione with amines by Paal-Knorr condensations at room temperature under solvent-free condition (Scheme 79) [105]. Rahmatpour (2011) has reported a one-pot synthesis of $N$-substituted pyrroles from condensation reactions of 2,5- hexanedione with amines or diamines using $\mathrm{ZrOCl}_{2} .8 \mathrm{H}_{2} \mathrm{O}$. For this reaction, Lewis acid catalyst was used at room temperature (Scheme 80) [106]. Banik and his colleagues (2012) have reported the simple synthesis of substituted pyrroles by using catalyst polystyrenesulfonate which gave an excellent yield in aqueous solution (Scheme 81) [107]. Darabi (2012) has reported a greener reaction to prepare pyrrole derivatives. Optimized conditions were applied while treating hexane-2,5-dione with 4-methoxyaniline. The best conditions were completed in ethanol with 5 mol \% of vitamin $\mathrm{B}_{1}$ during $1 \mathrm{~h}$ (Scheme 82) [108]. Darabi et al. (2012) have reported the synthesis of pyrroles via Paal-Knorr synthesis. Here, silica maintained antimony(III) chloride $\left(\mathrm{SbCl}_{3} / \mathrm{SiO}_{2}\right)$ which acts as a highly effective heterogeneous Lewis acid catalyst for the Paal-Knorr pyrrole synthesis. Condensation of hexane-2,5-dione with aromatic and aliphatic primary amines in hexane using $\mathrm{SbCl}_{3} / \mathrm{SiO}_{2}$ with $7.6 \mathrm{wt} \% \mathrm{SbCl}_{3}$ was the best reaction condition (Scheme 83) [119]. 


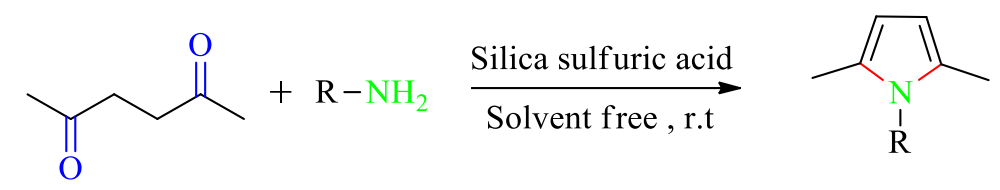

$$
\begin{aligned}
& \mathrm{R}=\mathrm{Alkyl} \text { or aryl }
\end{aligned}
$$

Scheme 78: Synthesis of pyrroles from $\gamma$-diketones and primary amines catalyzed by SSA room temperature under solvent-free conditions.

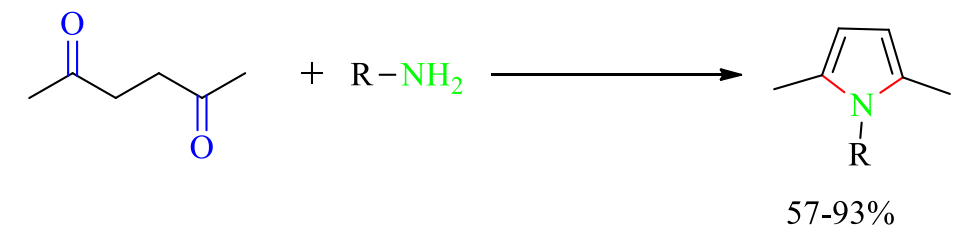

Scheme 79: Condition and reagents: (1) D001; (2) r.t., 0.5-2.5 h. a : $\mathrm{R}^{1 / 4} \mathrm{C}_{6} \mathrm{H}_{5}$; b : R $1 / 4$ 4-

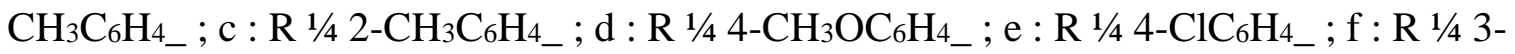

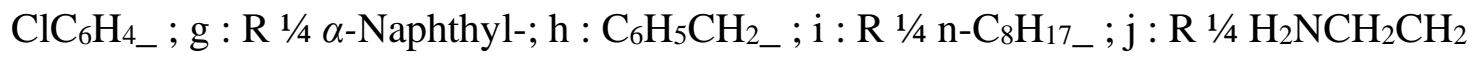

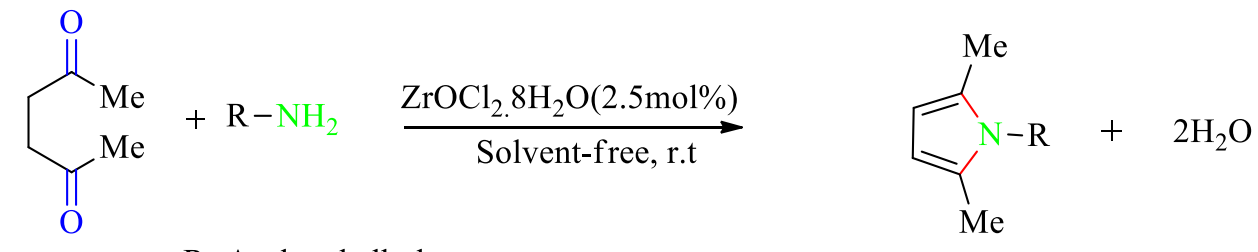

$$
\begin{aligned}
& \mathrm{R}=\mathrm{Aryl} \text { and alkyl } \\
& 60-93 \%
\end{aligned}
$$

Scheme 80: Synthesis of $N$-substituted pyrroles under solvent-free conditions at room temperature. 


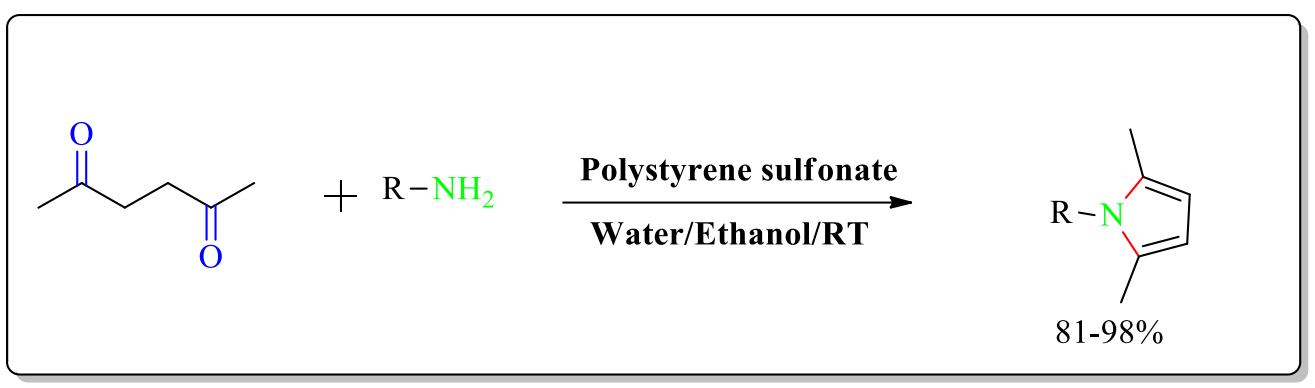

Scheme 81: Polystyrene sulfonate-catalyzed synthesis of $N$-substituted pyrroles.

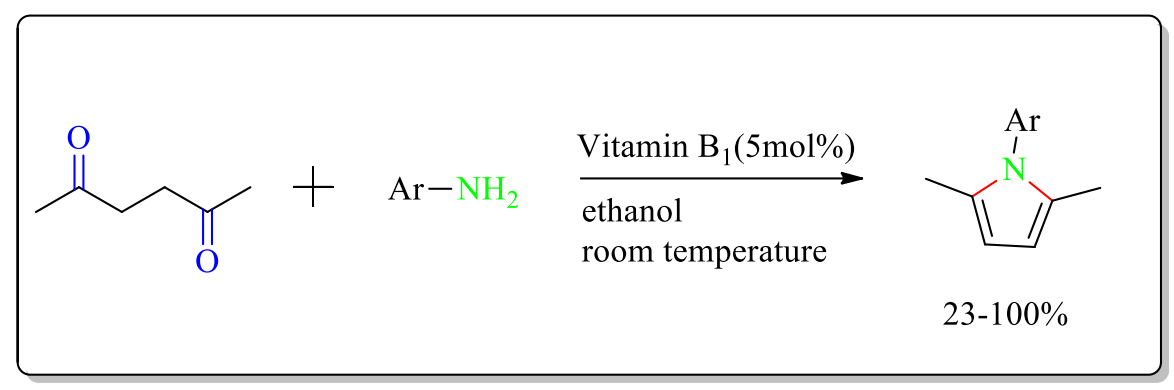

Scheme 82: Condensation of hexane-2,5-dione with amines catalyzed by vitamin $\mathrm{B}_{1}$ as a metal free organocatalyst.

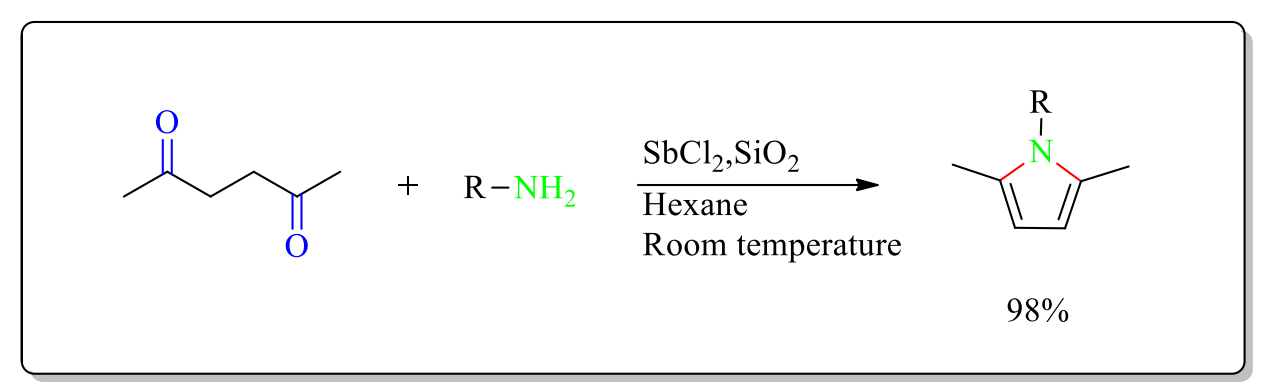

Scheme 83: Synthesis of Paal Knorr pyrrole.

\subsubsection{Synthesis of pyrrole using enones}

Chochois and his colleagues (2006) have reported the 1,4-carbonylation addition of arylboronic acid to methyl vinyl ketones using rhodium catalyst under carbon monoxide pressure. 1,4Diketones were also obtained using $\mathrm{Rh}(\mathrm{COD})_{2} \mathrm{BF}_{4} \quad\left(\mathrm{COD}_{1 / 4}^{1} 1,5\right.$-cyclooctadiene) and triphenylphosphine as catalyst even in small concentration of about $0.02 \%$. This carbonylation reaction when coupled with cyclization results in pyrroles or furan formation (Scheme 84) [110]. Jing and his colleagues (2009) have reported the one-pot preparation of highly substituted pyrroles using thiazolium salt as a catalyst. An aldehyde and unsaturated ketone undergo acyl anion 
conjugated addition reaction to form 1,4-dicarbonyl compounds; on further addition of amines, pyrroles are obtained through Paal-Knorr reaction (scheme 85, 86) [111].

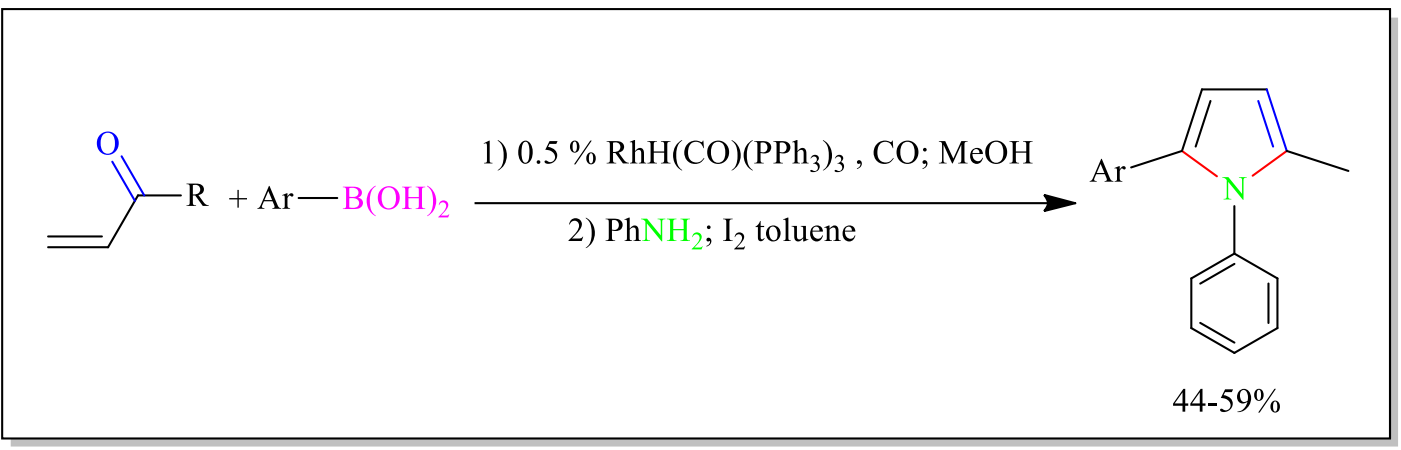

Scheme 84: Pyrrole synthesis via a rhodium catalysed aroylation of enones with arylboronic acids and carbon monoxide followed by a cyclisation step.

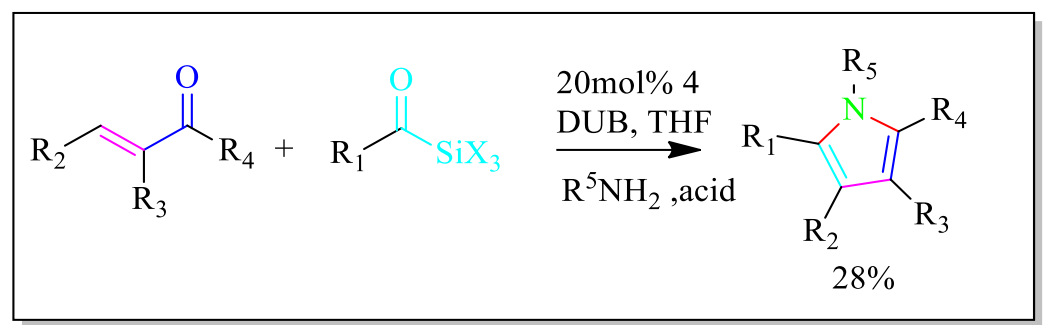

Scheme 85: Scheidt's general multicomponent pyrrole synthesis.

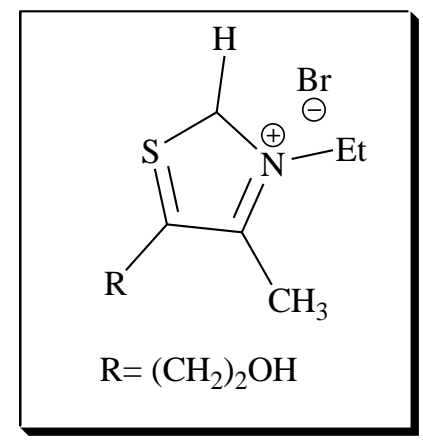

Thiazolium Salt (4) 


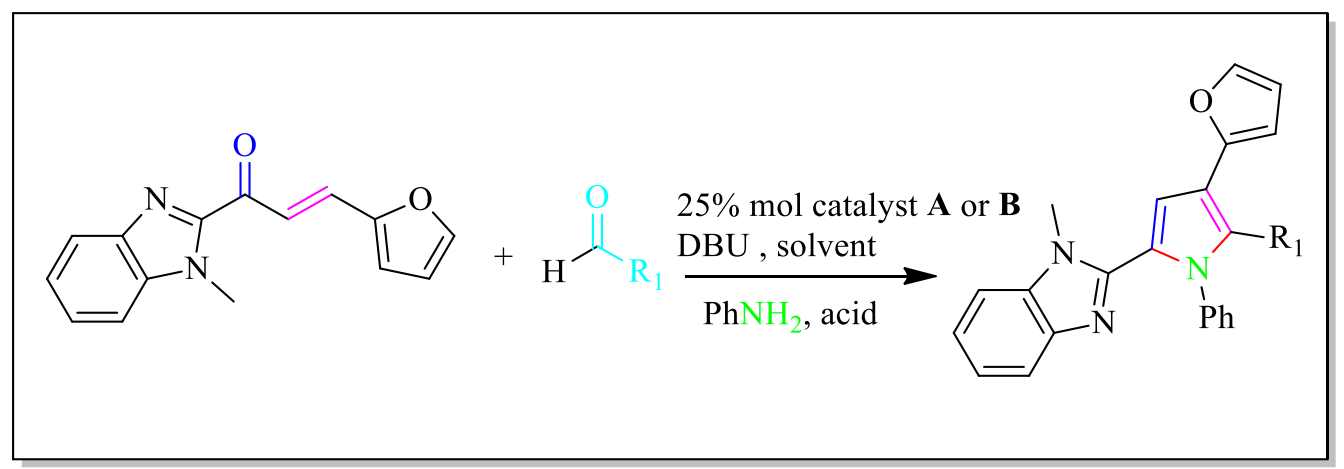

Scheme 86: Highly heterocycle-substituted pyrrole synthesis in different conditions

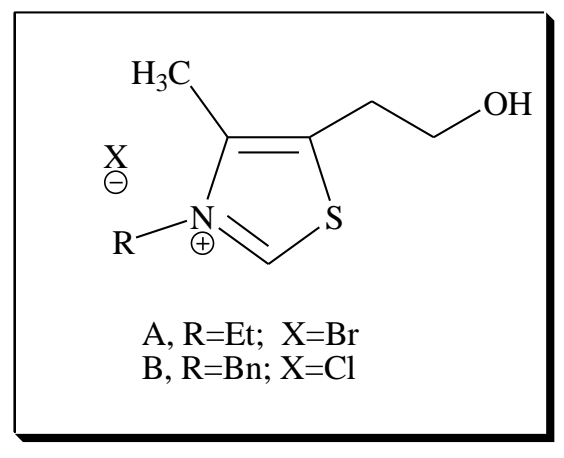

\section{Catalyst A and B}

Rueping and his co-worker (2010) have reported the synthesis of pyrroles by reaction of enaminones with $\beta$-bromonitrostyrenes, where the latter is a trifunctional synthon (Scheme 87) [112].

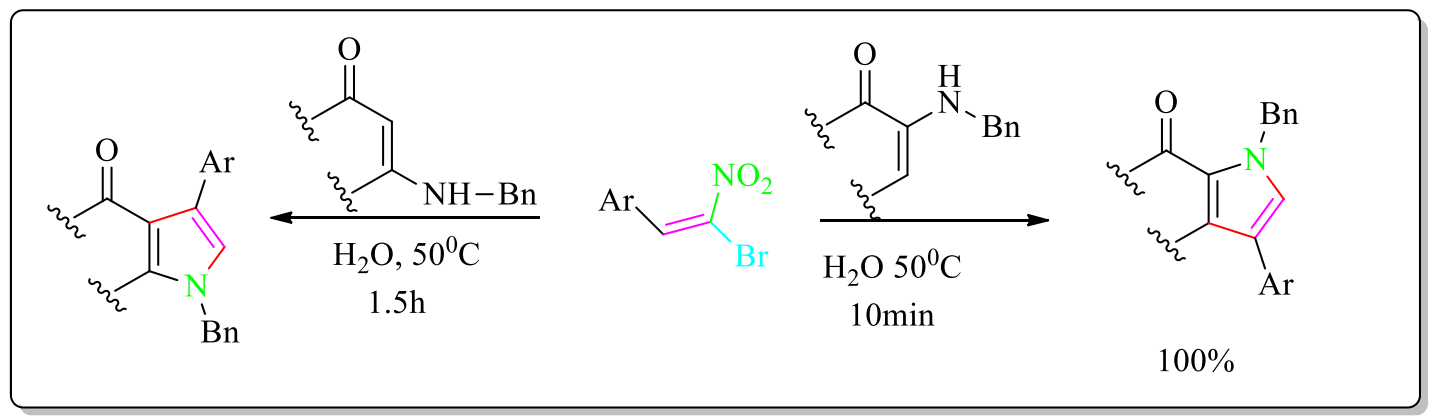

Scheme 87: Synthesis of Pyrroles by Domino Reaction.

Khajuria and Kapoor (2014) have reported the one-pot, solvent free and efficient synthesis of ethyl 3,5-disubstituted-1H-pyrrole-2-carboxylates by reacting 1,3-disubstituted propen-2-one and 
ethylnitroacetate, in the presence of diethylamine $\left(\mathrm{Et}_{2} \mathrm{NH}\right)$ and triethylphosphite $\left(\mathrm{P}(\mathrm{OEt})_{3}\right)$ in microwave (MW) irradiation through the cascade Michael-reductive cyclization (Scheme 88) [113]. Kalmode (2015) has reported the synthesis of 2,3,4-trisubstituted $1 H$-pyrroles by reacting 2-isocyanoacetate and $\alpha, \beta$-unsaturated ketones using chloine hydroxide which is an efficient base as well as providing the reaction media for the synthesis (Scheme 89) [114]. Shekarrao and his colleagues (2015) have developed the efficient one-pot three component synthesis of alkylated pyridine-substituted pyrrole substituted in high yield from $\beta$-bromovinyl aldehydes, primary amines and 2-alkynylpyridines (Scheme 90) [115].

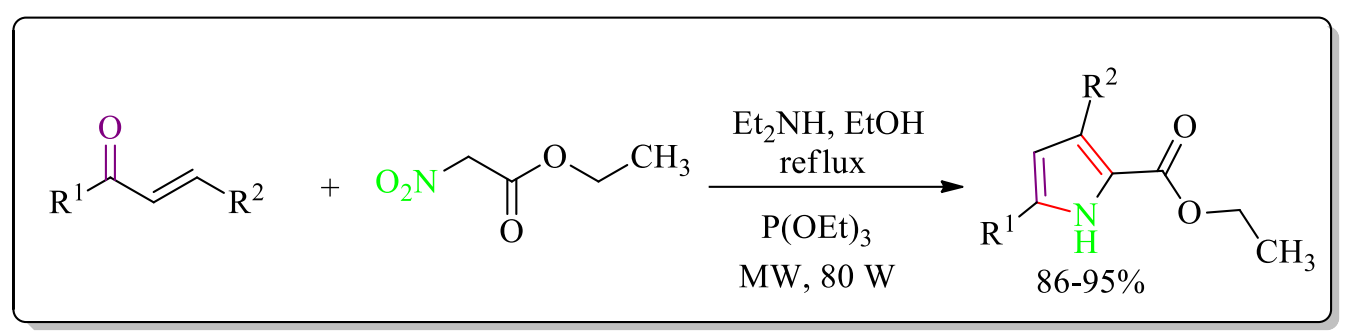

Scheme 88: $\mathrm{P}(\mathrm{OEt})_{3}$ mediated synthesis of ethyl 3,5-diaryl-1H-pyrrole-2-carboxylates.

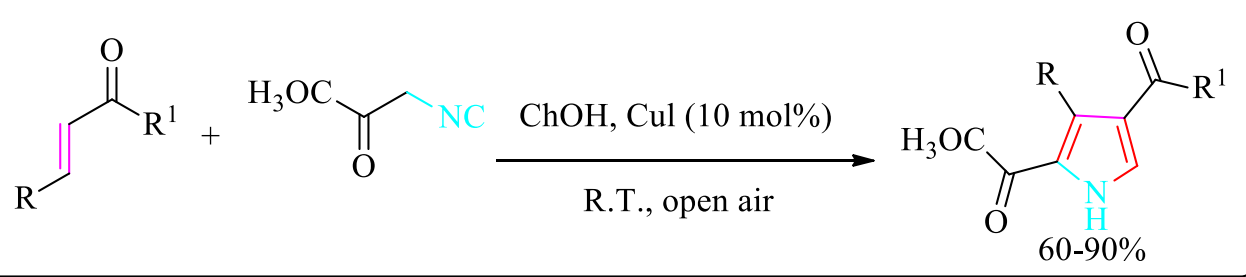

Scheme 89: General regioselective one-pot synthesis of 2,3,4-trisubstituted $1 \mathrm{H}$ -

pyrrole.

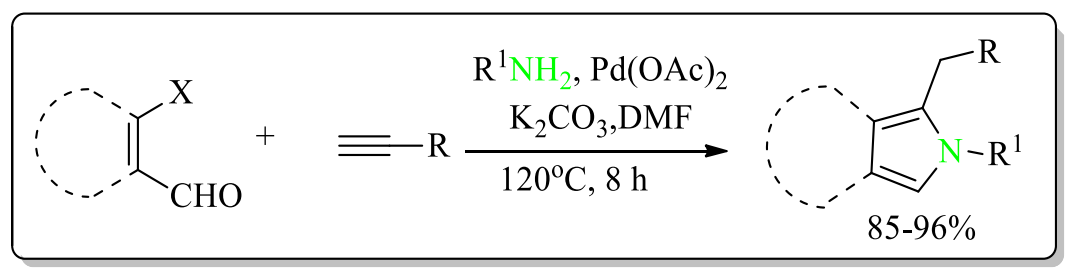

Scheme 90: Different annulation reactions of bromovinyl/aryl aldehydes.

\subsubsection{Synthesis of pyrroles using acetylene group}


Harrison and his colleagues (2006) have reported the synthesis of pyrrole from substituted $\beta$ alkynyl ketones and amines in the presence of $5 \mathrm{~mol} \%$ catalyst which can be either silver trifluoromethanesulfonate or a mixture of gold(I) chloride, silver trifluoromethanesulfonate, and triphenylphosphine (Scheme 91) [116]. Shindo (2007) have reported an effective technique for the synthesis of pyrrole by the mean of ynolates (Scheme 92) [117]. Cyr and his partner Arndtsen (2007) have reported the use of 1,3-dipolar cycloaddition of phosphonites, imines, and acid chlorides (Scheme 93) [118]. Cyr and his co-workers (2007) have reported the preparation of pyrroles using imines, acid chlorides, and alkynes facilitated with isocyanides (Scheme 94, 95) [119]. Lu and his partner (2008) have reported the preparation of pyrroles through $\alpha$-amidoethers and alkynes with aPd catalyst and suitable ligand under an atmosphere of $\mathrm{CO}$ (Scheme 96) [120]. Chen and his colleagues (2009) reported the three component syntheses of tetrasubstituted 3alkynylpyrroles from imines, phenylacetylene, and dialkylzinc (Scheme 97) [121].

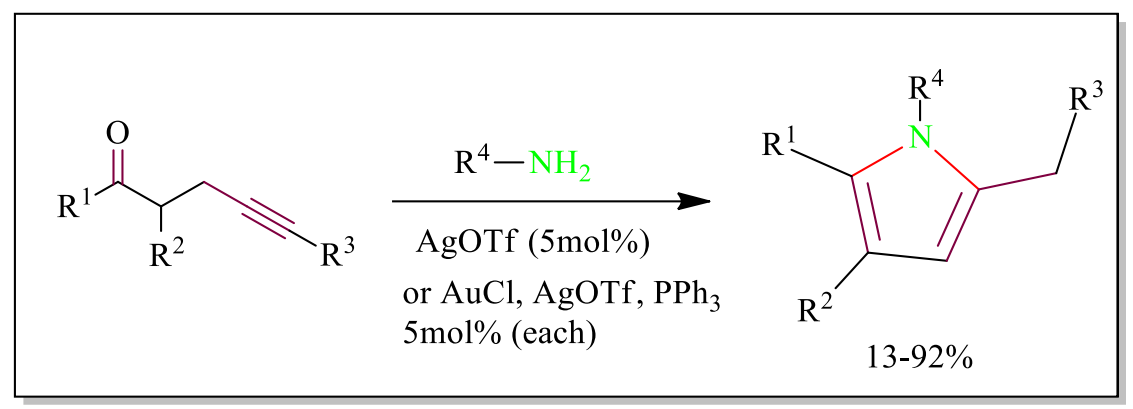

Scheme 91: AgOTf or Au(I)-catalyzed pyrrole formation.

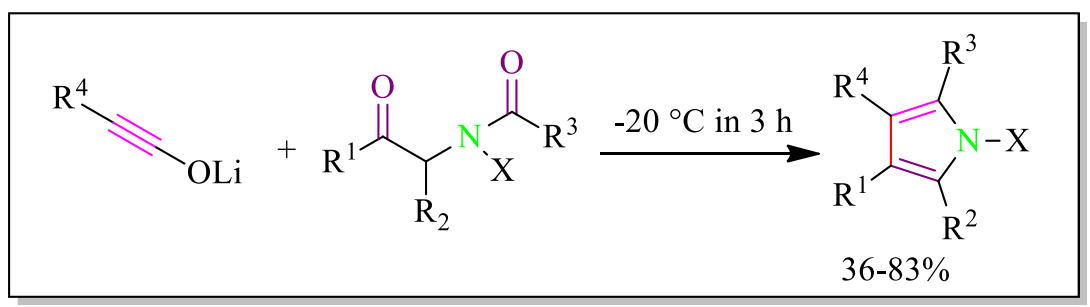

Scheme 92: One-Pot Synthesis of Pyrrole carbamates using $R$-acylaminoketones. 


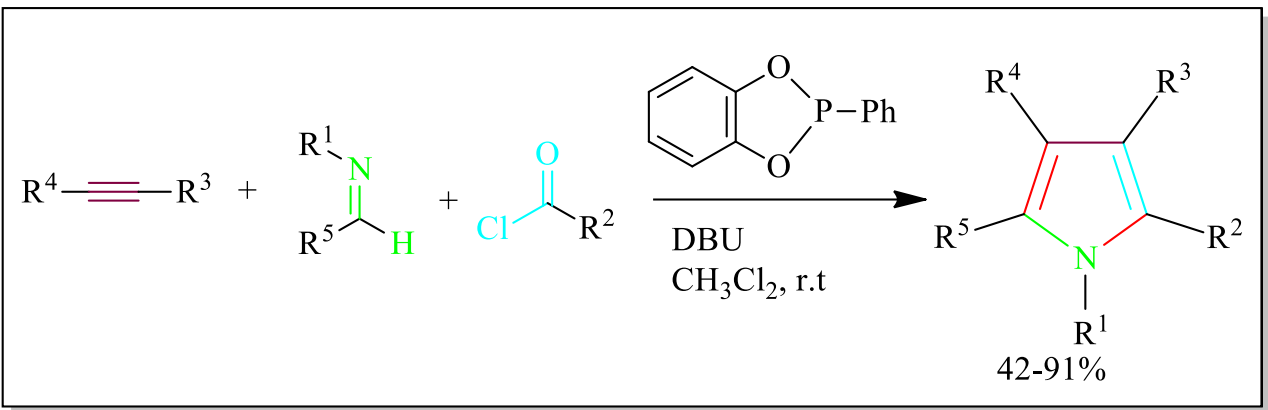

Scheme 93: Diversity of PhP(catechyl) Mediated Pyrrole Synthesis.

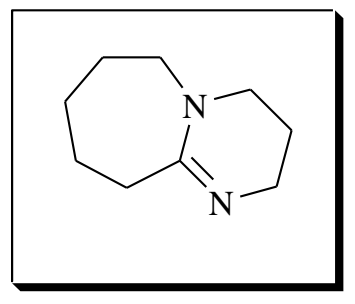

DBU (1,8-Diazabicyclo[5.4.0]undec-7-ene) .

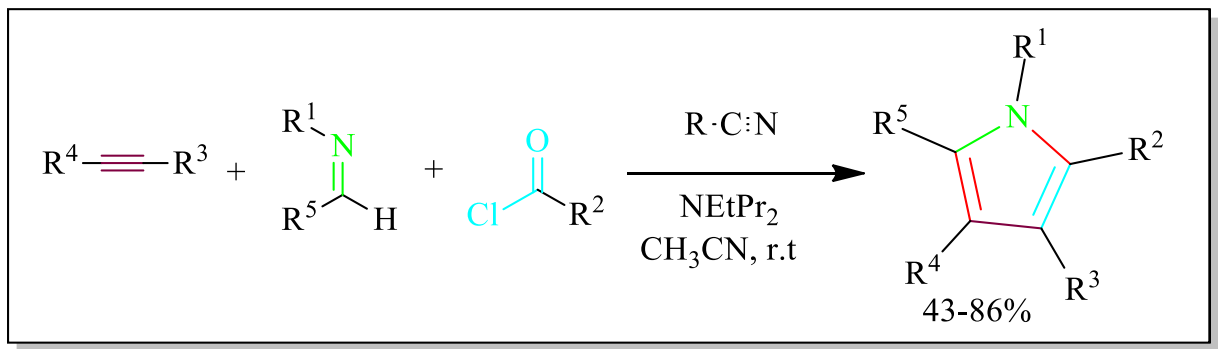

Scheme 94: Synthesis of pyrroles from imines, acid chlorides, and alkynes mediated by isocyanides.

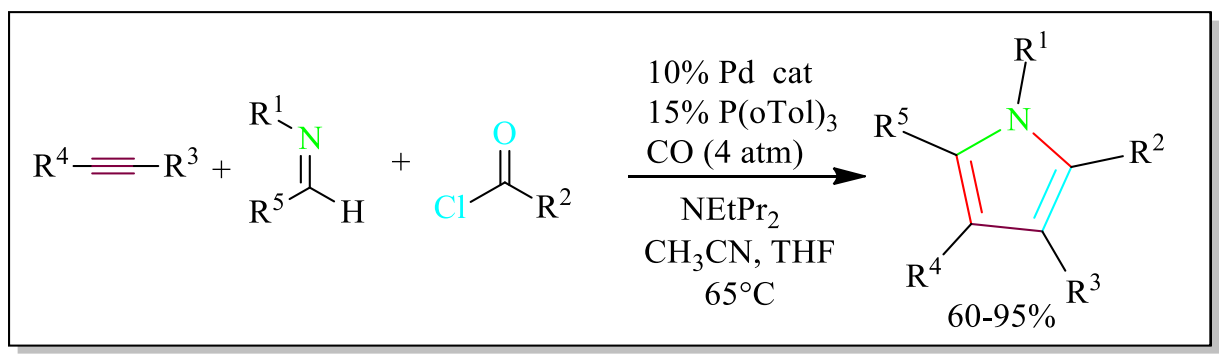

Scheme 95: Palladium-Catalyzed Pyrrole Synthesis. 


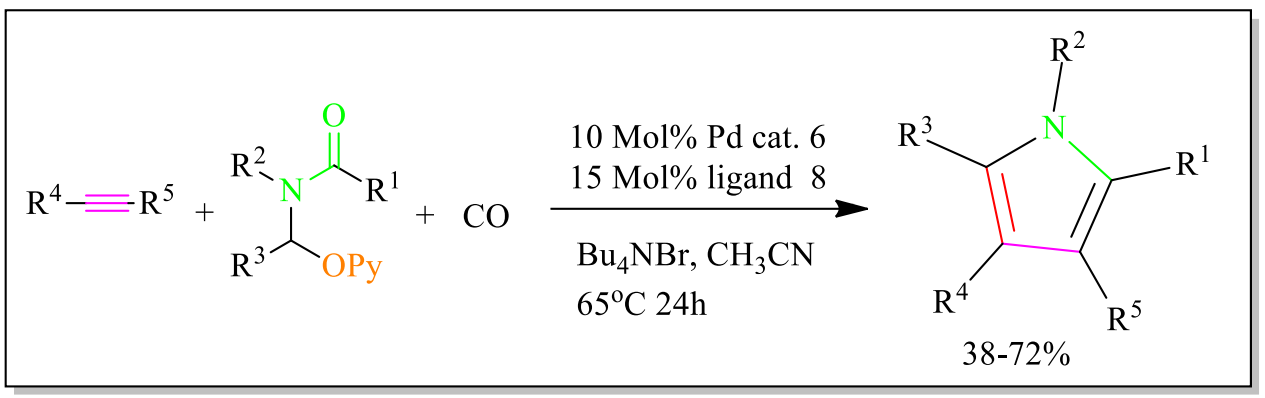

Scheme 96: Palladium-catalysed pyrrole synthesis from amidoether and alkynes. Catalyst used was $\left[\mathrm{Pd}\left(\eta^{2}-\mathrm{CH}(\right.\right.$ tol $\left.\left.) \mathrm{NBnCOPh}\right)\right] \mathrm{BF}_{4}\left(\mathrm{CH}_{3} \mathrm{CN}\right)_{2}(\mathbf{6})$ and $\mathrm{tBu}_{2} \mathrm{P}(2$-biphenyl) ligand (8)

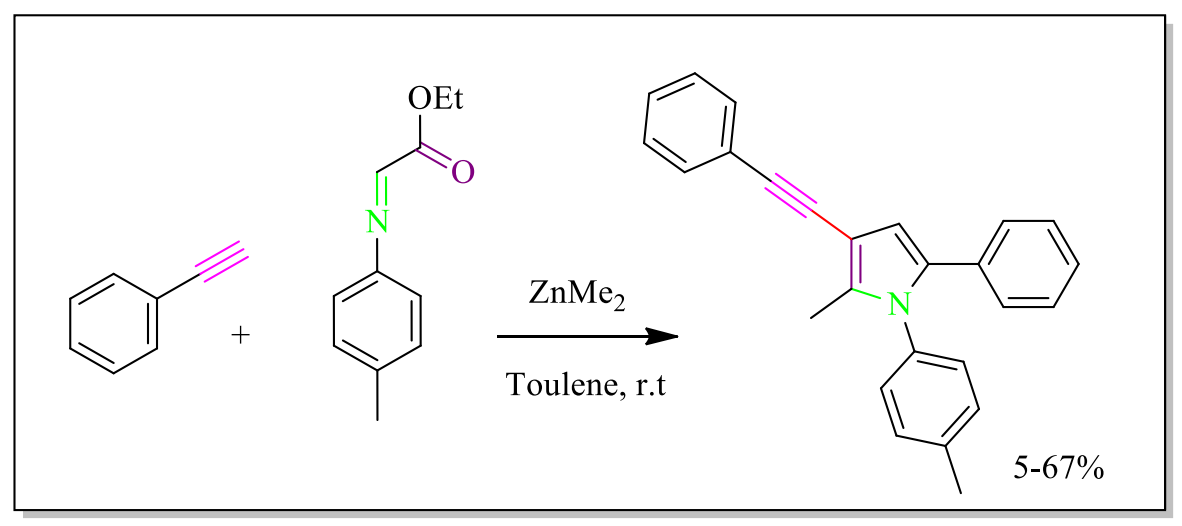

Scheme 97: Synthesis of tetrasubstituted 3-alkynylpyrrole.

Ngwerume (2010) has reported a concise synthesis of $d i^{-}$, tri-, and tetrasubstituted pyrroles using nucleophilic catalysis of the intermolecular addition of oximes to activated alkynes and thermal rearrangement of the in situ generated $O$-vinyl oximes to form pyrroles (Scheme 98) [122]. Liu (2010) has reported a process developed for the synthesis of substituted pyrrole derivatives from propargylic acetates, enoxysilanes and primary amines by using a convenient zinc (II) chloridecatalyzed regioselective propargylation/ amination/ cycloisomerization (Scheme 99) [123]. Wang et al. (2011) have reported the reaction of propargyl alcohols and terminal alkynes to give highly selective production of 1,4-diynes and polysubstituted furans/pyrroles. Water was used as a byproduct in this reaction (Scheme 100) [124]. Shen (2013) has reported an efficient one-pot procedure for the polysubstituted pyrroles (Scheme 101) [125]. Hu (2013) has reported a synthesis of tetrasubstituted pyrroles from the reaction of terminal alkynes and imines. Similarly, intermediate propargylamines can also react with imines to form tetrasubstituted pyrroles (Scheme 102) [126]. Miura (2013) has described a new synthetic pathway for polysubstituted pyrroles; 1- 
sulfonyl-1,2,3-triazoles, readily prepared from terminal alkynes and sulfonyl azides, were treated with allenes using nickel (0) catalyst (Scheme 103) [127].

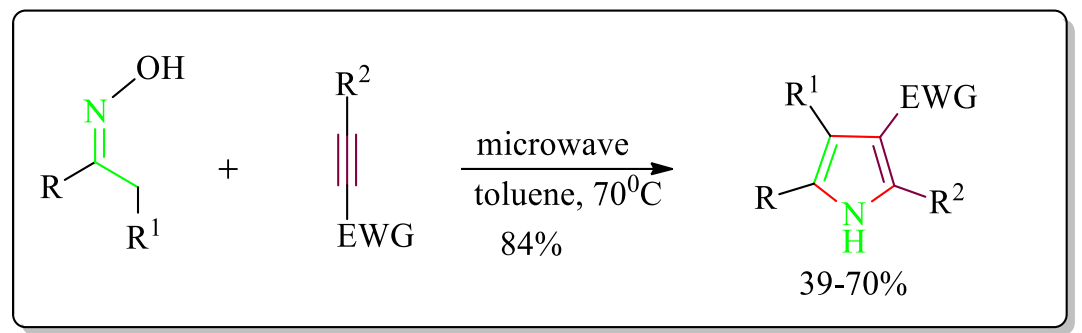

Scheme 98: One-pot Pyrrole Synthesis.

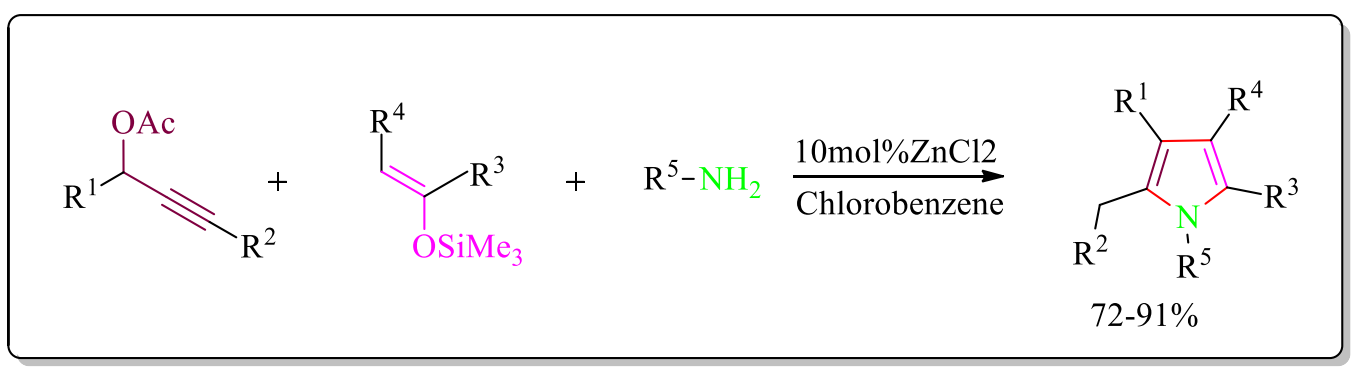

Scheme 99: Synthesis of pyrroles from propargylic acetates, enoxysilanes and primary amines.

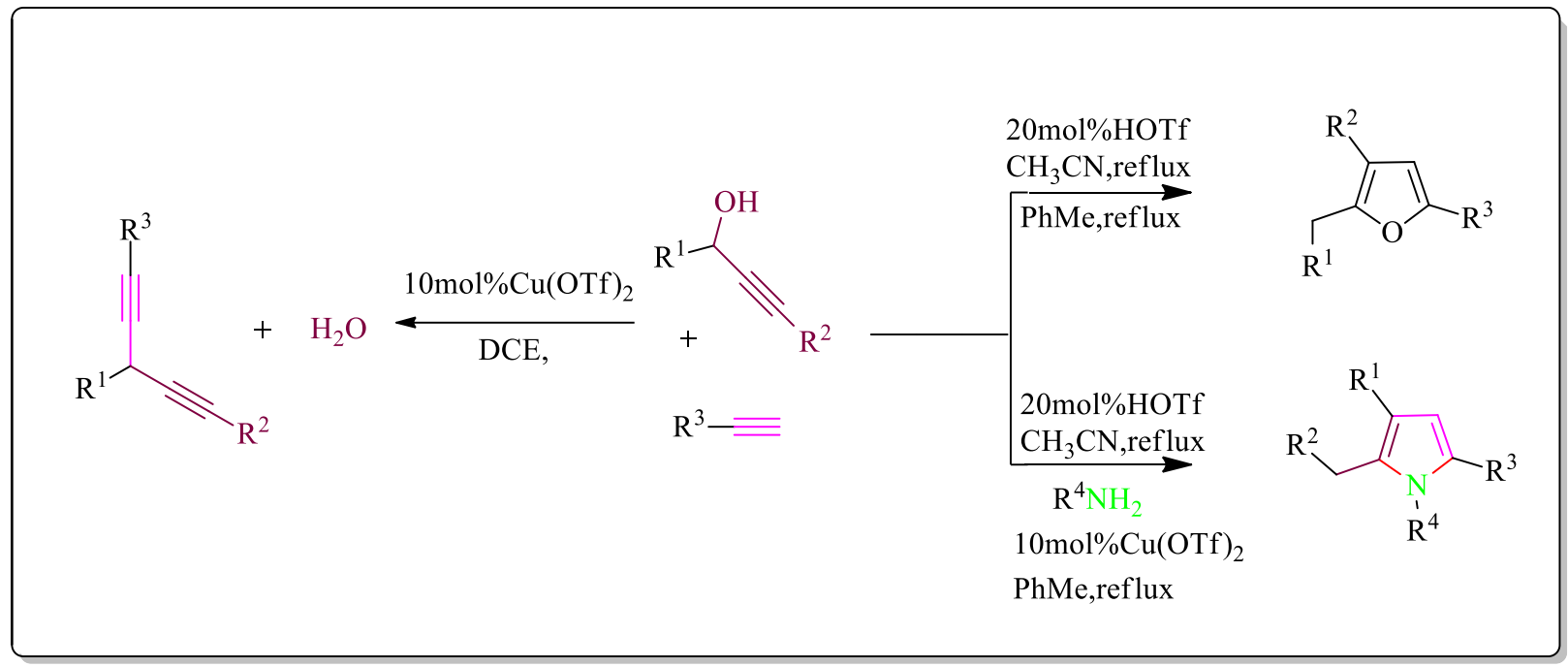

Scheme 100: One-Pot Synthesis of Pyrroles. 

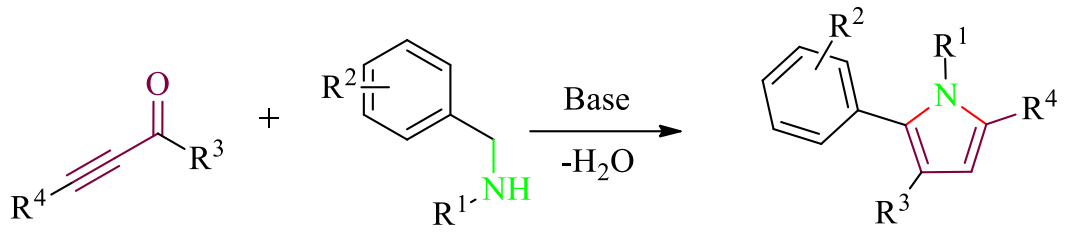

49-91\%

Scheme 101: Synthesis of pyrroles from nitroolefins.

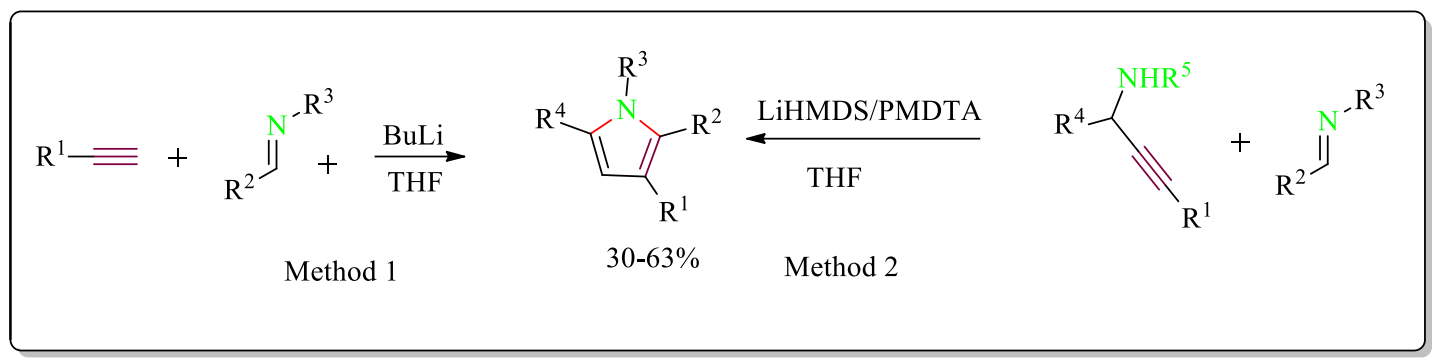

Scheme 102: Synthesis of Tetrasubstituted Pyrroles.

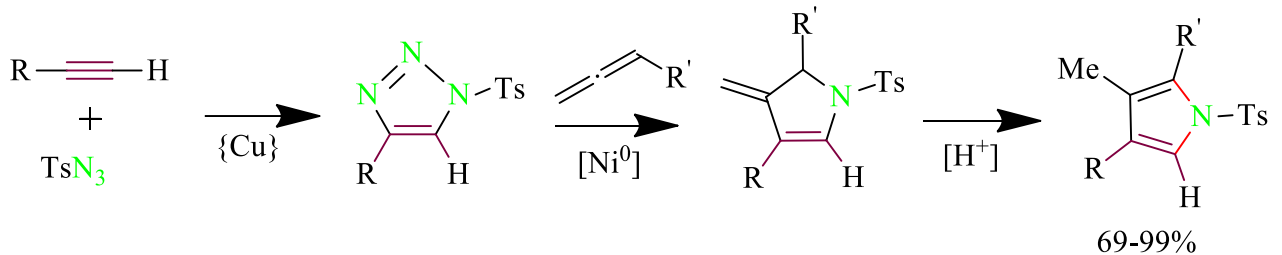

Scheme 103: Synthesis of Polysubstituted Pyrroles.

Kim (2014) has reported the synthesis of substituted pyrroles. Terminal alkynes produced 1sulfonyl-1,2,3-triazoles which were then used to generate $\alpha$-imino rhodium carbene complexes, which on further treatment with alkenyl alkyl ether gave the substituted pyrroles (Scheme 104) [128]. Zhao (2014) has developed the synthesis of substituted pyrroles by efficient palladium (II)catalyzed alkenyl C-H activation oxidative annulation of enamides and alkynes (Scheme 105) [129]. Li et.al. (2015) have described the synthesis of multi-substituted pyrroles through goldcatalyzed hydroamination/cyclization cascade reaction between $\alpha$-amino ketones and alkynes (Scheme 106) [130]. Zhag and his co-workers (2015) have reported the synthesis of 2,3,4,7tetrahydro- $1 \mathrm{H}$-pyrrolo[3,2-c]pyridine-4(5H)-ones by treating 1-acryloyl-1- $N$ arylcarbamylcyclopropane and amines under catalyst-free conditions via a domino ring- 
opening/cyclization/aza-addition sequence (Scheme 107) [131]. Wang (2017) has developed an effective one pot synthesis of 1,3-dihydro-2H-pyrrol-2-one via [3+2] cycloaddition (Scheme 108) [132].

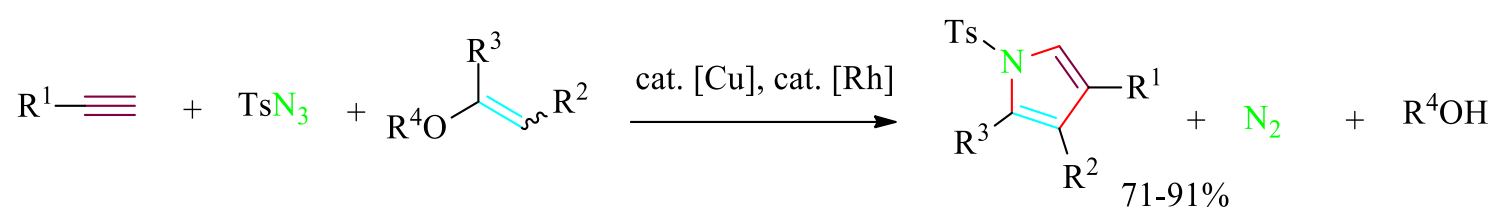

Scheme 104: synthesis of substituted pyrroles.

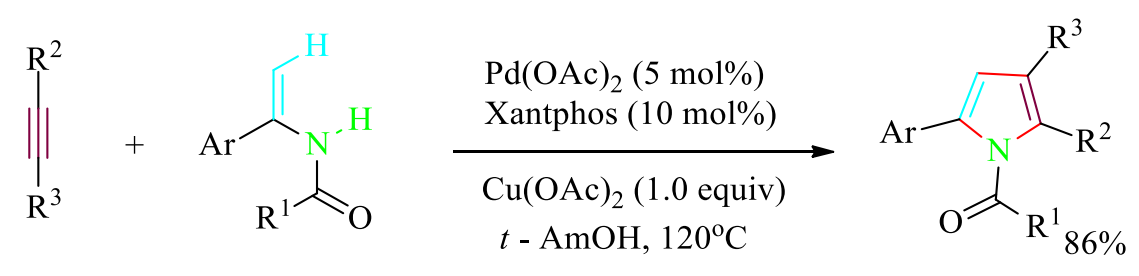

Scheme 105: Transition-Metal-Catalyzed Couplings of Enamides.

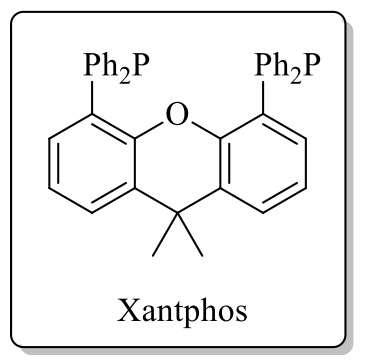

$$
\begin{aligned}
& \mathrm{R}^{3}=\mathrm{R}^{4}+\mathrm{R}^{1} \stackrel{\mathrm{O}}{\mathrm{O}^{\mathrm{H}}} \mathrm{R}_{\mathrm{R}^{2}} \stackrel{\text { cat. } \mathrm{Au}^{+} \mathrm{L}}{\longrightarrow} \\
& \mathrm{R}^{2}=\text { aryl } \quad 94-55 \%
\end{aligned}
$$

Scheme 106: Gold-Catalyzed Route to Pyrroles. 


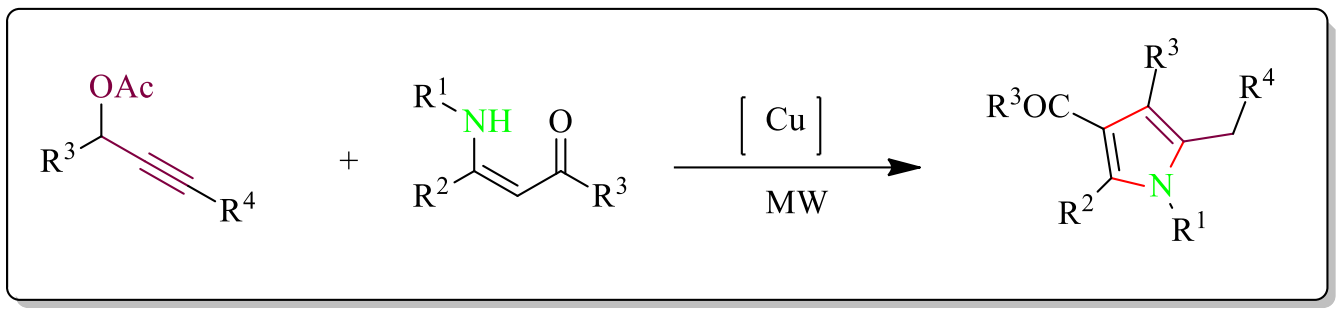

Scheme 107: Design for the Synthesis of $\alpha$-Arylsubstituted Pyrroles.

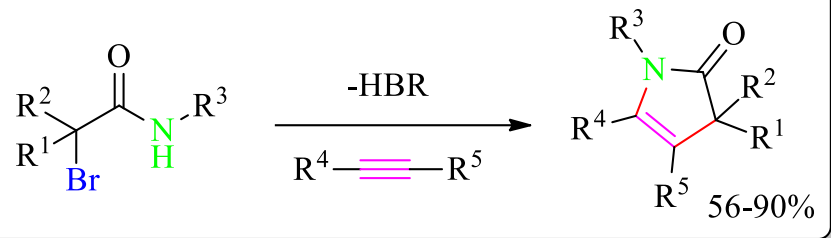

Scheme 108: Synthesis of 1,3-dihydro-2H-pyrrol-2-one derivatives. 


\section{References}

[1] Katritzky, A. R.; Rees, C. W.; Scriven, E. F. Comprehensive heterocyclic chemistry II. Pergamon, 1996.

[2] Gandi, S.; Baire, B. Chem. Sel. 2017, 2, 3964-3968.

[3] Jones, R. A. Pyrrole, Part 1: The synethesis and the physical and chemical aspects of pyrrole ring. Mishawaka, U.S.A: Wiley-Interscience, 1990.

[4] Bayat, M.; Nasri, S.; Notash, B. Tetrahedron, 2017, 73, 1522-1527.

[5] Jones, R. A.; Bean, G. P. The Chemistry of Pyrroles: Org. Chem. A Series of Monographs (Vol. 34). Academic Press, 2013, 34, 538.

[6] Jordan, P. M. New comp. bio. 1991, 19, 1-66.

[7] Schobert, R.; Schlenk, A. Bioorg. Med. Chem. 2017, 16, 4203-4221.

[8] kibriz, I, E.; sacmaci, M.; sahin, E.; yildirim, I. Tetrahedron, 2017, 73, 1795-1802.

[9] Bivava, M.; Fioravanti, R.; porreta, G. C.; Deidda, D.; Maullu, C.; Pomei, R. Bioorg. Med. Chem. Lett. 1990, 9, 2983-2988.

[10] Clive, D. L. J.; Cheng, P. The marinopyrroles. Tetrahedron, 2013, 69, 5059-5066.

[11] Dmitriev, M. V.; Salnikova, T. V.; Silaichev, P. S.; Maslivets, A. N. Tetrahedron Lett. 2017, $58,67-70$.

[12] Jana, G. H.; Jain, S.; Arora, S. K.; Sinha, N. Bioorg. Med. Chem. Lett. 2005, 15, 3592-3595.

[13] Liu, J.; Du, Y-Q.; Li, C-J.; Li, L.; Chen, F-Y.; Yang, J-Z.; Chen, N-H.; Zhang, D-M. RSC Advances, 2017, 7, 35417-35425.

[14] Etcheverry, S. B.; Barrio, D. A.; Cortizo, A. M.; Williams, P. A. Eur. J. I. Chem. 2002, 88, 94-100.

[15] Lmbri, D.; Tauber, J.; Opatz, T. Synthetic Approaches to the Lamellarins-A Comprehensive Review. Marine Drugs, 2014, 12, 6142-6177.

[16] Ham, J. Y.; Kang, H. J. A novel cytotoxic alkaloid of lamellarin class from a marine ascidian Didemnum sp. Bulletin of the Korean Chemical Society, 2002, 23, 163-166.

[17] Roth, B. D. In Prog. Med. Chem. 2002, 40, 1-22.

[18] Goel, A.; Agarwal, N.; Fateh, V.; Sharon, A.; Tiwari, P.; Dixit, M.; Pratap, R.; Srivastava, A. K.; Maulik, P. R.; Ram, V. J. Bioorg. Med. Chem. Lett. 2004, 14, 1089-1092.

[19] Mai, A.; Massa, S.; Ragno, R.; Cerbara, I.; Jesacher, F.; Loidl, P.; Brosch, G. J. Med. Chem. 2003, $46,512-524$. 
[20] Kashman, Y.; Koren-Goldshlager, G.; Garcia-Gravalos, M. D.; Schleyer, M. Tetrahedron Lett. 1999, 40, 997-1000.

[21] Huang, X. C.; Xiao, X.; Zhang, Y. K.; Talele, T. T.; Salim, A. A.; Chen, Z. S.; Capon, R. J. Marine drugs, 2014, 12, 3818-3837.

[22] Papaetis, G. S.; Syrigos, K. N. Bio Drugs, 2009, 23, 377-389.

[23] Härri, E.; Loeffler, W.; Sigg, H. P.; Stähelin, H.; Tamm, C.; Ch, S.; Wiesinger, D. Helv. Chim. Acta 1962, 45, 839-853.

[24] Williamson, N. R.; Simonsen, H. T.; Ahmed, R. A.; Goldet, G.; Slater, H.; Woodley, L.; Leeper, F. J.; Salmond G. P. Mole. microbiol. 2017, 56, 971-989.

[25] Williamson, N. R.; Fineran, P. C.; Gristwood, T.; Chawrai, S. R.; Leeper, F. J.; Salmond, G. P. Future microbiol. 2007, 2, 605-618.

[26] Basit, F.; Cristofanon, S.; Fulda, S. Cell death differ. 2013, 20, 1161-1173.

[27] Gribble. G. W. (1996) Comprehensive Heterocyclic Chemistry (Vol. II). Hanover, NH, USA. [28] Kang, Y. S.; Park, E-J.; Park, W-k.; Kim, H. J.; Choi, G.; Jung, M. E.; Seo, H. J.; Kim, M. J.; Pae, A. N.; Kim, J.; Lee, J. Bioorg. Med. Chem. 2010, 18, 6156-6169.

[29] Patil, V.M.; Sinha, R.; Masand, N.; Jain, J. Digest. J. Nanomat. Biostru. 2009, 4, 471-477.

[30] Carson, J. R.; Carmosin, R. J.; Pitis, P. M.; Vaught, J. L.; Almond, H. R.; Stables, J. P.; Wolf, H. H.; Swinyard, E. A.; White, H. S. J. med. Chem. 1997, 40, 1578-1584.

[31] Gourley, B. S.; Molesworth, P. P.; Rayan J. H.; Smith, J. A. Tetrahedron Lett. 2006, 47, 799801.

[32] Rivera, S.; Bandyopadhyay, D.; Banik, B. K. Tetrahedron Lett., 2009, 50, 5445-5448.

[33] Abid, M.; Landge, S. M.; Torok, B. Org. Prep. Proced. Int. 2009, 38, 495-500.

[34] Wilson, M. A.; Filzen, G.; Welmaker, G. S. Tetrahedron Lett. 2009, 50, 4807-4809.

[35] Abid, M.; Teixeira, L.; Torok, B. Tetrahedron let. 2007, 48, 4047-4050.

[36] Cárdenas, R. A. V.; Leal, B. O. Q.; Reddy, A.; Bandyopadhyay, D.; Banik, K. B. Org. Med. Chem. Lett. 2012, 24.

[37] Hosseini-Sarvari, M.; Najafvand-Derikvandi, S.; Jarrahpour, A.; Heiran, R. Chem. Heterocyl. Comp. 2014, 49, 1732-1739.

[38] Alizadeh, A.; Masrouri, H.; Rostamnia, S.; Movahedi , F. Helv. Chim. Acta. 2006, 89, 923926.

[39] Galliford, C. V.; Scheidt, K. A. J. org. chem. 2007, 72, 1811-1813. 
[40] Kassaee, M. Z.; Masrouria, H.; Movahedi, F.; PartovI, T. Helv. Chim. Acta. 2008, 91, $227-$ 331.

[41] Yavari, I.; Kowsari, E. Mol Divers, 2009, 13, 519-528.

[42] Yavari, I.; Kowsari, E. Synlett, 2008, 6, 0897-0899.

[43] Ghabraie, E.; Balalaie, S.; Bararjanian, M.; Bijanzadeh, H.R.: Rominger, F. Tetrahedron, 2011, 67, 5415-5420.

[44] Han, Y.; Sun, Y.; Sun, J.; Yan, C-G. Tetrahedron, 2012, 68, 8256-8260.

[45] Feng, X.; Wang, Q.; Lin, W.; Dou, G-L.; Huang, Z-B.; Shi, D-Q. Org. Lett. 2013, 15, 25422545.

[46] Khan, A.T.; Ghosh, A.; Khan, M. M. Tetrahedron Lett. 2012, 53, 2622-2626.

[47] Sajadikhah, S.S.; Hazer, N.; Maghsoodlou, M.T.s; Khorassani, S.M.H.; Beigbabaei, A.; Willis, A.C. Iranian Chem. Soc. 2013, 10, 863-871.

[48] Sajadikhah, S.S.; Hazeri, N.; Maghsoodlou, M.T.; Khorassani, S.M.H.; Barani, K.K. Chem. res. 2013, 37, 40-42.

[49] Sayyed-Alangi, S.Z.; Hossaini, Z.; Rostami-Charati, F. CCL. 2012 ,23,1119-1121.

[50] Ardakani-A, H.; Noei, M.; Tabarzad, A. CCL. 2012, 23, 45-48.

[51] Rana, S.; Brown, M.; Dutta.; Bhaumik, A.; Mukhopadhyay, C. Tetrahedron Lett. 2013, 54, 1371-1379.

[52] Zhao, M-N.; Ren, Z-H.; Wang, Y-Y.; Ghaun, Z-H. Chem. Eur. J. 2014, 20, 1839-1842.

[53] Reddy, L. M.; Chandrashekar, P.; Reddy, A. R.; Reddy, C. K. Rus. J. Gen. Chem. 2015, 85, $155-161$.

[54] Zarei, M.; Sajadikhah, S. S. Research on Chemical Intermediates, 2016, 42, 7005-7016.

[55] Kangani, M.; Maghsoodlou, M.; Hazeri, N. Chin. Chem. Lett. 2016, 27, 66-70.

[56] Soltani, M.; Mohammadpoor-Baltork, I.; Khosropour, A. R.; Moghadam, M.;

Tangestaninejad, S.; Mirkhani, V. Comptes Rendus Chimie, 2016, 19, 381-389.

[57] Dhinakaran, I.; Padmini, V.; Bhuvanesh, N. ACS Comb. Sci. 2016, 18, 236-242.

[58] Rahmani, F.; Darehkordi, Synlett, 2017, 28, 1224-1226.

[59] Kangani, M.; Hazeri, N.; Maghsoodlou, M-T. J. Saudi Chem. Soc. 2017, 21, 160-164.

[60] Demir, A. S.; Emrullahoglu, M. Tetrahedron, 2006, 62, 1452-1458.

[61] Metten, B.; Kostermans, M.; Baelen, G. V.; Smet, M.; Dehaen. W. Tetrahedron, 2006, 62, 6018-6028. 
[62] Cadierno, V.; Gimeno, J.; Nebra, N. Chem. Eur. J. 2007, 13, 9973-998.

[63] Wang, Y-F.; Toh, K. K.; Chiba, S.; Narasaka, K. Org. Lett. 2008, 21, 5019-5022.

[64] Alizadeh, A.; Babaki, M.; Zohreh, N. Tetrahedron, 2009, 65, 1704-1707.

[65] Reddy, G.R.; Reddy, T.R.; Joseph, S.C.; Reddy, K.S.; Reddy, L.S.; Kumar, P.M.; Krishna, G.R.; Reddy, C.R.; Rambabu, D.; Kapavarapu, R.; Lakshmi, C.; Meda, T.; Priya, K.K.; Parsad, K.V.L.; Pal, M. Chem. Commun. 2011, 47, 7779-7781.

[66] Magar, D.R.; Ke, V-J.; Chen, K. Org.Chem. 2013, 2, 330-335.

[67] Umeda, R.; Mashino, T.; Nishiyama, Y. Tetrahedron, 2014, 70, 4395-4399.

[68] Nandeesh, K. N.; Raghavendra, G. M.; Revanna, C. N.; Vijay, T. A. J.; Rangappa, K. S.;

Mantelingu, K. Synth. Commun: Int. J. Rap. Commun. Synth. Chem. 2014, 44, 1103-1110.

[69] Gujarathi, S.; Liu, X.; Song, L.; Hendrickson, H.; Zheng, G. Tetrahedron, 2014, 70, 52675273.

[70] Karamthulla, S.; Pal, A.; Khan, M. N.; Choudhury, L. H. Synlett, 2014, 25, 1926-1936.

[71] Shinde, V. V.; Lee, S. D.; Jeong, Y.S.; Jeong, Y. T. Tetrahedron Lett. 2015, 56, 859-865.

[72] Ghashang.; Shaterian, M.; Reza, H. CCL. 2011, 29, 1851-1855.

[73] Lin, X.; Mao, Z.; Dai, X.; Lu, P.; Wang, Y. Chem. Commun. 2011, 47, 6620-6622.

[74] Yavari. I.; Ghanbari, E.; Hosseinpour, R. Helv. Chim. Acta 2014, 97, 1004-1008.

[75] Zheng, Y.; Wang, Y.; Zhou, Z. Chem. Commun. 2015, 51, 16652-16655.

[76] Farahi, M.; Davoodi, M.; Tahmasebi, M. Tetrahedron Lett. 2016, 57, 1582-1584.

[77] Bellur, E.; Langer, P. Tetrahedron Lett. 2006, 47, 2151-2154.

[78] Khalili, B.; Jajarmi, P.; Sis-E, B.; Hashemi, M. M. J. Org. Chem. 2008, 73, 2090-2095.

[79] Dou, G.; Shi, C.; Shi, D. J. Comb. Chem. 2008, 10, 810-813810.

[80] Liu, X-T.; Huang, L.; Zheng, F-J.; Zhana, Z-P. Adv. Synth. Catal. 2008, 350, 2778-2788.

[81] Cadierno, V.; Gimeno, J.; Nebra, N. Heterocycl. Chem. 2010, 47, 233-236.

[82] Tamaddon, F.; Farahi, M.; KaramI, B. Mol. Catal. A: Chem. 2012, 356, 85-89.

[83] Este’vez, V.; Villacampa, M.; Mene’ndez, J.C. Chem. Commun. 2013, 49, 591-593.

[84] Bhat, S. I.; Trived, D.R. Tetrahedron Lett. 2013, 54, 5577-5582.

[85] Abdelmohsen, S. A.; El-Ossaily, Y. A. Heterocycl. Commun. 2015, 21.

[86] Goyal, S.; Patel, J. K.; Gangar, M.; Kumar, K.; Nair, V. A. RSC Adv. 2015, 5, 3187-3195.

[87] Reddy, G. N.; Likhar, P. R. Res. Chem. Int. 2016, 42, 6873-6879.

[88] Yu, Y.; Mang, Z.; Yang, W.; Li, H.; Wang, W. Catal. 2016, 6, 169. 
[89] Shahvelayati, A. S.; Sabbaghan, M.; Banihashem, S. Monatshefte fur Chemie, 2017, 148, 1123-1129.

[90] Maiti, S.; Biswas, S.; Jana, U. J. Org. Chem. 2010, 75, 1674-1683.

[91] Khan, A.T.; Lal, M.; Bagdi, P.R.; Basha, R.S.; Saravanan, P.; Patra, S. Tetrahedron Lett., 2012, 53, 4145-4150.

[92] Reddy, G.R.; Reddy, T.R.; Joseph, S.C.; Reddy, K.S.; Pal, M. RSC Adv. 2012, 2, 3387-3395.

[93] Saeidian, H.; Abdoli, M.; Salimi, R. Comptes Rendus Chimie, 2013, 16, 1063-1070.

[94] Atar, A.B.; Jeong, Y.T. Tetrahedron Lett. 2013, 54, 5624-5628.

[95] Li, B-L.; Li, P-H.; Fang, X-N.; Li, C-X.; Sun, J-L.; Mo, L-P.; Zhang, Z-H. Tetrahedron, 2013, 69, 7011-7018.

[96] Gupta, N.; Singh, K. N.; Singh, J. J. Mol. Liq. 2014, 199, 470-473.

[97] Gajengi, A. L.; Bhanage, B. M. Catal. Lett., 2016, 146, 1341-1347.

[98] Li, B-L.; Zhang, M.; Hu, H-C.; Du, Xia.; Zhang, Z-H. New J. Chem. 2014, 38, 2435-2442.

[99] Tang, L.; Yang, M.; Yang, M.; Wang, L.; Dong, W.; Wang, G. New J. Chem. 2015, 39, 49194923.

[100] Hu, H.; Liu, Y.; Li, B.; Cui, Z.; Zhang, Z. RSC Adv. 2015, 5, 7720-7728.

[101] Moghaddam, F. M.; Foroushani, B. K.; Reza, H. RSC Adv. 2015, 5, 18092-18096.

[102] Gajengi, A. L.; Fernandes, C. S.; Bhanage, B. M. Mol. Chem. 2018, 451, 13-19.

[103] Chen, J.; Yang, X.; Liu, M.; Wu, H.; Ding, J.; Su, Weike.; Synth. Commun. 2009, 39, 41804198.

[104] Veisi, H. Tetrahedron Lett., 2010, 51,2109-2114.

[105] Yuan, S. Z.; Liu, J.; Xu, L. CCL. 2010, 21, 664-668.

[106] Rahmatpour, A. Appl. Organomet. Chem. 2011, 25,585-590.

[107] Banik, M.; Ramirez, B.; Reddy, A.; Bandyopadhyay, D.; Banik, B.K. Org. Med. Chem. Lett. 2012, 2:11

[108] Darabi, H. R.; Aghapoor, K.; Farahani, A.D.; Mohsenzadeh, F. Environment. Chem. Lett. 2012,10, 369-375.

[109] Darabi, H. R.; Poorheravi, M. R.; Aghapoor, K.; Mirzaee, A.; Mohsenzadeh, F.; Asadollahnejad, N.; Taherzadeh, H.; Balavar, Y. Environment Chem. Lett. 2012, 10, 5-12.

[110] Chochois, H.; Sauthier, M.; Maerten, E.; Castanet, Y.; Mortreux, A. Tetrahedron, 2006, 62, 11740-11746. 
[111] Jing, X.; Pan, X.; Li, Z.; Bi, X.; Yan, C.; Zhu, H. Synth. Commun. 2009, 39, 3833-3844.

[112] Rueping, M.; Parra, A. J. Org. let. 2010, 12, 5281-5283.

[113] Khajuria, R.; Kapoor, K. K. Curr. Microwave Chem. 2014, 1, 110-118.

[114] Kalomode, H. P., Vadagaonkar, K. S.; Murugan, K.; Prakash, S.; Chaskar, A. C. RSC Adv. 2015, 5, 35166-35174.

[115] Shekarrao, K.; Kaishap, P. P.; Gogoi, S.; Boruaha, R. C. Adv. Synth. Catal. 2015, 357, 11871192.

[116] Harrison, T. J.; Kozak, J. A.; Pane, M. C.; Dake, G. R. J. org. chem. 2006, 71, 4525-4529.

[117] Shindo, M.; Yoshimura, Y.; Hayashi, M.; Soejima, H.; Yoshikawa, T.; Matsumoto, K.; Shishido, K. Org. Lett. 2007, 9, 1963-1966.

[118] Cy, D. J.; Arndtsen, B. A. J. Am. Chem. Soc. 2007, 129, 12366-12367.

[119] Cyr, D. J. S.; Martin, N.; Arndtsen, B. A. Org. Lett. 2007, 9, 449-452.

[120] Lu, Y.; Arndtsen, B. A. Angew. Chem. 2008, 120, 5510-5513.

[121] Chen, X.; Hou, L.; Li, X. Synlett. 2009, 5, 0828-0832.

[122] Ngwerume, S.; Camp, E.J. Org. Chem. 2010, 75, 6271-6274.

[123] Liu, X-T.; Hao, L.; Lin, M.; Chen, L.; Zhan, Z-P. Org. Biomol. Chem. 2010, 8, 3064-3072.

[124] Wang, T.; Chen, X-L.; Chen, L.; Zhan, Z-P. Org. Lett. 2011, 13, 3324-3327.

[125] Shen, J.; Cheng, G.; Cui, X. Chem. Commun. 2013,49, 10641-10643.

[126] Hu, Y.; Wang, C.; Wang, D.; Wu, F.; Wan, B. Org. Lett. 2013, 15, 3146-3149.

[127] Miura, T.; Hiraga, K.; Biyajima, T.; Nakamuro, T.; Murakami, M. Org. chem. 2013, 15, 3298-3301.

[128] Kim, C.; Park, S.; Eom, D.; Seo, B.; Lee, P. H. Org. Lett. 2014, 16, 1900-1903.

[139] Zhao, M-N.; Ren, Z-H.; Wang, Y-Y.; Guan, Z-H. Org. Lett. 2014, 16, 608-611

[130] Li, X.; Chen, M.; Xie, X.; Sun, N.; Li, S.; Liu, Y. Org. Lett. 2015, 17, 2984-2987.

[131] Zhang, Z.; Zhang, F.; Wang, H.; Wu, H.; Duan, X.; Liu, Q.; Liu, T.; Zhang, G. Adv. Synth. Catal. 2015, 357, 2681-2686.

[132] Wang, G.; Rongxing, C.; Wu, M.; Sun, S.; Luo, X.; Chen, Z.; Guo, H.; Chong, C.; Xing, Y. Tetrahedron Lett. 2017, 58, 847-850. 